\title{
Polyethylene wear in total hip arthroplasty
}

Citation for published version (APA):

Geerdink, C. H. (2010). Polyethylene wear in total hip arthroplasty. [Doctoral Thesis, Maastricht University]. Maastricht University. https://doi.org/10.26481/dis.20101215cg

Document status and date:

Published: 01/01/2010

DOI:

$10.26481 /$ dis.20101215cg

Document Version:

Publisher's PDF, also known as Version of record

\section{Please check the document version of this publication:}

- A submitted manuscript is the version of the article upon submission and before peer-review. There can be important differences between the submitted version and the official published version of record.

People interested in the research are advised to contact the author for the final version of the publication, or visit the DOI to the publisher's website.

- The final author version and the galley proof are versions of the publication after peer review.

- The final published version features the final layout of the paper including the volume, issue and page numbers.

Link to publication

\footnotetext{
General rights rights.

- You may freely distribute the URL identifying the publication in the public portal. please follow below link for the End User Agreement:

www.umlib.nl/taverne-license

Take down policy

If you believe that this document breaches copyright please contact us at:

repository@maastrichtuniversity.nl

providing details and we will investigate your claim.
}

Copyright and moral rights for the publications made accessible in the public portal are retained by the authors and/or other copyright owners and it is a condition of accessing publications that users recognise and abide by the legal requirements associated with these

- Users may download and print one copy of any publication from the public portal for the purpose of private study or research.

- You may not further distribute the material or use it for any profit-making activity or commercial gain

If the publication is distributed under the terms of Article $25 \mathrm{fa}$ of the Dutch Copyright Act, indicated by the "Taverne" license above, 


\section{Polyethylene Wear in \\ Total Hip Arthroplasty}

Carel H. Geerdink 
Colophon

Thesis: Polyethylene wear in total hip arthroplasty

Author: Carel Hein Geerdink

Lay-out and printing: Simone Vinke, Ridderprint B.V., Ridderkerk, the Netherlands

Cover illustration: Human hip bone texture

ISBN: 978-90-5335-341-7

\section{Copyright:}

C.H. Geerdink, Maastricht, The Netherlands, 2010. All rights reserved. No part of this publication may be reproduced without permission of the copyright owner. 


\section{Polyethylene Wear in \\ Total Hip Arthroplasty}

\section{Proefschrift}

Ter verkrijging van de graad van doctor aan de

Universiteit van Maastricht, op gezag van de Rector Magnificus Prof. mr. G.P.M.F. Mols, volgens het besluit van het College van Decanen, in het openbaar te verdedigen op woensdag 15 december 2010 om 10.00 uur

door

\section{Carel Hein Geerdink}

Geboren op 20 november 1971 te Schiedam 
Promotor:

Co-promotores:

Beoordelingscomissie:
Prof. dr. G.H.I.M. Walenkamp

Dr. A.J. Tonino, Atrium MC Heerlen

Dr. B.P.L. Grimm, Atrium MC Heerlen

Dr. I.C. Heyligers, Atrium MC Heerlen

\section{Prof. dr. M. van Kleef, voorzitter}

Prof. dr. S.K. Bulstra, UMC Groningen

Prof. dr. H. Kuipers

Prof. dr. L. van Rhijn 
Aan de totstandkoming van dit proefschrift hebben bijgedragen:

Biomet Nederland

Grünenthal

Nederlandse Orthopaedische Vereniging

Centrum Orthopaedie Rotterdam

Link Nederland

LIVIT Orthopaedie

Combined Quality Care

ABN AMRO Bank

Park Medisch Centrum

Park Kliniek Rotterdam

Bayer Healthcare

Merck Sharp \& Dohme

Janssen-Cilag

Arthrex Nederland

Bauerfeind Benelux

Synthes

Belasting- en Administratiekantoor Bravenboer

AstraTech Benelux

Boehringer Ingelheim

Otto Bock Benelux

Covidien Nederland

Johnson \& Johnson Medical

Foralda Inkoopspecialisten

Heraeus Medical

Oudshoorn Chirurgische Techniek 



\section{Contents}

Chapter 1 Introduction and outline of the thesis 9

Chapter 2 The determination of linear and angular penetration of the 25 femoral head into the acetabular component as an assessment of wear in total hip replacement.

A comparison of four computer-assisted methods

Chapter 3 Crosslinked polyethylene compared to conventional polyethylene in total hip replacement. Pre-clinical evaluation, in-vitro testing and prospective clinical followup study.

Chapter 4 Cross-linked Compared with Historical Polyethylene in THA. An 8-year Clinical Study

Chapter 5 Correlation of Technetium scintigraphy, progressive acetabular osteolysis and acetabular component loosening in total hip arthroplasty.

Chapter 6 Cementless Hemispheric Hydroxyapatite-Coated Sockets for Acetabular Revision.

Chapter 7 Summary and general discussion

$\begin{array}{lll}\text { Chapter } 8 & \text { Nederlandse samenvatting } & 107\end{array}$

Dankwoord 


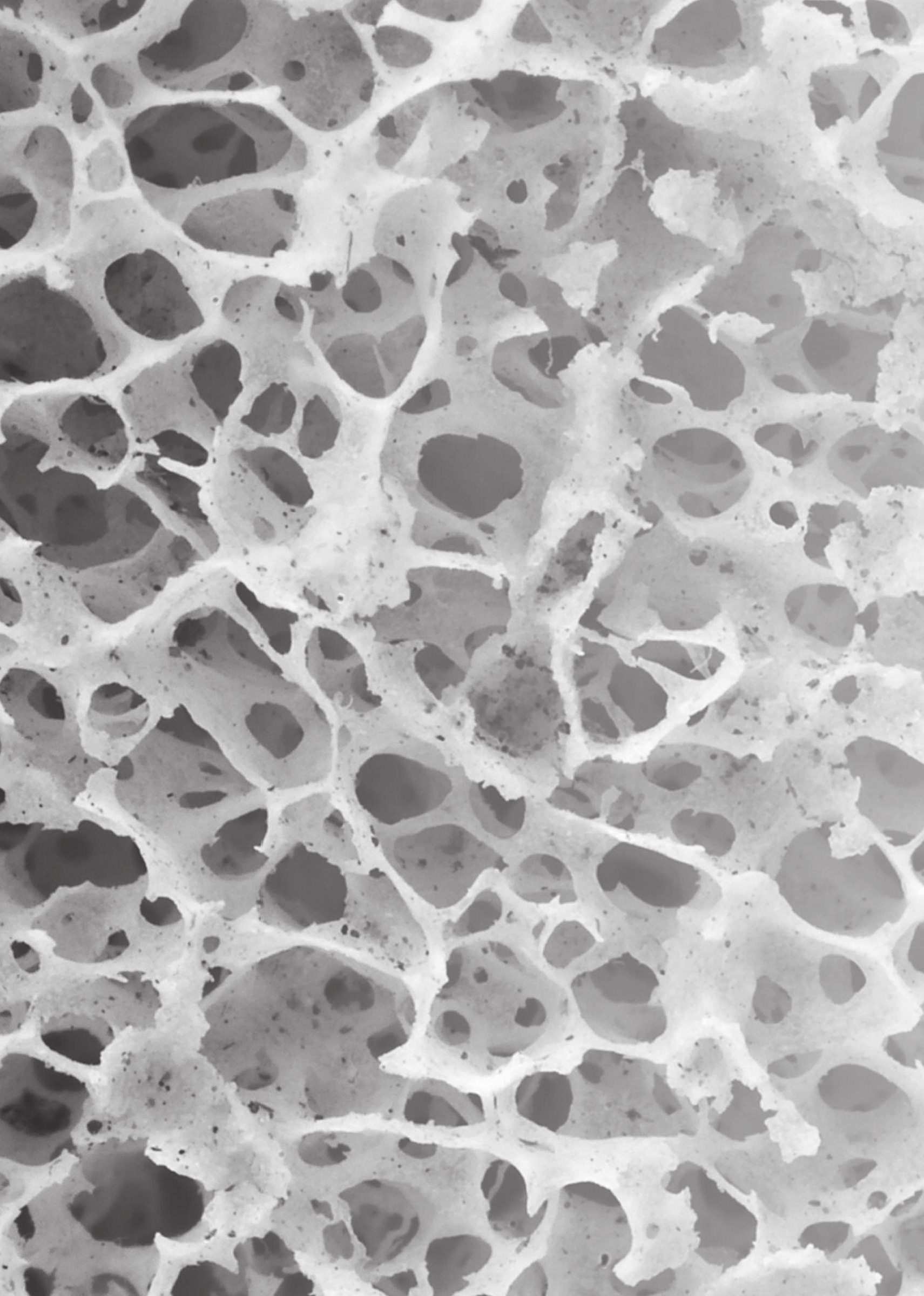




\section{Chapter 1}

Introduction and outline of the thesis 



\section{Introduction}

\section{History of polyethylene in total hip arthroplasty}

Clinical success and implant durability in total hip replacement is a multi-factorialdependent accomplishment that includes patient-, surgical- and implant- related factors. From an engineering and material science perspective, success in total hip replacement is enhanced by the achievement of solid and long term implant component fixation, maintenance of implant component structural integrity, and limitation of articular surface wear. ${ }^{1,2}$

Motion at the articular surface of a total hip arthroplasty produces particulate wear products that can initiate an inflammatory reaction of the tissues that surround and support prosthetic joint components. ${ }^{3,4}$ This tissue reaction may cause the loss of peri-prosthetic bone, compromising the fixation of the implant. This cascade of events following articular surface wear can contribute solely, or with other factors, to limiting the durability of the reconstructive implant. Today's advances in the success of total hip replacement are the result of improved understanding of the role and limitations of patient factors, surgical achievement, prosthetic component design and implant material properties.

Throughout history a variety of articular surface materials combined in many different ways were used for total hip replacement. Metal-on-metal bearing couples were utilized in the form of stainless steel and cobalt-chromium alloy components from the late 1930s onwards and, after many design changes, are still in use today. ${ }^{5-7}$ In the 1970s ceramic-on-ceramic articulation emerged. ${ }^{8}$ The predominant wear-couple in total hip replacement over the last 40 years however has been a polymer acetabular surface articulating against either a metal or ceramic femoral head.

In the late 1950s John Charnley first started clinical utilization of a polymer acetabular component. Polytetrafluoroethylene (PTFE) and Fluorosint-Polypenco both proved unsuccessful due to early wear-induced implant loosening and associated pain. ${ }^{9-11}$ When high-molecular-weight-polyethylene (HMWP) performed much better in wear simulator tests, John Charnley started using this new polyethylene in 1962. At the same time he introduced bone cement, also a polymer, for bonding the implanted components to the bone. Both inventions proved very succesful. To date approximately 20 million polyethylene-coupled total joint replacements have been performed worldwide, 15 million implants are still in service and 1,2 million new ones will be implanted this year. ${ }^{12}$ 
Polyethylene

The ethylene molecule has a molecular weight of $28 \mathrm{~g} / \mathrm{mole}$. It is one of the simplest organic compounds, having only two carbon and four hydrogen atoms. Ultra-highmolecular-weight-polyethylene (UHMWPE) is a linear semi-crystalline polymer of extreme length. The molecular weight influences the arrangement of the polymer chain, which in turn affects the material's properties. As typically used in orthopaedics today, UHMWPE has a molecular weight of 5 to 6 million g/mole. Although over time the basic material has remained the same since John Charnley started to use it, the molecular weight, purity and material consistency have improved over time and are the subject of many clinical trials today.

UHMWPE resin is polymerized as a fine powder with a particle size ranging from approximately 50 to $300 \mu \mathrm{m}$ in diameter. The identification of specific polyethylene resins historically used in orthopaedic devices can be confusing. Producers of UHMWPE have changed ownership, experienced name changes or changed resin designations over the history of orthopaedic use. The most commonly used UHMWPE resins in orthopaedic implant production currently include GUR 1050 and GUR 1020 from Ticona. The basis of the material consists of UHMWPE powder and must be consolidated into solid shapes in order to be useful as an orthopaedic implant. This can be achieved either by ram extrusion or compression molding. Ram extrusion is a discontinuous flow process where the UHMWPE resin powder is heated in a chamber while subject to pressure. In this process the time, temperature and pressure history of the material is controlled as the polymer powder is heated and compressed. Sometimes calcium stearate is added to facilitate the ram extrusion process and to help prevent corrosion of the processing equipment. Compression molding is a static process in which the time, temperature and pressure history of the UHMWPE resin is controlled as the material is contained within a mold cavity. Both ram extrusion and compression molding processes can produce UHMWPE components of complex geometry and high dimensional tolerance. ${ }^{12}$

\section{Cross-linking}

Almost from the onset of its use up to the present time UHMWPE components used in orthopaedics have been sterilized by exposure to ionizing radiation. The most common form is 25 to $40 \mathrm{kGy}$ of gamma radiation. Gamma rays penetrate entirely through the component and packaging resulting in both surface and subsurface sterilization. In addition to sterilization, radiation exposure can also alter the structure of the UHMWPE molecule. During the radiation process, the bond between carbon atoms and/or the bond between carbon and hydrogen atoms can be broken, producing shorter polymer 
chains and free radicals (unpaired electrons) within the material. These free radicals are reactive chemical species that can form branched chains, combine with other nearby elements, or simply recombine to re-establish the polymer chain. The formation of branch chains results from the formation of interchain covalent bonds and is generally referred to as cross-linking. ${ }^{12}$

\section{Oxidation}

Free radicals that do not recombine or result in cross-links can provide sites on the polymer chain where available oxygen can attach to the polymer. Since oxygen is a relatively small molecule it can diffuse into UHMWPE over time. ${ }^{13}$ The oxidation of polyethylene can occur in any oxidized environment, including the in-vivo environment, and can be associated with changes in the material's mechanical properties. ${ }^{14}$ The chemical changes resulting from oxidation can result in reduced strength and reduced ductility. ${ }^{15-17}$ To reduce the effects of oxidation in the implant storage environment, most gamma-radiation-sterilized UHMWPE components are now provided in packaging with low oxygen content. ${ }^{14,18-24}$ However, when removed from an oxygen-protected environment and placed in an oxygen-containing environment such as body fluids, oxidation of the polyethylene will occur. ${ }^{19}$ Therefore concerns have been expressed related to the lack of clinical performance data, changes in mechanical properties and changes in the oxidative degradation for these oxygen-protected components invivo. $^{13,20}$

To reduce or eliminate free radicals after cross-linking many orthopaedic implant manufacturers add an important processing step. Following irradiation of the polyethylene, the material will either be heated below melting temperature (annealed) or remelted by heating above the melting temperature (about $137^{\circ} \mathrm{C}$ ). The concentration of residual free radicals is typically measured by electron spin resonance (ESR). With ESR the lowest detection limit is $10^{14}$ residual free radicals per gram of material. Post-irradiation melting has been reported to result in no detectable residual free radicals within the UHMWPE. In contrast post-irradiation annealing below the melt temperature followed by gamma-sterilization can produce a material with a residual free radical concentration greater than that in some conventional gamma sterilized polyethylenes..$^{25,26}$

\section{Polyethylene wear}

These changes in the chemical and mechanical properties of materials due to oxidation do have consequences. They increase the risk of elevated in-vivo polyethylene wear. Extensive data are available from hip simulator studies showing significant improvement 
in the wear resistance of UHMWPE after cross-linking procedures, even in the presence of third body particles. ${ }^{15-17,23,27-30}$

There are a number of historical, retrospective evaluations of experimental UHMWPEs with increased cross-link density. These studies each involved a small number of patients without matched control groups. ${ }^{31,32}$ Several total hip acetabular components were made using cross-linked polyethylene, and patients have been followed-up since 1998. Early radiographic follow-up studies including high-precision measurement with radiostereometric analysis (RSA) show a significant decrease in femoral head penetration into the cross-linked polyethylene liner in comparison with conventional polyethylene liners. ${ }^{33-35}$ So the in-vitro benefit of cross-linking UHMWPE was confirmed in-vivo after a short follow-up time.

Although laboratory data may suggest that new preparations of UHMWPE show improvements, the utility of these new materials in total hip replacement can only be determined in well controlled and carefully conducted long-term clinical trials. Several such trials are ongoing and their results will in time improve our understanding of the benefits of evolutionary changes in the manufacture of UHMWPE total hip components. This thesis adds a little piece to this scientific challenge.

\section{Outline of the thesis}

Although UHMWPE has been the most commonly used acetabular bearing material for more than 40 years, product development and improvement over the years have been partly driven by early clinical failure. ${ }^{36}$

Wear particles of the polyethylene acetabular component can invoke an inflammatory tissue response in the adjacent bone, leading to peri-prosthetic osteolysis and loosening of the implant. ${ }^{36-46}$ Polyethylene wear might also cause late instability of the hip, leading to dislocation in some cases ${ }^{47}$ The osteolytic effect of the wear debris depends on the cytotoxicity of the material, the size and morphology of the debris particles, the pathways available for particle migration, and the volume of wear particles produced and released into the peri-prosthetic tissue. ${ }^{43}$ Several authors have established that lower wear rates substantially reduce the incidence of osteolysis and increase the survival of the implants. With standard 28-mm heads, linear wear rates greater than $0.2 \mathrm{~mm}$ per year always produce wear particle-induced osteolysis, whereas this is mostly absent at annual wear rates of less than 0.05 to $0.1 \mathrm{~mm}$ per year. ${ }^{48-55}$ Therefore, increasing wear resistance in the PE for acetabular cups has been, and still is, a major target.

In this thesis polyethylene wear measurement, wear behaviour of a cross-linked polyethylene, the role of technetium scintigraphy in diagnosing periacetabular osteolysis 
and revision of the acetabular component with use of an uncemented component will be discussed.

Chapter 2 describes the problem of in-vivo measurement of polyethylene wear in cases of total hip arthroplasty. Various techniques have been developed to measure polyethylene wear in-vivo, to monitor critical polyethylene wear in individual patients in the clinical setting and to compare the wear performance of different polyethylene inserts. All the methods of measurement of wear are based on quantifying the displacement (penetration) of the femoral head with reference to the acetabular component between two radiographs obtained at different follow-up times (paired analysis), or on a single radiograph (single analysis) assuming a concentric position of the femoral head and acetabular component directly after implantation before any wear could have occurred. Initially this was done by hand, on conventional radiographs using a compass, ruler and calliper, as described by Livermore, Ilstrup and Morrey ${ }^{56}$, Charnley and Halley ${ }^{57}$, and Kabo et $\mathrm{al}^{58}$ and more recently by Kang et al. ${ }^{59}$ These techniques can result in high variability between different users, and they lack the precision required to yield useful information over shorter periods, or in cases in which relatively small amounts of displacement of the femoral head have occurred. ${ }^{60}$ In the 1990s computer-assisted techniques were developed to reduce variability in measurement, to improve repeatability, and to increase the accuracy of measurement of penetration of the femoral head into the acetabular component compared to manual techniques. ${ }^{61-64}$ These programs combine the use of image analysis software with the determination of bone and prosthesis landmarks by hand or automated by a computer using an edge detection algorithm. Computer methods can determine wear twodimensionally on anteroposterior (AP) radiographs, such as in the manual methods, and some can calculate three-dimensional wear vectors combining information from matching AP and cross-table lateral radiographs. All geometrical methods to assess wear only measure linear penetration. When measurements for volumetric wear are given, values are estimated from the linear penetration and a formula correlating these, based on simple geometric assumptions, substantiated in some cases by geometrical implant data. ${ }^{65}$ Standard radiological assessment of penetration by the femoral head into the polyethylene liner does not enable clinicians to distinguish between the two processes which cause movement of the head, namely true wear (the removal of polyethylene particles) and so-called bedding-in (creep and settling of the liner) which occurs in the early post-operative phase. ${ }^{46,66,67}$ In the literature, measurements of penetration are correlated directly with wear. Röentgen Stereophotogrammetric Analysis (RSA), developed by Selvik ${ }^{68}$, is considered the most accurate method for determining the magnitude of three-dimensional relative displacements, such as penetration of the femoral head, from radiological images. ${ }^{35,} 69$ The requirement for tantalum beads to be placed in the implants and bone generally limits the use of this method to a small group of patients, and it can only be used in a prospective setting. 
At present there is a tendency for cemented acetabular components to be used in elderly, less active patients with less exposure to the risks of polyethylene wear, and for uncemented acetabular components to be used in relatively young and still active patients with a higher chance of suffering the consequences of wear. Thus, polyethylene wear measurement is of greater importance in patients who have uncemented metalbacked components implanted. Several computer-assisted methods to determine linear penetration are commercially available. From the available literature it is unclear whether these methods produce comparable results. The aim of our study presented in chapter two was to find the easiest, most precise and most practical of four computerassisted programs of wear measurement, and to see whether the values derived from different programs could be compared with each other.

Chapter 3 describes the wear behavior of a moderately cross-linked polyethylene called Duration ${ }^{\circledR}$ in comparison with historical or conventional polyethylene. The resistance of ultra-high-molecular-weight polyethylene to adhesive and abrasive wear can be increased by increasing the degree of cross-linking, the formation of covalent bonds between the backbone molecular chains. ${ }^{70}$ Polyethylene cross-linking for clinical application is achieved by irradiation. During the irradiation process, the level of cross-linking can be influenced by the type of radiation, the dose (20-100 kGy), the atmosphere (air, nitrogen, argon), and/or post-radiation treatment (e.g. sequential radiation, annealing, remelting). These process parameters also influence the degree of unwanted side effects of radiation cross-linking, such as the creation of free radicals which lead to oxidation, embrittlement and accelerated wear during ageing. Annealing can induce further cross-linking by promoting recombination of free radicals. Early polyethylene was irradiated mainly for the purpose of sterilization at low doses (ca 20-30kGy) and in air, leading only to low cross-link densities and to oxidation and embrittlement during ageing. This "conventional" polyethylene was used clinically until the late 1990s when it was gradually replaced by subsequent generations of moderately and highly cross-linked polyethylenes. These highly cross-linked materials show promising low wear rates in hip simulator studies ${ }^{15}$, but due to their relative novelty, there have been relatively few clinical studies, either with a follow-up time that has been too short ${ }^{32,}$ or patient groups without randomized well-matched controls. This is a problem, as clinical wear rates can vary enormously depending on patient demographics; even sophisticated computer-based wear measurement methods produce errors, making follow-up times of less than 3 years unreliable. ${ }^{71}$ In addition, comparison of wear rates from different studies using different techniques must also be interpreted with caution. ${ }^{72}$ The study in chapter three compares the wear rates and radiographic signs of osteolysis of conventional polyethylene with those of Duration ${ }^{\circledR}$ - a new, moderately cross-linked polyethylene-in a 5-year randomized clinical follow-up study. Wear of both materials was assessed in a hip simulator study and by basic characterization of their material properties, to assess the advantages 
(or disadvantages) of the elevated cross-link density of the newer polyethylene. Our

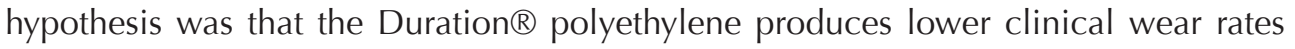
and fewer radiographic signs of osteolysis, and that this superior wear resistance invivo is reflected by the in-vitro test results.

Chapter 4 describes the in-vivo wear behavior after eight years of follow-up of the Duration ${ }^{\circledR}$ polyethylene described in chapter three. Our wear simulator study suggested that wear reduction of moderately cross-linked PE over historical PE is between $32 \%$ and $45 \%$ by volumetric wear rates. ${ }^{73}$ As was mentioned in chapter three, cross-linking is a process usually initiated by gamma irradiation whereby hydrogen atoms are removed from the PE molecules, creating free radicals, which recombine by linking with free radicals of neighboring PE molecule chains. This new network of cross-linked PE chains dramatically increases the wear resistance but also increases the stiffness of the PE and makes it more brittle. ${ }^{15,32} \mathrm{~A}$ PE that is too stiff or brittle may have reduced fatigue strength, which in clinical applications may lead to stress cracking and subsequent failure of the locking mechanism, or when impingement occurs, the insert rim may crack and delaminate. ${ }^{74}$ However, not all free radicals created by the irradiation recombine to form cross-links. These residual free radicals are highly reactive and are responsible for early oxidation (ageing) of the PE. ${ }^{75}$ Oxidized PE exhibits accelerated wear and delamination. Free radicals can be removed using two post-irradiation heat treatments, remelting or annealing. Remelted PE is more oxidation-resistant but has less mechanical strength than historical PE. In annealed PE, strength is maintained, but because of residual-free radicals, oxidation should appear, which could lead to accelerating long-term wear rates. ${ }^{75,76}$ Our primary study question in chapter four was whether cross-linked PE could maintain its increased wear resistance for a period of up to 8 years when oxidation and ageing effects may have affected its original properties. A secondary study question was whether the reduced wear rate of cross-linked PE led to reduced signs of osteolysis.

Chapter 5 describes the correlation between technetium scintigraphy and progressive osteolysis behind the acetabular component in patients with a total hip arthroplasty. There is a relationship between the magnitude of polyethylene wear and the likelihood of osteolysis developing. ${ }^{46,77}$ Higher wear rates give higher rates of osteolysis and result in the appearance of osteolysis in shorter follow-up times. ${ }^{78}$ Measurement of linear wear rates, as described in chapter two, is a powerful tool for discovering patients at risk. Osteolytic lesions can be progressive or stable, localised or diffuse. Lesions behind the acetabular component are more likely to expand. ${ }^{79-81}$ At revision, osteolytic lesions are usually much larger in extent than the size suggested by pre-operative radiographs. $^{82,83}$ Generally, cementless acetabular components show localized, expansile lesions (balloon like) with the cup remaining stable for a long time. ${ }^{39}$ Not all patients with augmented polyethylene wear have progressive acetabular osteolysis 
as seen previously in fully polyethylene-cemented cups. However some patients with uncemented metal-backed cups implanted show only minimal polyethylene wear but hugh osteolytic lesions while the cup is still stable. This last group of patients is of particular interest as they lose bone stock very rapidly while having no, or minimal, clinical symptoms. As well as serial radiographs, bone scintigraphy has always played a prominent role in the diagnosis of aseptic loosening of a total hip arthroplasty. ${ }^{84}$ But if parts of the cup surface remain well fixed while progressive osteolysis is going on, how can we diagnose the risk for this group of patients? In chapter five we looked at our prospective series of uncementend hydroxyapatite coated hip arthroplasties. Patients in this group were subjected annually to bone scintigraphy. We investigated whether bone scintigraphy could diagnose progressive acetabular osteolysis and thereby help us move forward with the task of cup revision.

In chapter $\mathbf{6}$ a possible treatment is described for loosening of the acetabular component due to polyethylene wear-induced osteolysis. Revision of a failed acetabular component is a major challenge, as both bone reconstruction and restoration of the anatomical hip center must be taken into consideration. Revision techniques include combinations of cemented cups with grafts and bipolar prostheses with bulk or morselized grafts or uncemented cups. These have all been tried, with varying success rates. ${ }^{85-93}$ The advent of acetabular reconstruction rings, cages or meshes in combination with cemented cups and morselized bone grafts have improved survival rates..$^{93-97}$ Although the best method for revising the deficient acetabulum is not yet known, it has become obvious that initial stability of the cup on the host bone is an important goal for achieving long term cup fixation. As the host bone is highly compromised in revision cases, it is more difficult to achieve this initial stability. Fast bone ongrowth to the new implant is essential for shortening the time between primary mechanical stabilization and secondary biologic fixation. ${ }^{90,98,99}$ Relatively modern bone-bonding surfaces such as hydroxyapatite (HA) coatings have repeatedly been shown to promote and accelerate bone ongrowth and lead to a stable and reliable biologic fixation in primary hip arthroplasty. ${ }^{100-105}$ We performed acetabular revision with a HA coated component under the hypothesis that the coating could theoretically compensate for the reduced amount and the reduced vitality of the host bone. Because fixation by bone ongrowth to the new cup has to come directly from the host bone and is related to the contact area, larger cups were used to enhance this effect. In the final study of this thesis we report the intermediate results of 72 cups, which were revised for aseptic loosening with a cementless HA-coated hemispherical acetabular component. 


\section{References}

1. Dumbleton JH, Manley MT, Edidin AA. A literature review of the association between wear rate and osteolysis in total hip arthroplasty. J Arthroplasty. 2002 Aug;17(5):649-61. Review.

2. Dumbleton JH, Manley MT. Letter to the editor. J Arthroplasty. 2003 Jun;18(4):537-8.

3. Schmalzried TP, Kwong LM, Jasty M, Sedlacek RC, Haire TC, O'Connor DO, Bragdon CR, Kabo JM, Malcolm AJ, Harris WH. The mechanism of loosening of cemented acetabular components in total hip arthroplasty. Analysis of specimens retrieved at autopsy. Clin Orthop Relat Res. 1992 Jan;(274):60-78.

4. McKellop HA, Campbell P, Park SH, Schmalzried TP, Grigoris P, Amstutz HC, Sarmiento A. The origin of submicron polyethylene wear debris in total hip arthroplasty. Clin Orthop Relat Res. 1995 Feb;(311):320.

5. Amstutz HC, Grigoris P. Metal on metal bearings in hip arthroplasty. Clin Orthop Relat Res. 1996 Aug;(329 Suppl):S11-34. Review.

6. McKee GK. Total hip replacement--past, present and future. Biomaterials. 1982 Jul;3(3):130-5.

7. Sieber HP, Rieker CB, Köttig P. Analysis of 118 second-generation metal-on-metal retrieved hip implants. J Bone Joint Surg Br. 1999 Jan;81(1):46-50.

8. Nich C, Sariali el-H, Hannouche D, Nizard R, Witvoet J, Sedel L, Bizot P. Long-term results of aluminaon-alumina hip arthroplasty for osteonecrosis. Clin Orthop Relat Res. 2003 Dec;(417):102-11. Erratum in: Clin Orthop Relat Res. 2006 Jan;442:283.

9. Charnley J. Lancet. 1961 May 27;1(7187):1129-32. Arthroplasty of the hip. A new operation.

10. Charnley J. Faltin lecture: evolution of total hip replacement. Ann Chir Gynaecol. 1982;71(2):103-7.

11. Wroblewski BM, Siney PD. Charnley. Low-friction arthroplasty of the hip. Long-term results. Clin Orthop Relat Res. 1993 Jul;(292):191-201.

12. Callaghan JJ, Rosenberg AG, Rubash HE. Textbook The Adult Hip, second edition, 2007

13. Rimnac CM, Klein RW, Betts F, Wright TM. Post-irradiation aging of ultra-high molecular weight polyethylene. J Bone Joint Surg Am. 1994 Jul;76(7):1052-6.

14. Sutula LC, Collier JP, Saum KA, Currier BH, Currier JH, Sanford WM, Mayor MB, Wooding RE, Sperling DK, Williams IR, et al. The Otto Aufranc Award. Impact of gamma sterilization on clinical performance of polyethylene in the hip. Clin Orthop Relat Res. 1995 Oct;(319):28-40.

15. McKellop H, Shen FW, Lu B, Campbell P, Salovey R. Development of an extremely wear-resistant ultra high molecular weight polyethylene for total hip replacements. J Orthop Res. 1999 Mar;17(2):157-67.

16. Muratoglu OK, Bragdon CR, O'Connor DO, Jasty M, Harris WH. A novel method of cross-linking ultra-high-molecular-weight polyethylene to improve wear, reduce oxidation, and retain mechanical properties. Recipient of the 1999 HAP Paul Award. J Arthroplasty. 2001 Feb;16(2):149-60.

17. Muratoglu OK, Bragdon CR, O'Connor DO, Jasty M, Harris WH, Gul R, McGarry F. Unified wear model for highly crosslinked ultra-high molecular weight polyethylenes (UHMWPE). Biomaterials. 1999 Aug;20(16):1463-70.

18. Bargmann LS, Bargmann BC, Collier JP, Currier BH, Mayor MB. Current sterilization and packaging methods for polyethylene. Clin Orthop Relat Res. 1999 Dec;(369):49-58.

19. Bostrom MP, Bennett AP, Rimnac CM, Wright TM. The natural history of ultra high molecular weight polyethylene. Clin Orthop Relat Res. 1994 Dec;(309):20-8.

20. Collier JP, Sutula LC, Currier BH, Currier JH, Wooding RE, Williams IR, Farber KB, Mayor MB. Overview of polyethylene as a bearing material: comparison of sterilization methods. Clin Orthop Relat Res. 1996 Dec;(333):76-86.

21. Currier BH, Currier JH, Collier JP, Mayor MB. Effect of fabrication method and resin type on performance of tibial bearings. J Biomed Mater Res. 2000;53(2):143-51.

22. Kurtz SM, Rimnac CM, Bartel DL. Degradation rate of ultra-high molecular weight polyethylene. J Orthop Res. 1997 Jan;15(1):57-61.

23. McKellop H, Shen FW, Lu B, Campbell P, Salovey R. Effect of sterilization method and other modifications on the wear resistance of acetabular cups made of ultra-high molecular weight polyethylene. A hipsimulator study. J Bone Joint Surg Am. 2000 Dec;82-A(12):1708-25. 
24. Shen FW, McKellop HA. Interaction of oxidation and crosslinking in gamma-irradiated ultrahigh molecular-weight polyethylene. J Biomed Mater Res. 2002 Sep 5;61(3):430-9.

25. Collier JP, Currier BH, Kennedy FE, Currier JH, Timmins GS, Jackson SK, Brewer RL. Comparison of crosslinked polyethylene materials for orthopaedic applications. Clin Orthop Relat Res. 2003 Sep;(414):289304.

26. Muratoglu OK, Merrill EW, Bragdon CR, O'Connor D, Hoeffel D, Burroughs B, Jasty M, Harris WH. Effect of radiation, heat, and aging on in vitro wear resistance of polyethylene. Clin Orthop Relat Res. 2003 Dec;(417):253-62.

27. Muratoglu OK, Bragdon CR, O'Connor D, Perinchief RS, Estok DM 2nd, Jasty M, Harris WH. Larger diameter femoral heads used in conjunction with a highly cross-linked ultra-high molecular weight polyethylene: a new concept. J Arthroplasty. 2001 Dec;16(8 Suppl 1):24-30.

28. Bragdon CR, Jasty M, Muratoglu OK, O'Connor DO, Harris WH. Third-body wear of highly cross-linked polyethylene in a hip simulator. J Arthroplasty. 2003 Aug;18(5):553-61.

29. McKellop H, Shen FW, DiMaio W, Lancaster JG. Wear of gamma-crosslinked polyethylene acetabular cups against roughened femoral balls. Clin Orthop Relat Res. 1999 Dec;(369):73-82.

30. Saikko V, Calonius O, Keränen J. Wear of conventional and cross-linked ultra-high-molecular-weight polyethylene acetabular cups against polished and roughened $\mathrm{CoCr}$ femoral heads in a biaxial hip simulator. J Biomed Mater Res. 2002;63(6):848-53.

31. Wroblewski BM, Siney PD, Fleming PA. Low-friction arthroplasty of the hip using alumina ceramic and cross-linked polyethylene. A ten-year follow-up report. J Bone Joint Surg Br. 1999 Jan;81(1):54-5.

32. Heisel C, Silva M, de la Rosa M A, Schmalzried T P. Short-term in vivo wear of cross-linked polyethylene. J Bone Joint Surg (Am) 2004; 86 (4): 748-51.

33. Digas G, Kärrholm J, Thanner J, Malchau H, Herberts P. Highly cross-linked polyethylene in cemented THA: randomized study of 61 hips. Clin Orthop Relat Res. 2003 Dec;(417):126-38.

34. Martell JM, Verner JJ, Incavo SJ. Clinical performance of a highly cross-linked polyethylene at two years in total hip arthroplasty: a randomized prospective trial. J Arthroplasty. 2003 Oct;18(7 Suppl 1):55-9.

35. Röhrl S, Nivbrant B, Mingguo L, Hewitt B. In vivo wear and migration of highly cross-linked polyethylene cups a radiostereometry analysis study. J Arthroplasty. 2005 Jun;20(4):409-13. References

36. Heisel C, Silva M, Schmalzried TP. Bearing surface options for total hip replacement in young patients. Instr Course Lect. 2004;53:49-65.

37. Cooper RA, McAllister CM, Borden LS, Bauer TW. Polyethylene debris-induced osteolysis and loosening in uncemented total hip arthroplasty: a cause of late failure. J Arthroplasty1992;7:285-90.

38. Harris WH. The problem is osteolysis. Clin Orthop 1995;311:46-53.

39. Zicat B, Engh CA, Gokcen E. Patterns of osteolysis around total hip components inserted with and without cement. J Bone Joint Surg [Am] 1995;77-A:432-9.

40. Willert HG, Bertram H, Buchhorn GH. Osteolysis in alloarthroplasty of the hip: the role of ultra-high molecular weight polyethylene wear particles. Clin Orthop 1990;258:95-107.

41. Wan Z, Dorr LD. Natural history of femoral focal osteolysis with proximal ingrowth smooth stem implant. J Arthroplasty 1996;11:718-25.

42. Joshi AB, Markovic L, Ilchmann T. Polyethylene wear and calcar osteolysis. Am J Orthop 1999;28:45-8.

43. Harris WH. Osteolysis and particle disease in hip replacement: a review. Acta Orthop Scand 1994;65:113-23.

44. Schmalzried TP, Jasty M, Harris WH. Periprosthetic bone loss in total hip arthroplasty: polyethylene wear debris and the concept of the effective joint space. J Bone Joint Surg [Am] 1992;74-A:849-63.

45. Orishimo KF, Claus AM, Sychterz CJ, Engh CA. Relationship between polyethylene wear and osteolyis in hips with a second-generation porous-coated cementless cup after seven years of follow-up. J Bone Joint Surg [Am] 2003;85-A:1095-9.

46. Dowd JE, Sychterz CJ, Young AM, Engh CA. Characterization of long-term femoral-head-penetration rates: association with and prediction of osteolysis. J Bone Joint Surg [Am] 2000;82-A:1102-7.

47. Parvizi J, Wade FA, Rapuri V, et al. Revision hip arthroplasty for late instability secondary to polyethylene wear. Clin Orthop 2006;447:66-9. 
48. Barrack R L, Folgueras A, Munn B, Tvetden D, Sharkey P. Pelvic lysis and polyethylene wear at 5-8 years in an uncemented total hip. Clin Orthop 1997; (335): 211-7.

49. Dumbleton J H, Manley M T, Edidin A A. A literature review of the association between wear rate and osteolysis in total hip arthroplasty. J Arthroplasty 2002; 17 (5): 649-61.

50. Harris W H. The lysis threshold: An erroneous and perhaps misleading concept? J Arthroplasty 2003; 18 (4): 506-10.

51. Orishimo K F, Claus A M, Sychterz C J, Engh C A. Relationship between polyethylene wear and osteolysis in hips with a second-generation porous-coated cementless cup after seven years of follow-up. J Bone Joint Surg (Am) 2003; 85 (6): 1095-9.

52. Shih C H, Lee P C, Chen J H, Tai C L, Chen L F, Wu J S, Chang W H. Measurement of polyethylene wear in cementless total hip arthroplasty. J Bone Joint Surg (Br) 1997; 79 (3): 361-5.

53. Sochart D H. Relationship of acetabular wear to osteolysis and loosening in total hip arthroplasty. Clin Orthop 1999; (363): 135-50.

54. Castoldi F, Rossi R, La Russa M, Sibelli P, Rossi P, Ranawat AS. Ten-year survivorship of the Anatomique Benoist Girard I total hip arthroplasty. J Arthroplasty. 2007;22:363-368.

55. Schmalzried TP, Shepherd EF, Dorey FJ, Jackson WO, dela Rosa M, Fa'vae F, McKellop HA, McClung CD, Martell J, Moreland JR, Amstutz HC. The John Charnley Award. Wear is a function of use, not time. Clin Orthop Relat Res. 2000;381:36-46.

56. Livermore J, Ilstrup D, Morrey B. Effect of femoral head size on wear of the polyethylene acetabular component. J Bone Joint Surg [Am] 1990;72-A:518-28.

57. Charnley J, Halley DK. Rate of wear in total hip replacement. Clin Orthop 1975;112:170-9.

58. Kabo JM, Gebhard JS, Loren G, Amstutz HC. In vivo wear of polyethylene acetabular components. J Bone Joint Surg [Br] 1993;75-B:254-8.

59. Kang JS, Park SR, Ebramzadeh E, Dorr LD. Measurement of polyethylene wear in total hip arthroplasty: accuracy versus ease of use. Yonsei Med J 2003;30:473-8.

60. Clarke JC, Black K, Rennie C, Amstutz HC. Can wear in total hip arthroplasties be assessed from radiographs? Clin Orthop 1976;121:126-42.

61. Martell JM, Berdia S. Determination of polyethylene wear in total hip replacements with use of digital radiographs? J Bone Joint Surg [Am] 1997;79-A:1635-41.

62. Devane PA, Bourne RB, Rorabeck CH, Hardie RM, Horne JG. Measurement of polyethylene wear in metal-backed acetabular cups. I: three-dimensional technique. Clin Orthop 1995;319:303-16.

63. Devane PA, Bourne RB, Rorabeck CH, MacDonald S, Robinson EJ. Measurement of polyethylene wear in metal-backed acetabular cups. II: clinical application. Clin Orthop 1995;319:317-26.

64. Shaver SM, Brown TD, Hillis SL, Callaghan JJ. Digital edge-detection measurement of polyethylene wear after total hip arthroplasty. J Bone Joint Surg [Am] 1997;79-A:690-700.

65. Charnley J, Kamangar A, Longfield MD. The optimum size of prosthetic heads in relation to the wear of plastic sockets in total replacement of the hip. Med Biol Eng 1969;7:31-9.

66. Sychterz CJ, Engh CA Jr, Yang A, Engh CA. Analysis of temporal wear patterns of porous-coated acetabular components: distinguishing between true wear and so-called bedding-in. J Bone Joint Surg [Am] 1999;81-A:821-30.

67. Sychterz CJ, Engh CA Jr, Shah N, Engh CA Sr. Radiographic evaluation of penetration by the femoral head into the polyethylene liner over time. J Bone Joint Surg [Am] 1997;79-A:1040-6.

68. Selvik G. A stereophotogrammetric system for the study of human movements. Scand J Rehabil Med Suppl 1978;6:16-20.

69. Röhrl SM, Nivbrant B, Ström H, Nilsson KG. Effect of augmented cup fixation on stability, wear, and osteolysis: a 5-year follow-up of total hip arthroplasty with RSA. J Arthroplasty 2004;19:962-71.

70. Wang A, Polineni V K, Stark C, Dumbleton J H. Effect of femoral head surface roughness on the wear of ultrahigh molecular weight polyethylene acetabular cups. J Arthroplasty 1998; 13 (6): 615-20.

71. Collier M B, Kraay M J, Rimnac C M, Goldberg V M. Evaluation of contemporary software methods used to quantify polyethylene wear after total hip arthroplasty. J Bone Joint Surg (Am) 2003; 85 (12): 2410-8.

72. Devane P A, Bourne R B, Rorabeck C H, MacDonald S, Robinson E J. Measurement of polyethylene wear in metal-backed acetabular cups. II. Clinical application. Clin Orthop 1995; (319): 317-26. 
73. Geerdink CH, Grimm B, Ramakrishnan R, Rondhuis J, Verburg AJ, Tonino AJ. Crosslinked polyethylene compared to conventional polyethylene in total hip replacement: pre-clinical evaluation, in-vitro testing and prospective clinical follow-up study. Acta Orthop. 2006;77:719-725.

74. Tower SS, Currier JH, Currier BH, Lyford KA, Van Citters DW, Mayor MB. Rim cracking of the crosslinked longevity polyethylene acetabular liner after total hip arthroplasty. J Bone Joint Surg Am. 2007;89:2212-1127.

75. Edidin A, Muth J, Spiegelberg S, Schaffner SR. Sterilization of UHMWPE in nitrogen prevents degradation for more than ten years. Trans Orthop Res Soc. 2000;25:0001.

76. Streicher RM. Ionizing irradiation for sterilization and modification of high molecular weight polyethylenes. Plast Rubber Proc Appl. 1988;10:221-229.

77. Kobayashi A, Freeman MA, Bonfield W, Kadoya Y, Yamac T, Al-Saffar N, Scott G, Revell PA. Number of polyethylene particles and osteolysis in total joint replacements. A quantitative study using a tissuedigestion method.J Bone Joint Surg Br. 1997 Sep;79(5):844-8.

78. Livingston BJ, Chmell MJ, Spector M, Poss R. Complications of total hip arthroplasty associated with the use of an acetabular component with a Hylamer liner. J Bone Joint Surg Am. 1997 Oct;79(10):1529-38

79. Rubash HE, Sinha RK, Paprosky W, Engh CA, Maloney WJ. A new classification system for the management of acetabular osteolysis after total hip arthroplasty.Instr Course Lect. 1999;48:37-42.

80. Haddad FS, Masri BA, Garbuz DS, Duncan CP. Femoral bone loss in total hip arthroplasty: classification and preoperative planning.Instr Course Lect. 2000;49:83-96.

81. Campbell DG, Masri BA, Garbuz DS, Duncan CP. Acetabular bone loss during revision total hip replacement: preoperative investigation and planning.Instr Course Lect. 1999;48:43-56.

82. Soto MO, Rodriguez JA, Ranawat CS. Clinical and radiographic evaluation of the Harris-Galante cup: incidence of wear and osteolysis at 7 to 9 years follow-up.J Arthroplasty. 2000 Feb;15(2):139-45

83. Schmalzried TP, Brown IC, Amstutz HC, Engh CA, Harris WH. The role of acetabular component screw holes and/or screws in the development of pelvic osteolysis.Proc Inst Mech Eng [H]. 1999;213(2):14753.

84. Temmerman OP, Raijmakers PG, David EF, Pijpers R, Molenaar MA, Hoekstra OS, Berkhof J, Manoliu RA, Teule GJ, Heyligers IC. A comparison of radiographic and scintigraphic techniques to assess aseptic loosening of the acetabular component in a total hip replacement. J Bone Joint Surg Am. 2004 Nov;86-A(11):2456-63

85. Harris $\mathrm{WH}$, Penenberg BL. Further follow-up on socket fixation using a metal-backed acetabular component for total hip replacement. A minimum ten-year follow-up study. J Bone Joint Surg Am 1987;69-8:1140.

86. Wilson MG, Nikpoor $\mathrm{N}$, Aliabadi $\mathrm{P}$, et al. The fate of acetabular allografts after bipolar revision arthroplasty of the hip. A radiographic review. J Bone Joint Surg Am 1989;71-10:1469.

87. Gates III HS, McCollum DE, Poletti SC, et al. Bonegrafting in total hip arthroplasty for protrusio acetabuli. A follow-up note. J Bone Joint Surg Am 1990; 72-2:248.

88. Jasty $M$, Harris WH. Salvage total hip reconstruction in patients with major acetabular bone deficiency using structural femoral head allografts. J Bone Joint Surg Br 1990;72-1:63.

89. Mulroy Jr RD, Harris WH. Failure of acetabular autogenous grafts in total hip arthroplasty. Increasing incidence: a follow-up note. J Bone Joint Surg Am 1990;72-10:1536.

90. Hooten Jr JP, Engh Jr CA, Engh CA. Failure of structural acetabular allografts in cementless revision hip arthroplasty. J Bone Joint Surg Br 1994; 76-3:419.

91. Marti RK, Schuller HM, van Steijn MJ. Superolateral bone grafting for acetabular deficiency in primary total hip replacement and revision. J Bone Joint Surg Br 1994;76-5:728.

92. Papagelopoulos PJ, Lewallen DG, Cabanela ME, et al. Acetabular reconstruction using bipolar endoprosthesis and bone grafting in patients with severe bone deficiency. Clin Orthop Relat Res 1995;314:170.

93. Shinar AA, Harris WH. Bulk structural autogenous grafts and allografts for reconstruction of the acetabulum in total hip arthroplasty. Sixteen-year-average follow-up. J Bone Joint Surg Am 1997;792:159. 
94. Garbuz D, Morsi E, Gross AE. Revision of the acetabular component of a total hip arthroplasty with a massive structural allograft. Study with a minimum five-year follow-up. J Bone Joint Surg Am 1996;785:693.

95. Schreurs BW, Slooff TJ, Buma P, et al. Acetabular reconstruction with impacted morsellised cancellous bone graft and cement. A 10- to 15-year follow-up of 60 revision arthroplasties. J Bone Joint Surg Br 1998;80-3:391.

96. Schreurs BW, van Tienen TG, Buma P, et al. Favorable results of acetabular reconstruction with impacted morsellized bone grafts in patients younger than 50 years: a 10- to 18-year follow-up study of 34 cemented total hip arthroplasties. Acta Orthop Scand 2001;72-2:120.

97. van der Linde $M$, Tonino A. Acetabular revision with impacted grafting and a reinforcement ring: 42 patients followed for a mean of 10 years. Acta Orthop Scand 2001;72-3:221.

98. Soballe K, Hansen ES, Brockstedt-Rasmussen $\mathrm{H}$, et al. Hydroxyapatite coating converts fibrous tissue to bone around loaded implants. J Bone Joint Surg Br 1993;75-2:270.

99. Nivbrant B, Karrholm J. Migration and wear of hydroxyapatite-coated press-fit cups in revision hip arthroplasty: a radiostereometric study. J Arthroplasty 1997;12-8:904.

100. Geesink RG, Hoefnagels NH. Six-year results of hydroxyapatite-coated total hip replacement. J Bone Joint Surg Br 1995;77-4:534.

101. Capello WN, D'Antonio JA, Manley MT, et al. Hydroxyapatite in total hip arthroplasty. Clinical results and critical issues. Clin Orthop Relat Res 1998;355:200.

102. Garcia Araujo C, Fernandez Gonzalez J, Tonino A. Rheumatoid arthritis and hydroxyapatite-coated hip prostheses: five-year results. International ABG Study Group. J Arthroplasty 1998;13-6:660.

103. Tonino AJ, Therin M, Doyle C. Hydroxyapatite-coated femoral stems. Histology and histomorphometry around five components retrieved at post mortem. J Bone Joint Surg Br 1999;81-1:148

104. Tonino AJ, Rahmy AI. The hydroxyapatite-ABG hip system: 5- to 7-year results from an international multicentre study. The International ABG Study Group. J Arthroplasty 2000;15-3:274.

105. Tonino A, Oosterbos C, Rahmy A, et al. Hydroxyapatite-coated acetabular components. Histological and histomorphometric analysis of six cups retrieved at autopsy between three and seven years after successful implantation. J Bone Joint Surg Am 2001;83-A-6:817. 


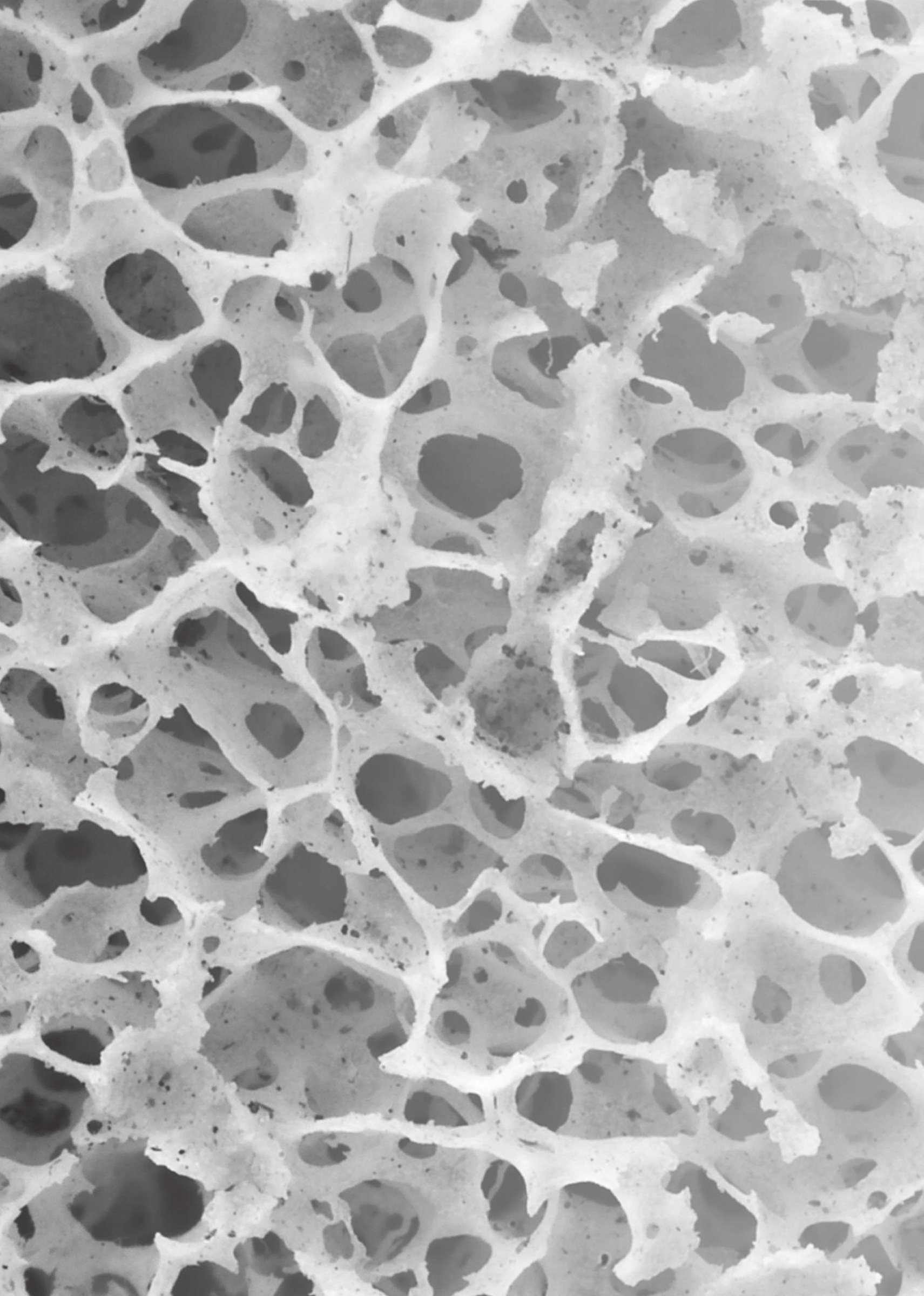




\section{Chapter Two}

The determination of linear and angular penetration of the femoral head into the acetabular component as an assessment of wear in total hip replacement A COMPARISON OF FOUR COMPUTER-ASSISTED METHODS

Geerdink CH, Grimm B, Vencken W, Heyligers IC, Tonino AJ.

J Bone Joint Surg Br. 2008 Jul;90(7):839-46. 


\begin{abstract}
We have compared four computer-assisted methods to measure penetration of the femoral head into the acetabular component in total hip replacement. These were the Martell Hip Analysis suite 7.14, Rogan HyperOrtho, Rogan View Pro-X and Roman $v 1.70$. The images used for the investigation comprised 24 anteroposterior digital radiographs and 24 conventional acetate radiographs which were scanned to provide digital images. These radiographs were acquired from 24 patients with an uncemented total hip replacement with a follow-up of approximately eight years (mean 8.1; 6.3 to 9.1). Each image was measured twice by two blinded observers. The mean annual rates of penetration of the femoral head measured in the eight-year single image analysis were: Martell, 0.24 (SD 0.19); HyperOrtho, 0.12 (SD 0.08); View Pro-X, 0.12 (SD 0.06); Roman, 0.12 (SD 0.07). In paired analysis of the sixmonth and eight-year radiographs: Martell, 0.35 (SD 0.22); HyperOrtho, 0.15 (SD 0.13); View Pro-X, 0.11 (SD 0.06); Roman, 0.11 (SD 0.07). The intra- and inter-observer variability for the paired analysis was best for View Pro-X and Roman software, with intraclass correlations of $0.97,0.87$ and 0.96, 0.87, respectively, and worst for HyperOrtho and Martell, with intraclass correlations of $0.46,0.13$ and $0.33,0.39$, respectively. The Roman method proved the most precise and the most easy to use in clinical practice and the software is available free of charge. The Martell method showed the lowest precision, indicating a problem with its edge detection algorithm on digital images.
\end{abstract}




\section{Introduction}

Wear of the polyethylene acetabular component is widely regarded as the primary factor limiting the longevity of total hip replacements (THRs). Particulate polyethylene debris invokes an inflammatory tissue response in the adjacent bone, leading to peri-prosthetic osteolysis and loosening of the implant. ${ }^{1-11}$ Polyethylene wear might also cause late instability of the hip, leading to dislocation in some cases. ${ }^{12}$ Various techniques have been developed to measure polyethylene wear in vivo, to monitor critical polyethylene wear in individual patients in the clinical setting and to compare the wear performance of different polyethylene inserts. All the methods of measurement of wear are based on quantifying the displacement (penetration) of the femoral head with reference to the acetabular component between two radiographs obtained at different times of followup (paired analysis), or on a single radiograph (single analysis) assuming a concentric position of the femoral head, and acetabular component directly after implantation before any wear could have occurred. Initially this was done by hand, on conventional radiographs using a compass, ruler and calliper, as described by Livermore, Ilstrup and Morrey, ${ }^{13}$ Charnley and Halley, ${ }^{14}$ and Kabo et al $^{15}$ and more recently by Kang et al. ${ }^{16}$ These techniques can result in a high variability between different users, and they lack the precision to yield useful information over shorter periods or in cases in which relatively small amounts of displacement of the femoral head have occurred. ${ }^{17}$ In the 1990s computerassisted techniques were developed to reduce the variability in measurement, to improve repeatability, and to increase the accuracy of measurement of penetration of the femoral head into the acetabular component compared with manual techniques. ${ }^{18-21}$ These programs combine the use of image analysis software with the determination of bone and prosthesis landmarks by hand or automated by a computer using an edge detection algorithm. Computer methods can determine wear twodimensionally on anteroposterior (AP) radiographs, such as in the manual methods, or some can calculate three-dimensional wear vectors combining information from matching AP and cross-table lateral radiographs. All geometrical methods to assess wear only measure linear penetration. When volumetric wear is given, values are estimated from the linear penetration and a formula correlating both, based on simple geometric assumptions, substantiated in some cases by geometrical implant data. ${ }^{22}$ Standard radiological assessment of penetration by the femoral head into the polyethylene liner does not enable clinicians to distinguish between the two processes which cause movement of the head, namely true wear (the removal of polyethylene particles) and so-called bedding-in (creep and settling of the liner) which occurs in the early postoperative phase. ${ }^{11,23,24}$ In the literature, measurements of penetration are correlated directly with wear. Röentgen sterophotogrammetric analysis (RSA), developed by Selvik, ${ }^{25}$ is considered the most accurate method for determining the magnitude of relative displacements, such as penetration of the femoral head, from radiological images. ${ }^{26,27}$ The requirement for tantalum beads to be placed into the implants and bone generally limits the use of this method to a small group of patients, and it can 
only be used in a prospective setting. There is a tendency for cemented acetabular components to be used in elderly, less active patients with less exposure to the risks of polyethylene wear, and for uncemented acetabular components to be used in relatively young and still active patients with a higher chance of suffering the consequences of wear. Thus, polyethylene wear measurement is of greater importance in patients who have uncemented metal-backed components. Several computer-assisted methods to determine linear penetration are commercially-available. From the available literature it is unclear whether these methods produce comparable results. The aim of our study was to find the easiest, most precise and most practical of four computer-assisted programs of wear measurement, and to see whether the values derived from different programs could be compared with each other. 


\section{Materials and Methods}

We performed in vivo wear measurement by determining the linear penetration of the femoral head into the acetabular component on radiographs of a cohort of 24 patients who had undergone THR using uncemented hydroxyapatite (HA)-coated components (ABG-II, Stryker, Mahwah, New Jersey). In 13 patients conventional airsterilised polyethylene inserts had been used and in 11 patients moderately crosslinked Duration polyethylene inserts (Stryker) were employed. The mean time of follow-up was 8.1 years (6.3 to 9.1). The primary diagnosis was osteoarthritis in all cases. The mean age at operation was 64 years (48 to 74). In 15 patients the left hip was replaced and in nine the right. An AP standing pelvic radiograph was obtained at six months and eight years post-operatively. The six-month image was scanned using a flatbed scanner (VIDAR Sierra plus, Ampronix Inc., Irvine, California) at a resolution of 300 dots per inch. The result was a 20 megapixel (MPix) image $(4375 \times 5375$ pixels). The eight-year digital image was made using a digital imager (AGFA Solo ADC, AGFA Gevaert NV, Peissenberg, Germany), producing a 5 Mpix image $(4300 \times 3500$ pixels). The radiographs were originally DICOM and transformed into TIFF greyscale without compression, as required for the Martell software. The penetration of the femoral head as a measure of polyethylene wear was assessed using four different computer- assisted methods: Martell Hip Analysis Suite version 7.14 (University of Chicago, Chicago, Illinois), Hyper- Ortho version 4.1 (Rogan Delft, Veenendaal, The Netherlands), View Pro-X version 2.0.1.11 (Rogan Delft), and Roman free to share software version V1.70 (Robert Jones \& Agnes Hunt Orthopaedic Hospital, Oswestry, United Kingdom). ${ }^{28}$ In all four programs the edges of the femoral head and the metal-backed acetabular component were determined manually by mouse-clicking on the edges. In the Martell Hip Analysis Suite clicking the edges of the femoral head and acetabular shell is used to guide the automated edge detection. The distance between the centre of the femoral head and the centre of the acetabular shell was measured after calibration of the image, using the known diameter of the femoral head to correct for magnification. Only the AP radiograph was measured (2D). In general, 2D measurements have been considered to underestimate the $3 \mathrm{D}$ wear value. ${ }^{19,29-31}$ Although there is controversy as to whether to use standing or supine radiographs, we used only standing radiographs for all our measurements. ${ }^{32-37}$

Martell Hip Analysis Suite version 7.14. This software uses TIFF greyscale images only. Automated edge detection software calculates the displacement of the femoral head. The penetration of the head and the angle of penetration are reported as the wear vector $(\mathrm{mm})$ and vector angle $\left(^{\circ}\right)$. The software uses a coordinate system which is similar to that of Livermore et al. ${ }^{13}$ The $y$ axis is a line drawn through the left and right ischial tuberosities. The $x$ axis is perpendicular to the $y$ axis. The centre of the coordinate system is the centre of the acetabular component. Medial and lateral cranially directed wear values are described as positive. Value angles are described between $-90^{\circ}$ and $+90^{\circ}$; laterallydirected angles are presented as a negative value. A 2D single measurement 
mode was chosen as the developer has reported that no accuracy is gained from the $3 \mathrm{D}$ analysis which the software also provides. ${ }^{29}$

HyperOrtho version 4.1. This software uses DICOM images only. The software calculates displacement of the femoral head by giving the cranial and medial displacement in millimeters according to the edge of the computer screen. The $x$ axis is the horizontal edge of the image; the $y$ axis is perpendicular to this line and thus independent of the patient's anatomy or position on the image, as well as the acetabular orientation. Medial and cranial directions of wear result in positive values. A wear angle can be calculated applying the Pythagoras' theorem. $^{38}$

View Pro-X 2.0.1.11. This software uses DICOM images only. The software calculates femoral head displacement $(\mathrm{mm})$ and the angle $\left(^{\circ}\right)$ as a representation of wear. The coordinate system used is different for each side of the patient. In the right hip, medial displacement is positive. Angles are given between $-180^{\circ}$ and $+180^{\circ}$. In the left hip lateral displacement is positive and angles are also given between $-180^{\circ}$ and $+180^{\circ}$. Roman free to share software version V1.70. This software accepts almost all image formats. We used TIFF greyscale images because they had to be converted in any case for the Martell method. Roman is a radiological measurement program designed for orthopaedic application in general, and the linear penetration of the head can be measured by applying a digital equivalent of the manual Livermore method using the compass and ruler function of the software. Circles of best fit are drawn around the femoral head and the acetabular component after identifying a minimum of three points for interpolation on the contours of both components, and using the ruler function to measure the displacement of the centres of each circle. An anglemeasuring tool is provided in the software to quantify the angle of displacement of the head. The coordinate system can be chosen as preferred by the user by determining the $x$ and $y$ axes.

Coordinate system.

As all four methods use different coordinate systems, it was necessary to transform them into one single system to compare the outcomes of the measurements. A cartesian coordinate system with reference to the acetabular component was considered more relevant for measurement of wear than those based on bony landmarks, which were more difficult to define and changed over time, or than the image itself, due to errors in positioning of the patient. The $x$ axis was set as the line of inclination of the acetabular component as defined by its medial and lateral margins. The y axis was the perpendicular line on the $x$ axis and travels through the centre of the acetabular component (Fig. 1). The result of a measurement is a vector which consists of a wear distance measured as the penetration of the head in $\mathrm{mm}$ and a wear penetration angle defined as ranging between $0^{\circ}$ and $360^{\circ}$, starting from the medial part of the $x$ axis. In this way, vectors for the left and right hips can be compared and potential confusion about negative wear is eliminated. Measurements and calculation. Intra-observer variability was determined 
for each method by determining the correlation coefficient of two measurements performed by one observer. Inter-observer variability was determined for each method by determining the correlation coefficient of two measurements performed by two different observers (CG, WV). Repeated measurements were performed after an interval of two weeks, and observers were blinded as to their first measurement. The average time to measure one AP radiograph was calculated for each of the methods. Correlation coefficients were determined to compare the rates of linear penetration of the head given by the four methods. The annual rates of penetration were calculated with single-image analysis using only the measurement of the eight-year radiographs, and in paired analysis using these at the six-month and the eight-year stage. Paired analysis was performed by combining the length of penetration and the direction in the six-month and eight-year images.

\section{Statistics.}

Pearson's correlation corefficient (r) was used to assess the agreement of the absolute values of linear penetration of the head in the four methods used. The intra-class correlation coefficient was used to address the intra- and inter-observer reliability of the four methods. We used SPSS 12.0 (SPSS Inc., Chicago, Illinois) for statistical analysis.

\section{Figure 1}

Definition of coordinate system

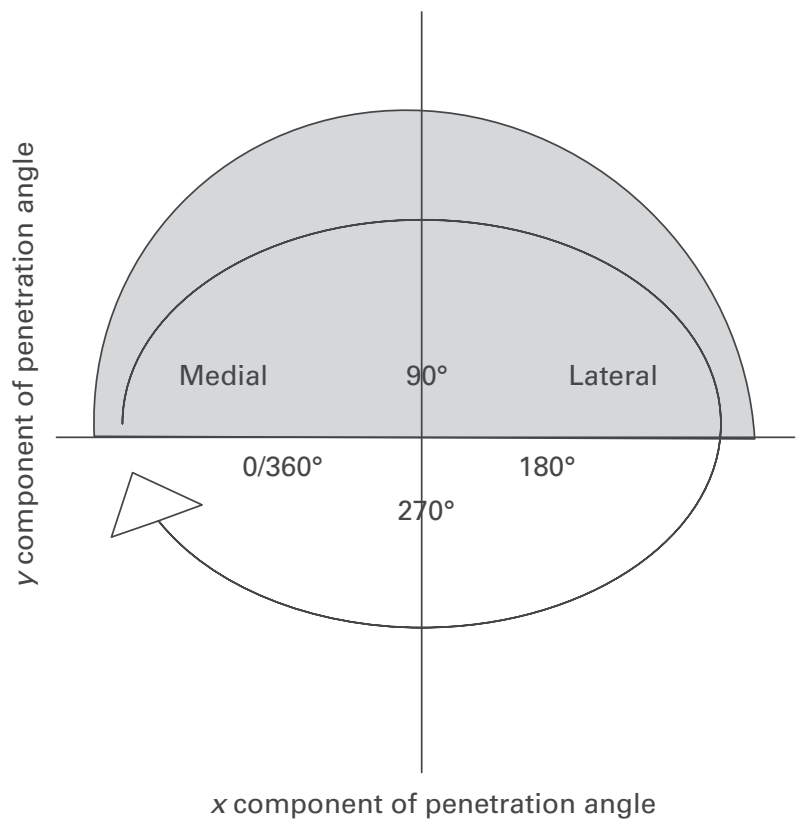




\section{Results}

When comparing the mean rates of linear penetration of the head measured for the entire group (Table I), both View Pro-X and Roman gave the same values, with a low standard deviation (SD) and small spread both for the single $(0.12 \mathrm{~mm} / \mathrm{yr})$ and paired analysis $(0.11 \mathrm{~mm} / \mathrm{yr})$. Hyper-Ortho gave the same mean rate in single-image analysis but a slightly higher result in paired analysis $(0.15 \mathrm{~mm} / \mathrm{yr})$, but the range and SD were larger for both analyses. The Martell Hip Analysis Suite produced quite different results, with a single measure analysis being as good as the other methods and approximately three times greater for the paired analyses. It also produced the greatest spread and SD of all the methods. Going from single-image analysis to paired analysis, the spread increased for all methods; in the Martell Hip Analysis Suite and HyperOrtho the SD also increased.

Intra-observer reliability for individual measurements of penetration was high and best for View Pro-X and Roman, with an intraclass correlation coefficient of 0.97 and 0.96, respectively in paired analysis at six months and eight years $(n=48)$. This was much lower for the Martell Hip Analysis Suite (0.33) and for HyperOrtho (0.46). The intraclass correlation coefficient was similar to these values when looking only at the eightyear images $(n=24)$, where total linear penetration is relatively high. Measuring the sixmonth images, when penetration is still low, the intra-class correlation coefficient was lower for all methods but remained highest for View-Pro-X and Roman $(n=24)$ (Table II).

Inter-observer reliability was generally less than intraobserver reliability, but was high and the best for View Pro-X and for Roman, with an intra-class correlation coefficient of 0.87 for both at paired analysis at six months and eight years $(n=48)$. The interobserver intra-class correlation coefficient was much lower for the Martell Hip Analysis Suite (0.39) and for HyperOrtho (0.13). Analysing only the eight-year images with high total penetration ( $\mathrm{n}=24$, single-image analysis), the inter-observer intraclass correlation coefficient was higher for all methods than for paired analysis, with View Pro- $X$ and Roman still providing the best results and the Martell Hip Analysis Suite and HyperOrtho remaining low. When looking at the sixmonth images only, when total penetration is still small, the inter-observer correlation was very low for all methods.

Comparing individual measurements of linear penetration of the head between the different programs showed a good correlation only between the Roman and View Pro-X for all measurements combined and for the eight-year images only (Pearson's $r=$ 0.90 and 0.91 , respectively). Measuring penetration of the head at six months showed a low correlation between all four programmes (Pearson's $r=-0.13$ to 0.30) (Table III). For paired analysis correlation was fair between the Roman and View Pro-X (Pearson's $r=0.61$ ), but a low correlation was found between the other programs (Pearson's $r=$ 0.05 to 0.38$)$.

The results of paired analysis and those of single-image analysis of the final follow-up at eight years for distance of penetration and the penetration angle were correlated (Table 
IV). Correlation between the distance measurements was high for View Pro-X (intraclass correlation coefficient 0.90) and Roman (intra-class correlation coefficient 0.87), and lower for Martell (intra-class correlation coefficient 0.43) and HyperOrtho (intraclass correlation coefficient 0.49 ). The correlation of measurements of the penetration angle was low for all programs.

Evaluation of the handling features in clinical practice revealed that the Roman software was best, apart from taking the longest time to make the measurements, with a mean of 2.63 minutes (2.51 to 2.72 ).

The Roman system can handle all common file formats and image qualities. Uniquely, it has the option to save images and analysis for later review or sharing, offers the adjustment of contrast and brightness, has a zoom function, and is free to download from the internet (Table V).

Table 1: Rates of linear penetration for each method of measurement.

\begin{tabular}{|c|c|c|c|c|c|c|}
\hline & \multicolumn{3}{|c|}{ Wear rate $8 y r s$ single analysis [mm/a] } & \multicolumn{3}{|c|}{ Wear rate $8 y r s$ paired analysis [mm/a] } \\
\hline & Mean & SD & range & Mean & SD & range \\
\hline View pro $\mathrm{x}$ & 0.12 & 0.06 & $0.04-0.26$ & 0.11 & 0.06 & $0.02-0.29$ \\
\hline Martell & 0.24 & 0.19 & $0.05-0.87$ & 0.35 & 0.22 & $0.02-0.85$ \\
\hline Roman & 0.12 & 0.07 & $0.04-0.29$ & 0.11 & 0.07 & $0.01-0.29$ \\
\hline Hyperortho & 0.12 & 0.08 & $0.00-0.38$ & 0.15 & 0.13 & $0.00-0.59$ \\
\hline
\end{tabular}

Table 2: Intra- and inter observer reliability.

\begin{tabular}{|c|c|c|c|c|c|c|}
\hline & \multicolumn{6}{|c|}{ Intraclass Correlations } \\
\hline & \multicolumn{2}{|c|}{6 months $n=24$} & \multicolumn{2}{|c|}{$8 y r s n=24$} & \multicolumn{2}{|c|}{6 months \& 8yrs $n=48$} \\
\hline & $\begin{array}{l}\text { Intra-obs. } \\
\text { reliability }\end{array}$ & $\begin{array}{l}\text { Inter-obs. } \\
\text { reliability }\end{array}$ & $\begin{array}{l}\text { Intra-obs. } \\
\text { reliability }\end{array}$ & $\begin{array}{l}\text { Inter-obs. } \\
\text { reliability }\end{array}$ & $\begin{array}{l}\text { Intra-obs. } \\
\text { reliability }\end{array}$ & $\begin{array}{l}\text { Inter-obs. } \\
\text { reliability }\end{array}$ \\
\hline View Pro-X & 0.68 & 0.04 & 0.96 & 0.91 & 0.97 & 0.87 \\
\hline Martell & 0.20 & -0.02 & 0.32 & 0.48 & 0.33 & 0.39 \\
\hline Roman & 0.53 & 0.35 & 0.98 & 0.91 & 0.96 & 0.87 \\
\hline HyperOrtho & 0.96 & 0.08 & 0.45 & 0.10 & 0.46 & 0.13 \\
\hline
\end{tabular}


Table 3: Correlation coefficients (Pearson's r) between the linear penetration results for each method.

\begin{tabular}{|c|c|c|c|}
\hline \multirow[b]{2}{*}{6 months $(n=24)$} & \multicolumn{3}{|c|}{ Correlation coefficient (Pearson's r) } \\
\hline & Martell & Roman & HyperOrtho \\
\hline View Pro-X & 0.30 & 0.03 & 0.26 \\
\hline Martell & & -0.13 & 0.19 \\
\hline Roman & & & 0.13 \\
\hline 8 years $(n=24)$ & Martell & Roman & HyperOrtho \\
\hline View Pro-X & 0.34 & 0.91 & 0.24 \\
\hline Martell & & 0.33 & 0.36 \\
\hline Roman & & & 0.16 \\
\hline Total $(n=48)$ & Martell & Roman & HyperOrtho \\
\hline View Pro-X & 0.38 & 0.90 & 0.26 \\
\hline Martell & & 0.32 & 0.30 \\
\hline Roman & & & 0.20 \\
\hline Paired $(n=24)$ & Martell & Roman & HyperOrtho \\
\hline View Pro-X & 0.27 & 0.61 & 0.05 \\
\hline Martell & & 0.15 & 0.38 \\
\hline Roman & & & 0.17 \\
\hline
\end{tabular}

Table 4: Correlation 8 year linear penetration and wear angle in paired versus single analysis.

\begin{tabular}{l|c|c|}
\hline & \multicolumn{2}{|c|}{ Intraclass Correlation } \\
\hline View Pro-X & 0.89 & Penetration angle \\
Martell & 0.43 & 0.68 \\
Roman & 0.87 & -0.11 \\
HyperOrtho & 0.49 & 0.58 \\
\hline
\end{tabular}


Table 5: Evaluation of software (best in bold).

\begin{tabular}{|c|c|c|c|c|}
\hline & View Pro X & Martell & Roman & Hyperortho \\
\hline Image requirement & DICOM & $\begin{array}{l}\text { TIFF greyscale; } \\
\text { minimum } \\
\text { resolution } 5 \mathrm{MPix}\end{array}$ & $\begin{array}{l}\text { All image } \\
\text { formats }\end{array}$ & DICOM \\
\hline Automated edge detection & No & Yes & No & No \\
\hline Saving of the image measured & Yes & No & Yes & No \\
\hline Saving of measurement results & Yes & Yes & Yes & No \\
\hline Contrast / brightness adjustment & Yes & No & Yes & Yes \\
\hline Region of interest zoom function & Yes & No & Yes & Yes \\
\hline $\begin{array}{l}\text { Avg. time to measure one image } \\
\text { [min] }\end{array}$ & 1.54 & 1.57 & 2.63 & 1.57 \\
\hline Other & $\begin{array}{l}\text { Part of PACS * } \\
\text { software }\end{array}$ & ca. $€ 3000$ & Free to share & ca. $€ 5000$ \\
\hline
\end{tabular}

*PACS, Picture archive and communications system

\section{Discussion}

We studied the variation in the measurement of the distances and angles of linear penetration of the femoral head into the polyethylene liners of acetabular components as a measure of wear in THR using four computer-assisted techniques. All these methods measured the distance between the centre of the femoral head and the centre of the metal acetabular shell with an accuracy and error limited partly by the individual pixel size. The digital images in this study were produced either by scanning the acetate radiographs at six months to provide images of $20 \mathrm{MPix}$, or at eight years by a digital imager, leading to images of $5 \mathrm{MPix}$. For an AP radiograph of the pelvis at six months this resulted in a pixel size of approximately $0.07 \mathrm{~mm}$, with $0.14 \mathrm{~mm}$ for the eightyear images setting a methodological limit to the accuracy of the measurement. In order to reduce error of measurement by $50 \%$, an image resolution four times greater is required. As this effect was the same for all four methods, it will not influence the comparison of the rates of linear penetration produced by each method. With a pixel size of approximately $0.14 \mathrm{~mm}$ in a $5 \mathrm{MPix}$ AP radiograph and the opinion that clinical linear penetration rates become important at approximately 0.05 to $0.10 \mathrm{~mm} /$ year, $^{11,39}$ the image resolution for studies of clinical wear should not be less. Comparing the annual rates of linear penetration, three of the four methods gave the same mean value and similar SD in single-image analysis. Only the Martell Hip Analysis Suite produced a much higher mean rate of linear penetration, as well as the largest SD and the widest 
range compared with the other three methods (Table I). The intra- and inter-observer reliabilities were also very low for this technique (Table II), as well as the correlations with the other programs (Table III). This disappointing result for the Martell method is in contrast to previous studies $29,30,40$ and suggests a systematic error, which we believe was caused by the inability of the automatic edge detection algorithm to correctly identify the mean between the femoral head and the polyethylene insert on direct digital images, which are less smooth than the scanned conventional radiographs used in the past. This explanation was validated when artificial smoothing of the direct digital images to emulate the appearance of scanned images improved the accuracy of edge detection and the reliability of the measurements of penetration. However, such image post-processing may alter the diagnostic quality of the radiograph, is timeconsuming, not standardised, and too complex to be recommended for routine measurements of clinical wear in practice, where direct digital images are increasingly becoming the standard format. Thus, Martell analysis was not repeated on the manipulated images. Methods relying on the observer to identify the edge were not affected by the difference between scanned and direct digital images, as the human eye can easily identify the borders of the femoral head and the acetabular component on both image types. Although Roman and View Pro-X produced measurements with the lowest SD, the best intra- and inter-observer reliability and the best correlations between the four methods, HyperOrtho performed less well regarding these parameters, despite giving identical mean rates of linear penetration in the single-image analysis. The reason for this is that HyperOrtho interpolates ellipses instead of circles, to be capable of measuring nonmetal-backed acetabular components. Elliptical interpolation causes large shifts of the centre of circles, reducing intra- and inter-observer reliability as well as the correlation of individual measurements with other methods.

In theory, paired analysis of penetration of the femoral head should give more accuracy than single-image analysis, as in paired analysis direct observation of the post-operative position of the head and the acetabular component is compared with their position at follow-up. In single-image analysis the head and the acetabular component are assumed to be concentric, with an initial displacement of zero. However, the single six-month measurement showed that for all methods the standard deviation was high and intra- and inter-observer reliability was low (Table II). Displacement of the femoral head at six months is not dominated by wear but distributed around zero, with an SD so high that it can only influence the accuracy of paired analysis in an adverse manner, resulting in a lower overall accuracy of a paired over single image analysis. In this study, View Pro-X and Roman were the most accurate and reliable methods, producing nearly identical average rates of linear penetration with equally low SD and ranges in both paired and single-image analyses. The intra and inter-observer reliability and the correlation between the two methods were better in single-image analysis, but only for the single eight-year measurement and not for those at six-months. Measurements at six months had very low correlation coefficients even between the most accurate 
methods (Table III), proving that the baseline measurement is too erratic to improve on the assumption of zero in a single-image analysis. In addition, The et $\mathrm{al}^{41}$ have shown that a significant error in measurement in a paired analysis is introduced by inevitable differences in the positioning between two follow-up radiographs, leading to inaccurate measurement of wear up to $0.4 \mathrm{~mm}$. Although correction algorithms can compensate for this error, it is currently not implemented in any commercial software. Considering the positioning error for paired images and the low accuracy of the baseline measurement, it seems that in clinical practice single-image analysis can be sufficient or even superior.

Measurement of the angles of penetration of the head was far less reliable than the measurement of the distance of penetration (Table IV). With linear penetration often measuring only a few multiples of the pixel size, the angle between two points can alter more in repeated measures than can the distance. As there are various definitions of wear angles and wear directions in the literature, comparison between published values is more difficult than for wear distance. The definition of wear angles in this study and applied to the measured angles of penetration avoids the misleading term 'negative wear'. In a recent publication of Wan, Boutary and Dorr, ${ }^{42}$ almost $50 \%$ of measurements performed with the Martell Hip Analysis Suite32 gave negative wear values and were attributed by the authors to error in measurements. However, negative wear distance or negative wear angles are only a function of the definition of the coordinate system, and these differ between the software methods used. Our coordinate system defines a vector consisting of a positive length and a positive angle ranging between $0^{\circ}$ and $360^{\circ}$. If, on the AP radiograph, the centre of the femoral head is located outside the acetabular component, this will not be the result of negative wear but can occur for several reasons including positioning of the patient in the radiation field ${ }^{41}$ the linear penetration pathway pushing the head out of the insert, radiographs acquired with the patient supine, with microseparation between the head and acetabular component and owing to the design of the acetabular component, which may be eccentric or hooded. The tolerances in the manufacturing might lead to an eccentric baseline position of the head and insert. An error could arise in measurement itself, especially when penetration is very small; and finally, there may be $2 \mathrm{D}$ projection of a $3 \mathrm{D}$ penetration pathway (Fig. 2). 


\section{Figure 2}

Due to the cup opening angle on a 2D radiograph, out of the cup directed wear vectors can still represent normal wear patterns (black arrows)

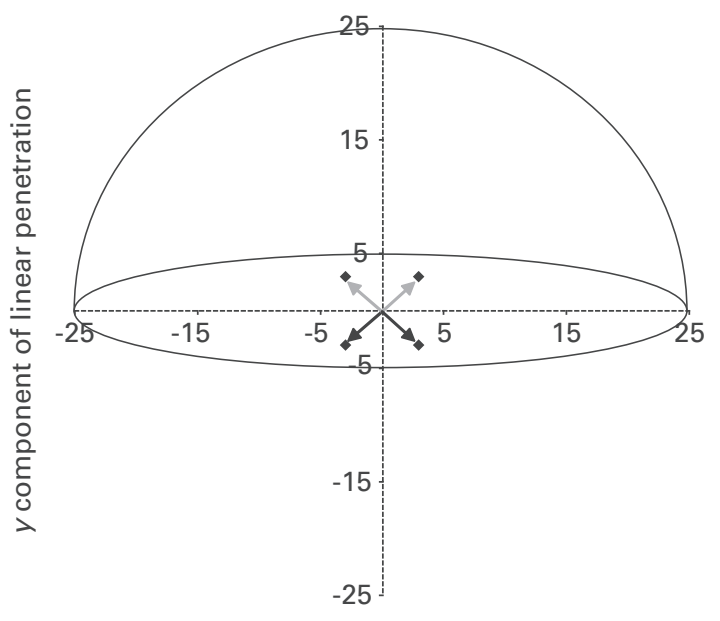

$x$ component of linear penetration

Computer-aided measurement of linear penetration of polyethylene can be accurate and reliable within the limits of image resolution, and a 5 MPix pelvic radiograph should be the minimum requirement. Edge detection by a human observer is more dependable with the new direct digital images than with automated software, and circular interpolation is superior for metal-backed components. We found that the Roman and View Pro-X software were the best for the assessment of linear penetration of the head as a measure of polyethylene wear in clinical practice. Although measurement with the Roman software takes slightly more time (Table V), its compatibility with all common image formats and its free availability make it an attractive option. 


\section{References}

1. Cooper RA, McAllister CM, Borden LS, Bauer TW. Polyethylene debris-induced osteolysis and loosening in uncemented total hip arthroplasty: a cause of late failure. J Arthroplasty 1992;7:285-90.

2. Harris WH. The problem is osteolysis. Clin Orthop 1995;311:46-53.

3. Zicat B, Engh CA, Gokcen E. Patterns of osteolysis around total hip components inserted with and without cement. J Bone Joint Surg [Am] 1995;77-A:432-9.

4. Willert HG, Bertram H, Buchhorn GH. Osteolysis in alloarthroplasty of the hip: the role of ultra-high molecular weight polyethylene wear particles. Clin Orthop 1990;258:95-107.

5. Wan Z, Dorr LD. Natural history of femoral focal osteolysis with proximal ingrowth smooth stem implant. J Arthroplasty 1996;11:718-25.

6. Joshi AB, Markovic L, Ilchmann T. Polyethylene wear and calcar osteolysis. Am J Orthop 1999;28:45-8.

7. Harris WH. Osteolysis and particle disease in hip replacement: a review. Acta Orthop Scand 1994;65:113-23.

8. Schmalzried TP, Jasty M, Harris WH. Periprosthetic bone loss in total hip arthroplasty: polyethylene wear debris and the concept of the effective joint space. J Bone Joint Surg [Am] 1992;74-A:849-63.

9. Dumbleton JH, Manley MT, Edidin AA. A literature review of the association between wear rate and osteolysis in total hip arthroplasty. J Arthroplasty 2002;17:649-61.

10. Orishimo KF, Claus AM, Sychterz CJ, Engh CA. Relationship between polyethylene wear and osteolyis in hips with a second-generation porous-coated cementless cup after seven years of follow-up. J Bone Joint Surg [Am] 2003;85-A:1095-9.

11. Dowd JE, Sychterz CJ, Young AM, Engh CA. Characterization of long-term femoral-head-penetration rates: association with and prediction of osteolysis. J Bone Joint Surg [Am] 2000;82-A:1102-7.

12. Parvizi J, Wade FA, Rapuri V, et al. Revision hip arthroplasty for late instability secondary to polyethylene wear. Clin Orthop 2006;447:66-9.

13. Livermore J, Ilstrup D, Morrey B. Effect of femoral head size on wear of the polyethylene acetabular component. J Bone Joint Surg [Am] 1990;72-A:518-28.

14. Charnley J, Halley DK. Rate of wear in total hip replacement. Clin Orthop 1975;112:170-9.

15. Kabo JM, Gebhard JS, Loren G, Amstutz HC. In vivo wear of polyethylene acetabular components. J Bone Joint Surg [Br] 1993;75-B:254-8.

16. Kang JS, Park SR, Ebramzadeh E, Dorr LD. Measurement of polyethylene wear in total hip arthroplasty: accuracy versus ease of use. Yonsei Med J 2003;30:473-8.

17. Clarke JC, Black K, Rennie C, Amstutz HC. Can wear in total hip arthroplasties be assessed from radiographs? Clin Orthop 1976;121:126-42.

18. Martell JM, Berdia S. Determination of polyethylene wear in total hip replacements with use of digital radiographs? J Bone Joint Surg [Am] 1997;79-A:1635-41.

19. Devane PA, Bourne RB, Rorabeck CH, Hardie RM, Horne JG. Measurement of polyethylene wear in metal-backed acetabular cups. I: three-dimensional technique. Clin Orthop 1995;319:303-16.

20. Devane PA, Bourne RB, Rorabeck CH, MacDonald S, Robinson EJ. Measurement of polyethylene wear in metal-backed acetabular cups. II: clinical application. Clin Orthop 1995;319:317-26.

21. Shaver SM, Brown TD, Hillis SL, Callaghan JJ. Digital edge-detection measurement of polyethylene wear after total hip arthroplasty. J Bone Joint Surg [Am] 1997;79-A:690-700.

22. Charnley J, Kamangar A, Longfield MD. The optimum size of prosthetic heads in relation to the wear of plastic sockets in total replacement of the hip. Med Biol Eng 1969;7:31-9.

23. Sychterz CJ, Engh CA Jr, Yang A, Engh CA. Analysis of temporal wear patterns of porous-coated acetabular components: distinguishing between true wear and socalled bedding-in. J Bone Joint Surg [Am] 1999;81-A:821-30.

24. Sychterz CJ, Engh CA Jr, Shah N, Engh CA Sr. Radiographic evaluation of penetration by the femoral head into the polyethylene liner over time. J Bone Joint Surg [Am] 1997;79-A:1040-6.

25. Selvik G. A stereophotogrammetric system for the study of human movements. Scand J Rehabil Med Suppl 1978;6:16-20. 
26. Röhrl SM, Nivbrant B, Ström H, Nilsson KG. Effect of augmented cup fixation on stability, wear, and osteolysis: a 5-year follow-up of total hip arthroplasty with RSA. J Arthroplasty 2004;19:962-71.

27. Röhrl S, Nivbrant B, Mingguo L, Hewitt B. In vivo wear and migration of highly cross-linked polyethylene cups: a radiostereometry analysis study. J Arthroplasty 2005;20:409-13.

28. No authors listed. Roman free to share software version V1.70. http:// www.Keele.ac.uk/depts/rjah/ (date last accessed 21 May 2008).

29. Martell JM, Berkson E, Berger R, Jacobs J. Comparison of two and three-dimensional computerized polyethylene wear analysis after total hip arthroplasty. J Bone Joint Surg [Am] 2003;85-A:1111-17.

30. Hui AJ, McCalden RW, Martell JM, et al. Validation of two and three-dimensional radiographic techniques for measuring polyethylene wear after total hip arthroplasty. J Bone Joint Surg [Am] 2003;85A:505-11.

31. Sychterz CJ, Yang AM, McAuley JP, Engh CA. Two-dimensional versus threedimensional radiographic measurements of polyethylene wear. Clin Orthop 1999;365:117-23.

32. Digas G, Kärrholm J, Thanner J, Malchau H, Herberts P. Highly cross-linked polyethylene in cemented THA: randomized study of 61 hips. Clin Orthop 2003;417:126-38.

33. Smith PN, Ling RS, Taylor R. The influence of weight-bearing on the measurement of polyethylene wear in THA. J Bone Joint Surg [Br] 1999;81-B:259-65.

34. Bragdon CR, Thanner J, Greene ME, et al. Standing versus supine radiographs in RSA evaluation of femoral head penetration. Clin Orthop 2006;448:46-51.

35. Digas G, Kärrholm J, Thanner J, Malchau H, Herberts P. Highly cross-linked polyethylene in total hip arthroplasty: randomized evaluation of penetration rate in cemented and uncemented sockets using radiostereometric analysis. Clin Orthop 2004;429:6-16.

36. Martell JM, Leopold SS, Liu X. The effect of joint loading on acetabular wear measurement in total hip arthroplasty. J Arthroplasty 2000;15:512-18.

37. Moore KD, Barrack RL, Sychterz CJ, et al. The effect of weight-bearing on the radiographic measurement of the position of the femoral head after total hip arthroplasty. J Bone Joint Surg [Am] 2000;82-A:62-9.

38. MacFarlane A. The pythagorean theorem. Science 1911;34:181-2.

39. Barrack RL, Folgueras A, Munn B, Tvetden D, Sharkey P. Pelvic lysis and polyethylene wear at 5-8 years in an uncemented total hip. Clin Orthop 1997;335:211-17.

40. Martell JM, Verner JJ, Incavo SJ. Clinical performance of a highly cross-linked polyethylene at two years in total hip arthroplasty: a randomized prospective trial. J Arthroplasty 2003;18(7 Suppl 1):55-9.

41. The B, Mol L, Diercks RL, van Ooijen PM, Verdonschot N. Correction of error in two-dimensional wear measurements of cemented hip arthroplasties. Clin Orthop 2006;442:180-6.

42. Wan Z, Boutary M, Dorr LD. Precision and limitation of measuring two-dimensional wear on clinical radiographs. Clin Orthop 2006;449:267-74. 


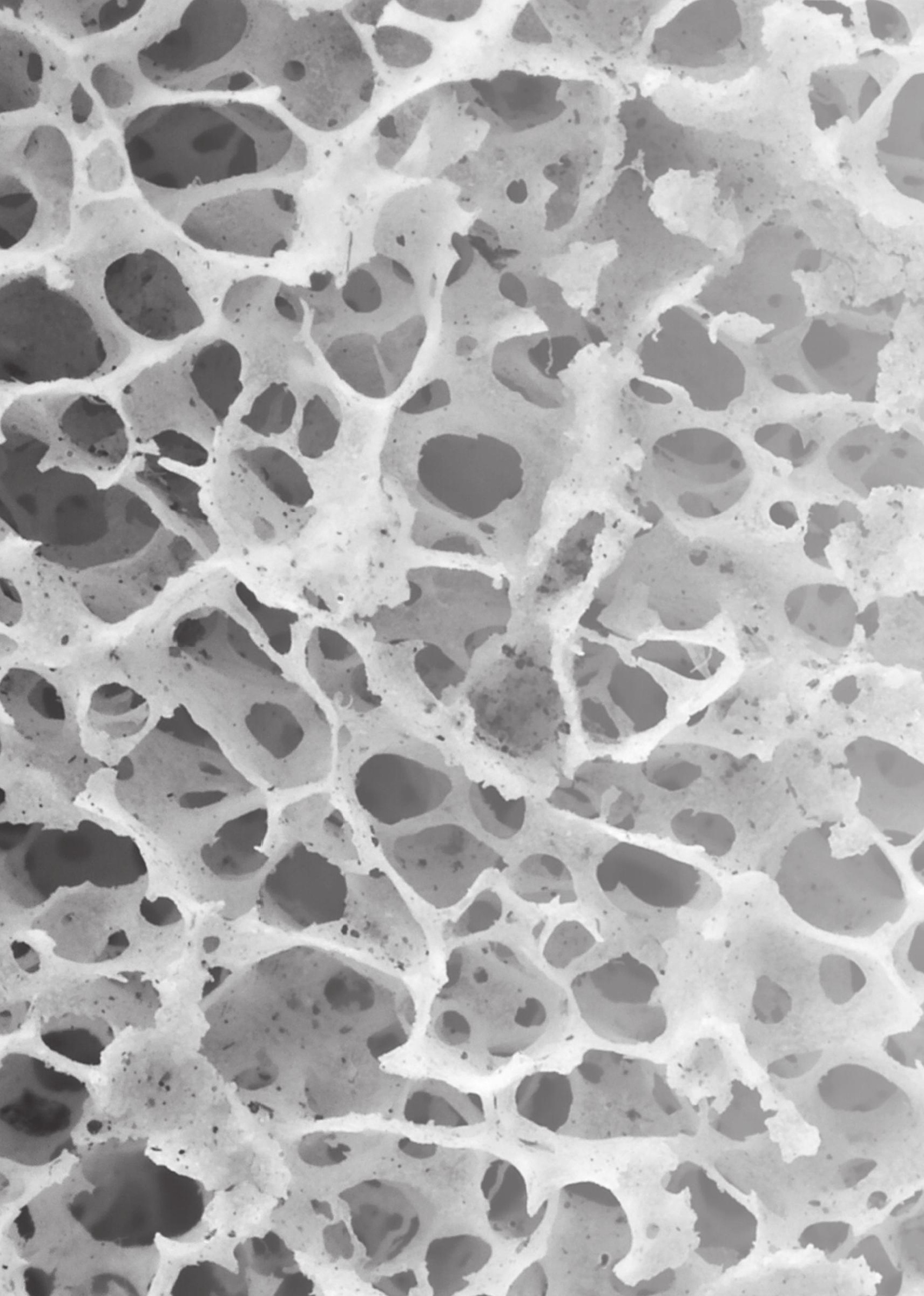




\section{Chapter Three}

Crosslinked polyethylene compared to conventional polyethylene in total hip replacement Pre-clinical evaluation, in-vitro testing and prospective clinical followup study

Geerdink CH, Grimm B, Ramakrishnan R, Rondhuis J, Verburg AJ, Tonino AJ.

Acta Orthop. 2006 Oct;77(5):719-25. 


\begin{abstract}
Polyethylene wear-induced osteolysis is a major cause of implant loosening in total hip arthroplasty. New crosslinked polyethylenes are presumed to give lower wear rates, but no long-term clinical results are available yet. We compared basic material characteristics and MTS hip joint simulator wear rates of a crosslinked polyethylene (Duration) to those of conventional polyethylene. In a randomized double-blind 5-year clinical follow-up study, 133 hips (67 conventional, 66 Duration) in 127 patients were followed-up for an average of 5 (3-6) years. Wear rates were measured using a computer-based edge detection method. The radiographic appearances of wearrelated phenomena were recorded. The Duration polyethylene showed a significantly lower in-vitro wear rate in the simulator study (mean 22 (SD 2.3) vs. 40 (SD 1.5) $\mathrm{mm} 3 / 106$ cycles). Also, the in-vivo wear was lower for Duration (mean 0.083 (SD $0.056) \mathrm{mm} /$ year) than for conventional polyethylene mean 0.123 (SD 0.082) $\mathrm{mm} /$ year). All radiographic signs of osteolysis were less frequent in the Duration group. Our study has given a substantial body of evidence-from lower wear rates, less frequent signs of osteolysis, and higher survival rates after a mean follow-up of 5 years-that Duration provides better clinical outcomes than conventional polyethylene.
\end{abstract}




\section{Introduction}

In total hip arthroplasty, wear particle-induced osteolysis is a major cause of aseptic implant loosening. The osteolytic effect of the wear debris depends on the cytotoxicity of the material (polyethylene, ceramic or metal), the size and morphology of the debris particles, the pathways available for particle migration, and the volume of wear particles produced and released into the periprosthetic tissue. Several authors have established that lower wear rates substantially reduce the incidence of osteolysis and increase the survival of the implants. ${ }^{1-7}$ The resistance of ultra-high-molecular-weight polyethylene to adhesive and abrasive wear can be increased by increasing the degree of crosslinking, the formation of covalent bonds between the backbone molecular chains. ${ }^{8}$ Polyethylene crosslinking for clinical application is achieved by irradiation. During the irradiation process, the level of crosslinking can be influenced by the type of radiation (e.g. Co60 gamma, electron beam), the dose (20-100 kGy), the atmosphere (air, nitrogen, argon), and/or post-radiation treatment (e.g. sequential radiation, annealing, remelting). These process parameters also influence the degree of unwanted side effects of radiation crosslinking, such as the creation of free radicals which lead to oxidation, embrittlement and accelerated wear during ageing. Annealing can induce further crosslinking by promoting recombination of free radicals. Early polyethylene was irradiated mainly for the purpose of sterilization at low doses (ca 20-30 kGy) and in air, leading only to low crosslink densities and to oxidation and embrittlement during ageing. This "conventional" polyethylene was used clinically until the late 1990s when it was gradually replaced by subsequent generations of moderately and highly crosslinked polyethylenes. These highly crosslinked materials show promisingly low wear rates in hip simulator studies ${ }^{9}$, but due to their relative novelty, there have been relatively few clinical studies, either with a follow-up that has been too short ${ }^{10}$ or patients have not been randomized to a well-matched control. This is a problem, as clinical wear rates can vary enormously depending on patient demographics; even sophisticated computer- based wear measurement methods produce errors, making follow-up times of less than 3 years unreliable. ${ }^{11}$ In addition, comparison of wear rates from different studies using different techniques must also be interpreted with caution. ${ }^{12}$ This study compares the wear rates and radiographic signs of osteolysis of conventional polyethylene with those of Duration - a new, moderately crosslinked polyethylene-in a 5-year randomized clinical follow-up study. Wear of both materials was assessed in a hip simulator study and by basic characterization of their material properties, to assess the advantages (or disadvantages) of the elevated crosslink density of the newer polyethylene. Our hypothesis was that the Duration polyethylene produces lower clinical wear rates and fewer radiographic signs of osteolysis, and that this superior wear resistance in-vivo is reflected by the in-vitro test results. 


\section{Material and methods}

\section{Preparation of material}

All acetabular cup inserts were manufactured from ram-extruded rods converted from Hoechst GUR 415 resin by the Standard Specification for Ultra-High-Molecular-WeightPolyethylene Powder and Fabricated Form for Surgical Implants (Poly-Hi Solidur), with a molecular weight between 5 and $6106 \mathrm{~g} / \mathrm{mol}$. Two materials, conventional and Duration polyethylene were produced by different radiation and sterilization processes in order to be used in preclinical testing and the clinical study. The inserts to be named conventional polyethylene were packaged and sealed into a double plastic blister surrounded by air, and the package was then irradiated at a dose of $30 \mathrm{kGy}$. The inserts to be labeled Duration were placed in two blisters which were evacuated and then flushed with nitrogen prior to sealing. The oxygen concentration in the inner blister was less than $0.5 \%(\mathrm{v} / \mathrm{v})$ and the concentration in the outer blister was less than $5 \%(\mathrm{v} / \mathrm{v})$ at the time of packaging. The completed package was then gamma-irradiated at a dose of $30 \mathrm{kGy}$. Following irradiation, the package was placed in an oven for annealing at a temperature of $50^{\circ} \mathrm{C}$ for $144 \mathrm{~h}$. The annealing was meant to increase crosslink density by promoting free radical recombination.

\section{Characterization of materials}

For a basic comparison, preclinical tests of a physical, chemical and mechanical nature were performed (Table 1) on both the conventional polyethylene and the Duration polyethylene, with particular interest in measuring differences in crosslink density using the Small Punch Test. ${ }^{13}$ For each test, 4 samples were analyzed and compared using the unpaired two-sided Student t-test.

Table 1: Methods for derivation of basic polyethylene properties.

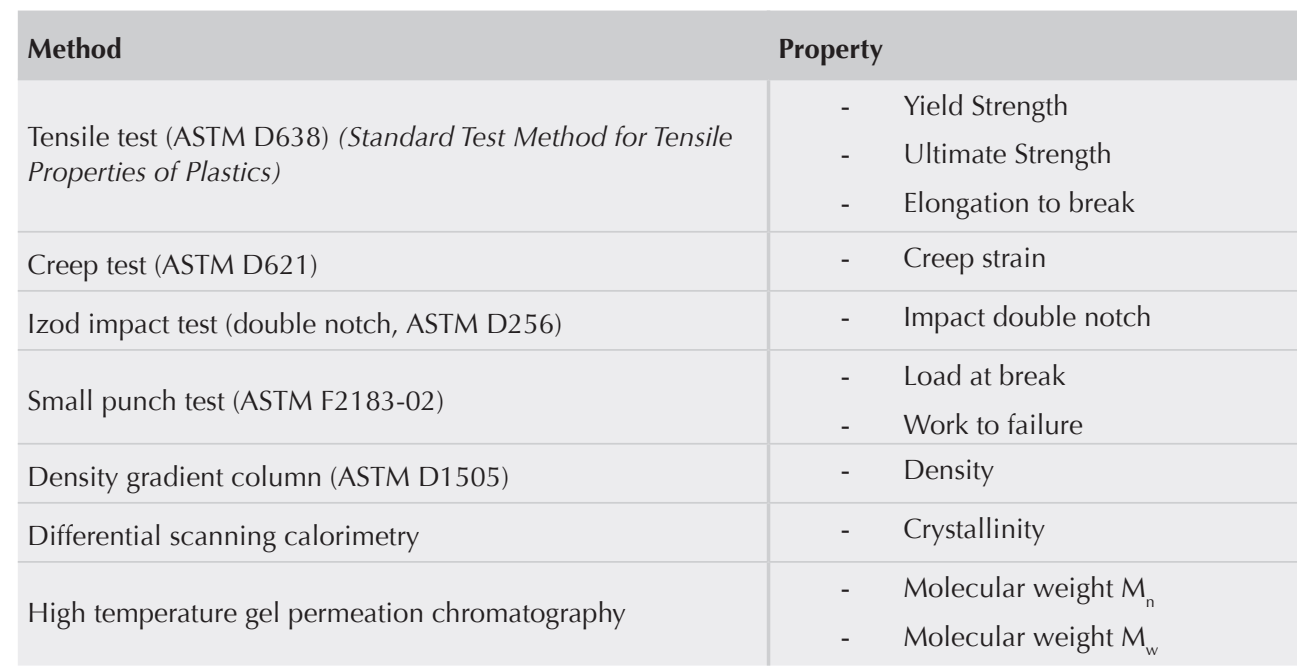




\section{Hip simulator}

Tribological tests were performed on an MTS hip joint simulator with biaxial rocking through a $23^{\circ}$ load angle according to a Paul-type physiological curve. Peak load was 2,450 N and load frequency was $1 \mathrm{~Hz}$. Sterile-filtered bovine calf serum (Sigma) was used as a lubricant, with the addition of $0.3 \%$ sodium azide to prevent degradation. Test chambers were sealed with polyethylene bags to prevent contamination and evaporation. Wear was determined gravimetrically every 250,000 cycles using soak controls to compensate for fluid sorption. The test was terminated after 10 million cycles and the average linear and volumetric wear rates were calculated.

\section{Randomized clinical study}

After obtaining informed consent and ethical approval, 127 patients (133 hips) were included in a randomized prospective clinical study performed at 3 hospitals by 3 surgeons. We included patients with osteoarthritis, rheumatoid arthritis, avascular necrosis of the femoral head, or posttraumatic arthritis of the hip. The mean age was 63 (37-74) years. Patients were excluded if they had had prior hip surgery at the site of operation. Following inclusion, patients were assigned to either a conventional insert or the Duration insert by double-blind block randomization. Both inserts were of the same hemispherical design and were mated to an ABG-II hydroxyapatite-coated hemispherical acetabular shell made of titanium alloy (Stryker, Mahwah, NJ). The femoral implant was not controlled, but consisted of either a press-fit hydroxyapatitecoated stem or a cemented ABG-II stem. All femoral heads were of CoCr alloy and measured $28 \mathrm{~mm}$ in diameter; thus, a major factor influencing wear was standardized. Clinical follow-up parameters were assessed at postoperative patient visits after less than 6 weeks, and at 1, 2, 3 and 5 years postoperatively. Standard radiographs were obtained for measurement of wear and identification of migration, loosening, and potentially wear-related phenomena such as radiolucencies and osteolysis in both the femur and acetabulum. Findings were expressed according to the 7 Gruen regions for the femur and the 3 DeLee and Charnley regions for the acetabulum. The zerowear baseline radiographs were obtained at more than 28 days and less than 6 weeks postoperatively, in order to minimize the effects of joint laxity on the seating of the femoral head into the acetabular liner. Wear was measured by a single observer using a validated computer-based edge-detection technique, which has been described previously. ${ }^{14}$ The technique uses sequentially applied custom convolution kernels to the region of interest, thereby extracting the best-fit circles defining the femoral head and the acetabular shell. Edge detection and extraction is performed in a completely automated manner, thereby reducing inter- and intraobserver errors. While both anteroposterior (AP) and lateral radiographs were obtained at each interval, only the AP radiographs were used to assess wear. ${ }^{15}$ Volumetric wear was calculated from the 2D anterior-posterior radiograph based on the amount of linear wear, the wear angle with respect to the cup face (beta angle), and the size of the femoral head, using a modified version of previously described geometric relationships. ${ }^{16}$ 


\section{Statistics}

Linear and volumetric wear rates were compared using the non-paired, two-tailed Student t-test and the Mann-Whitney $U$ test. Survival analysis was performed with radiographic evidence of the onset of osteolysis as the endpoint.

\section{Results}

\section{Characterization of material}

All material properties measured were not statistically significantly different between the conventional polyethylene and the Duration polyethylene, apart from the "load at break" in the Small Punch Test (Table 1). While the average "load at break" for conventional polyethylene was mean 84 (SD 2.2) N, the Duration material scored mean 94 (SD 3.3) N, giving evidence of elevated crosslink density. Virgin, non-irradiated polyethylene tested as reference showed a mean "load at break" of 71 (SD 2.2) N, indicating the level of additional crosslink density achieved.

Hip simulator

The mean volumetric wear rate measured after 2 million cycles was 40 (SD 1.5) $\mathrm{mm} 3 / 106$ cycles for the conventional polyethylene, and only 22 (SD 2.3) mm3/106 cycles for the Duration inserts, a $45 \%$ reduction $(p=0.03)$. The difference in wear rates diminished with time, so that at 10 million cycles the reduction in wear rate achieved by the Duration inserts was down to $32 \%$ (Figure 1 ).

Figure 1: Accumulated wear volumes during hip simulator testing (mean $\pm S D$ ).

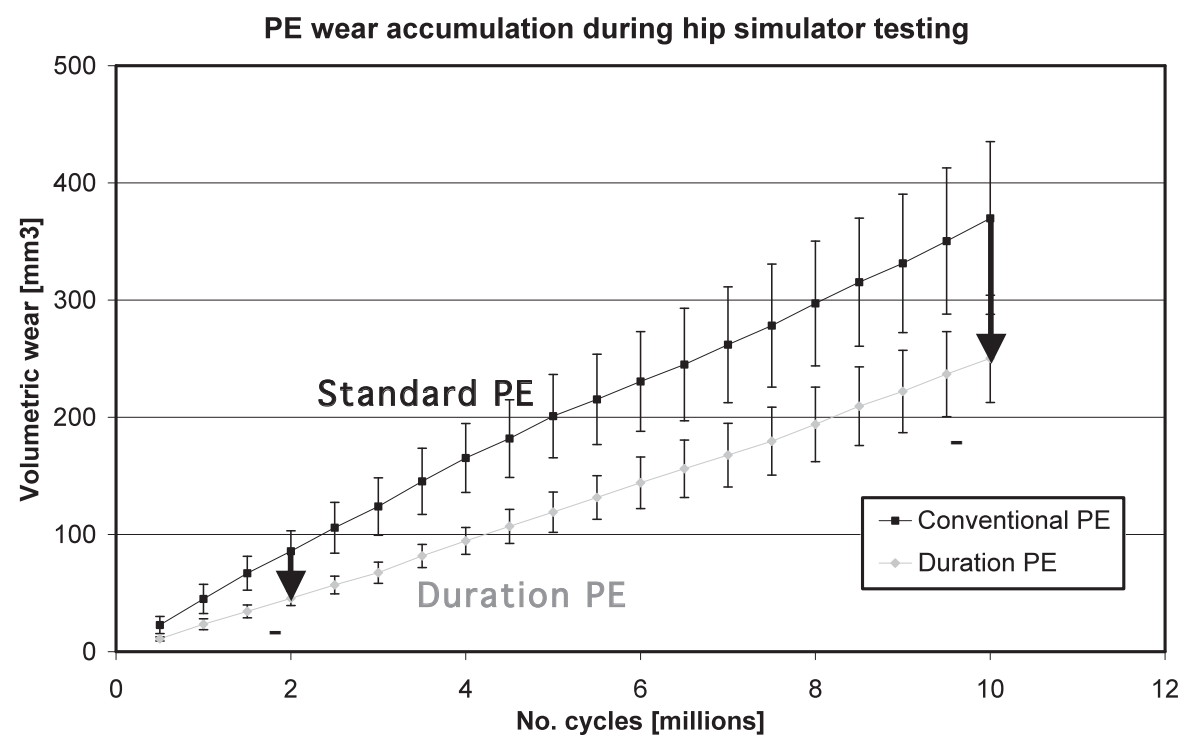




\section{Randomized clinical study}

127 patients with 133 implants (67 conventional, 66 Duration) had a mean follow-up of 4.7 (3-6) years. 6 patients (3 conventional, 3 Duration) died after a mean follow-up period of 3.5 years. The cause of death was unrelated to the prosthesis. 2 stems paired to conventional polyethylene inserts were revised after a mean period of 3 years because of excessive thigh pain, but no osteolysis was bserved in these cases. No Duration insert had to be revised. For the remaining 125 implants, 10 cases (4 conventional, 6 Duration) were lost due to inadequate follow-up ( $<36$ months) and a further 15 were lost because the quality of the radiographs was insufficient for accurate wear measurement (5 conventional, 10 duration). This left 54 conventional implants and 45 Duration implants for statistical analysis. The two groups were well matched for age, body mass index, follow-up time, liner thickness, cup diameter, use of uncemented or cemented stem, and primary diagnosis (Table 2).

Table 2: Patients demographics. There are no significant differences between groups.

\begin{tabular}{|c|c|c|c|}
\hline & & Conventional PE & Duration PE \\
\hline \multicolumn{2}{|l|}{ Total } & 54 & 45 \\
\hline Age: & $\begin{array}{l}\text { Mean } \pm \text { SD. (range) } \\
\text { [years] }\end{array}$ & $62.8 \pm 6.3(37-72)$ & $63.58 \pm 5.1(45-74)$ \\
\hline BMI: & Mean \pm SD. (range) & $26.9 \pm 4.5(21.3-49.0)$ & $27.6 \pm 4.3(21.1-39.5)$ \\
\hline \multicolumn{2}{|l|}{ Follow up: } & $4.72(3.3-5.9)$ & $4.74(3.1-5.5)$ \\
\hline \multicolumn{2}{|c|}{ Ratio stem uncemented/cemented } & $42 / 12$ & $36 / 9$ \\
\hline Cup diameter: & $\begin{array}{l}\text { Mean } \pm \text { SD. (range) } \\
{[\mathrm{mm}]}\end{array}$ & $54.1 \pm 2.9(48-60)$ & $54.1 \pm 3.4(48-60)$ \\
\hline Liner thickness: & $\begin{array}{l}\text { Mean } \pm \text { SD. (range) } \\
{[\mathrm{mm}]}\end{array}$ & $9.06 \pm 1.43(6-12)$ & $9.04 \pm 1.69(6-12)$ \\
\hline $\begin{array}{r}\text { Primary diagnos } \\
\text {-osteoarthrit } \\
\text {-post trauma } \\
\text {-reumatoid }\end{array}$ & hritis & $\begin{array}{l}51 \\
2 \\
1\end{array}$ & $\begin{array}{l}43 \\
2 \\
-\end{array}$ \\
\hline
\end{tabular}

\section{Polyethylene wear}

Between baseline and last follow-up, conventional polyethylene produced a linear wear rate of 0.12 (SD 0.082) $\mathrm{mm} /$ year and a volumetric wear rate of 60 (SD 43) mm3/ year. The Duration polyethylene wore significantly more slowly, at a linear rate of 0.083 (SD 0.056) mm/year and a volumetric rate of 44 (SD 34) $\mathrm{mm} 3 /$ year, a reduction of $33 \%$ and $28 \%$ respectively $(p=0.008$ and $p=0.04$; Mann-Whitney U-test). No correlation between wear rate and age, body mass index, liner thickness, cup diameter or method of stem fixation (uncemented/ cemented) could be found. The distribution of linear wear rates was narrower with Duration polyethylene and it lacked the high value outliers observed for conventional polyethylene (Figure 2). 
Figure 2: Histogram of in-vivo linear wear rates.

Histogram in-vivo linear wear rates

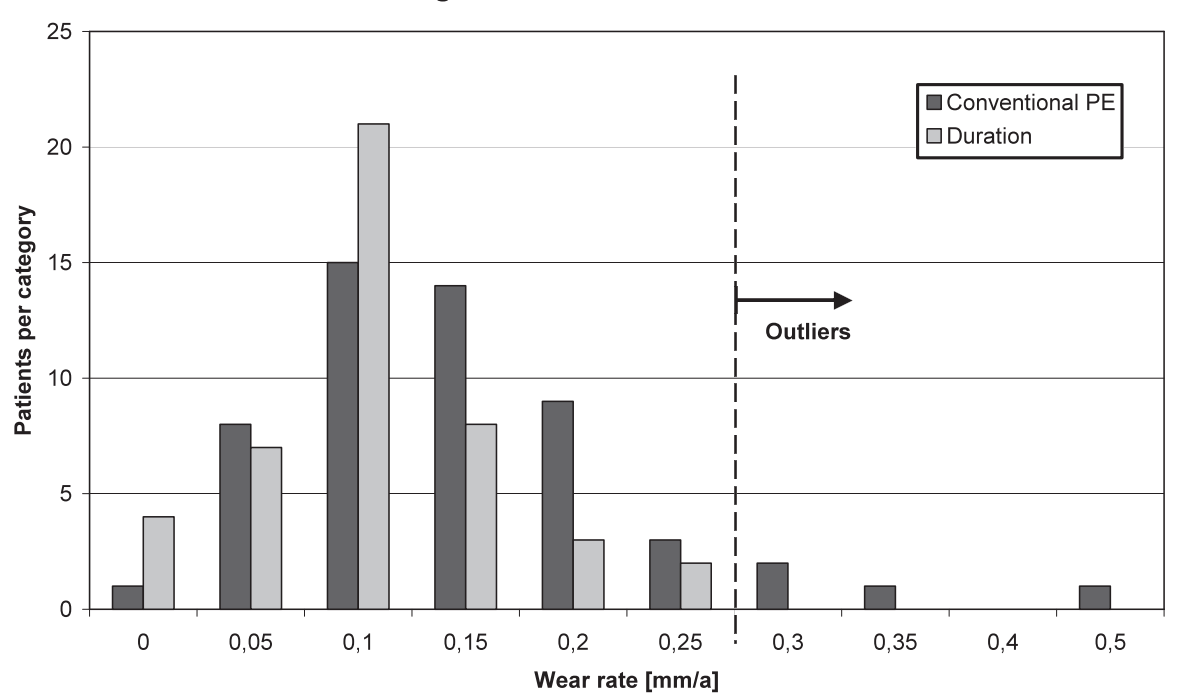

Radiographic evaluation

Phenomena that are potentially wear particleinduced, such as radiolucencies in the proximal Gruen regions 1 and 7, acetabular radiolucencies, femoral osteolysis and femoral aseptic loosening, were much more common with conventional polyethylene than with the Duration material. Polyethylene penetration occurred 2.4 times more often in conventional inserts than in Duration inserts (Table 3). The survival rates for not having femoral osteolysis at 5 -year follow-up were $92 \%$ for conventional polyethylene and $98 \%$ for Duration polyethylene. 
Table 3: Radiographic observations at maximum follow-up.

\begin{tabular}{|c|c|c|c|c|}
\hline \multirow{2}{*}{$\begin{array}{l}\text { Radiographic } \\
\text { Phenomenon }\end{array}$} & \multicolumn{2}{|c|}{ Counts } & \multicolumn{2}{|c|}{ Percentage [\%] } \\
\hline & Conventional & Duration & Conventional & Duration \\
\hline \multicolumn{5}{|l|}{ Femoral Radiolucencies } \\
\hline - None & 28 & 28 & 45.2 & 49.1 \\
\hline - Gruen zones 1 or 7 & 7 & 2 & 11.3 & 3.5 \\
\hline - Gruen zones 2-6 & 31 & 28 & 50.0 & 49.1 \\
\hline \multicolumn{5}{|l|}{ Acetabular Radiolucencies } \\
\hline - None & 50 & 44 & & \\
\hline - DeLee \& Charnley zone 1 & 2 & 1 & 3.7 & 2.2 \\
\hline - DeLee \& Charnley zone 2 & 1 & 0 & 1.9 & 0 \\
\hline - DeLee \& Charnley zone 3 & 1 & 0 & 1.9 & 0 \\
\hline Femoral osteolysis & 5 & 1 & 8.1 & 1.8 \\
\hline Femoral aseptic loosening & 3 & 1 & 4.8 & 1.8 \\
\hline Acetabular aseptic loosening & 0 & 0 & 0 & 0 \\
\hline PE Penetration & 8 & 3 & 12.9 & 5.3 \\
\hline \multicolumn{5}{|l|}{ Femoral Hypertrophy } \\
\hline - Cancellous & 23 & 30 & 37.1 & 52.6 \\
\hline - Cortical & 17 & 12 & 27.4 & 21.1 \\
\hline Corticocancellisation & 23 & 24 & 37.1 & 42.1 \\
\hline
\end{tabular}

\section{Discussion}

Crosslink density and wear resistance of the new polyethylene Duration could be raised without increasing the radiation dose above the conventional sterilization levels, but by modification of the process only (nitrogen atmosphere, annealing at $50^{\circ} \mathrm{C}$ for $144 \mathrm{~h}$ ). At the same time, other mechanical properties such as crystallinity, creep strain, yield strength and elongation at break remained unchanged, suggesting that elevated crosslink density was achieved without increasing brittleness. The annealing process accelerates recombination of radicals formed during irradiation. If annealing is performed in an inert atmosphere such as nitrogen, the recombining radicals form additional crosslinks rather than bind with oxygen. ${ }^{17}$ This increases crosslink density further-instead of forming hydroperoxy radicals in an atmosphere of air, causing continual chain scission, long-term degradation and shelf ageing. ${ }^{18}$ While the newest generation of polyethylenes for orthopedic application has now reached radiation 
levels of approximately $100 \mathrm{kGy}$, beyond which no further increase in crosslinking can be expected (product information from Sulzer Medica, Orthopedic Division, Winterthur, Switzerland), further optimization may come from process modifications such as annealing, which reduces the number of non-crosslink chemical events that tend to occur during irradiation.

Our study has given a chain of evidence from lower wear rates, less frequent signs of osteolysis and higher survival, to suggest that Duration can provide better clinical outcomes than conventional polyethylene. In comparison to the newest generation of highly crosslinked polyethylenes, the Duration material can only be considered to be moderately crosslinked. However, we found that even the relatively small step from conventional polyethylene gammasterilized in air to polyethylene gamma-sterilized in nitrogen with subsequent annealing was sufficient to reduce wear rates, diminish highvalue outliers, reduce radiographic evidence of osteolysis, and to increase survival during a randomized 5-year study.

One deficiency in our clinical study was the relatively high loss to follow-up because of radiographs of insufficient quality. The wear measurement method we used is superior to the established manual methods such as the Livermore method, but requires wellcentered radiographs with highly congruent patient alignment between follow-up points. ${ }^{14}$ This led to the exclusion of several radiographs, some of which could have been measured with a conventional manual method. However, we decided to prioritize consistency and accuracy of the method over limitation of loss to follow-up.

The advantage of Duration over conventional polyethylene in terms of clinical wear rate was confirmed in our wear simulator study, with the relative reduction in vitro being only slightly higher than in vivo. This adds strength to the clinical evidence and suggests that the even lower simulator wear rates reported for the newest highly crosslinked polyethylene ${ }^{9}$ can produce corresponding clinical advantages at midterm follow-up. We found that the absolute wear rates measured in vivo were higher than in vitro. This could be expected from other studies comparing laboratory and clinical results. ${ }^{19-21}$ Clinical wear rates tend to be elevated by individual patient outliers whose wear rates are many times the mean. ${ }^{22,23}$ Our simulator study showed that the reduction in wear of Duration relative to conventional polyethylene became less with increasing number of cycles. Long-term clinical measurements of wear will be required to determine whether the benefits of Duration polyethylene diminish over time in the same way as in the hip simulator, and whether wear debris leading to osteolysis and implant loosening also remains significantly reduced during a long-term follow-up. 


\section{References}

1. Barrack R L, Folgueras A, Munn B, Tvetden D, Sharkey P. Pelvic lysis and polyethylene wear at 5-8 years in an uncemented total hip. Clin Orthop 1997; (335): 211-7.

2. Shih C H, Lee P C, Chen J H, Tai C L, Chen L F, Wu J S, Chang W H. Measurement of polyethylene wear in cementless total hip arthroplasty. J Bone Joint Surg (Br) 1997; 79 (3): 361-5.

3. Sochart D H. Relationship of acetabular wear to osteolysis and loosening in total hip arthroplasty. Clin Orthop 1999; (363): 135-50.

4. Dumbleton J H, Manley M T, Edidin A A. A literature review of the association between wear rate and osteolysis in total hip arthroplasty. J Arthroplasty 2002; 17 (5): 649-61.

5. Dumbleton J H, Manley M T. Letter to the editor. J Arthroplasty 2003; 18: 537-8.

6. Harris W H. The lysis threshold: An erroneous and perhaps misleading concept? J Arthroplasty 2003; 18 (4): 506-10.

7. Orishimo K F, Claus A M, Sychterz C J, Engh C A. Relationship between polyethylene wear and osteolysis in hips with a second-generation porous-coated cementless cup after seven years of follow-up. J Bone Joint Surg (Am) 2003; 85 (6): 1095-9.

8. Wang A, Polineni V K, Stark C, Dumbleton J H. Effect of femoral head surface roughness on the wear of ultrahigh molecular weight polyethylene acetabular cups. J Arthroplasty 1998; 13 (6): 615-20.

9. McKellop H, Shen F W, Lu B, Campbell P, Salovey R J. Development of an extremely wear-resistant ultra high molecular weight polyethylene for total hip replacements. Orthop Res 1999; 17 (2): 157-67.

10. Heisel C, Silva M, de la Rosa MA, Schmalzried T P. Shortterm in vivo wear of cross-linked polyethylene. J Bone Joint Surg (Am) 2004; 86 (4): 748-51.

11. Collier M B, Kraay M J, Rimnac C M, Goldberg V M. Evaluation of contemporary software methods used to quantify polyethylene wear after total hip arthroplasty. J Bone Joint Surg (Am) 2003; 85 (12): 2410-8.

12. Devane P A, Bourne R B, Rorabeck C H, MacDonald S, Robinson E J. Measurement of polyethylene wear in metal-backed acetabular cups. Il. Clinical application. Clin Orthop 1995; (319): 317-26.

13. Standard test method for tensile properties of plastics. ASTM D 638-95, 2003.

14. Martell J M, Berdia S. Determination of polyethylene wear in total hip replacements with use of digital radiographs. J Bone Joint Surg (Am) 1997; 79 (11): 1635-41.

15. Martell J M, Berkson E, Berger R, Jacobs J. Comparison of two and three-dimensional computerized polyethylene wear analysis after total hip arthroplasty. J Bone Joint Surg (Am) 2003; 85 (6): 1111-7.

16. Kabo J M, Gebhard J S, Loren G, Amstutz H C. In vivo wear of polyethylene acetabular components. J Bone Joint Surg (Br) 1993; 75 (2): 254-8.

17. Streicher R M. Ionizing irradiation for sterilization and modification of high molecular weight polyethylenes. Plast Rubber Proc Appl 1988; 10: 221-9.

18. Edidin A A, Muth J, Spiegelberg S, Schaffner S R. Sterilization of UHMWPE in Nitrogen Prevents Degradation for more than Ten Years. Orthopaedic Research Society 2000: Orlando, FL.

19. McKellop H, Clarke I, Markolf K, Amstutz H. Friction and wear properties of polymer, metal, and ceramic prosthetic joint materials evaluated on a multichannel screening device. J Biomed Mater Res 1981; 15 (5): 619-53. Acta Orthopaedica 2006; 77 (5): 719-725 725

20. McKellop HA, Clarke I C. Evolution and evaluation of materials-screening machines and joint simulators in predicting in vivo wear phenomena. Fundamental Behavior of Orthopedic Biomaterials. P. Ducheyne and G. W. Hastings. Boca Raton, CRC Press, Inc. 1984: 51-85.

21. Wang A. A unified theory of wear for ultra-high molecular weight polyethylene in multi-directional sliding. Wear 2001; 248: 38-47.

22. Martell J M, Leopold S S, Liu X. The effect of joint loading on acetabular wear measurement in total hip arthroplasty. J Arthroplasty 2000; 15 (4): 512-8.

23. Schmalzried T P, Shepherd E F, Dorey F J, Jackson W O, dela Rosa M, Fa'vae F, McKellop H A, McClung C D, Martell J, Moreland J R, Amstutz H C. The John Charnley Award. Wear is a function of use, not time. Clin Orthop 2000; (381): 36-46. 


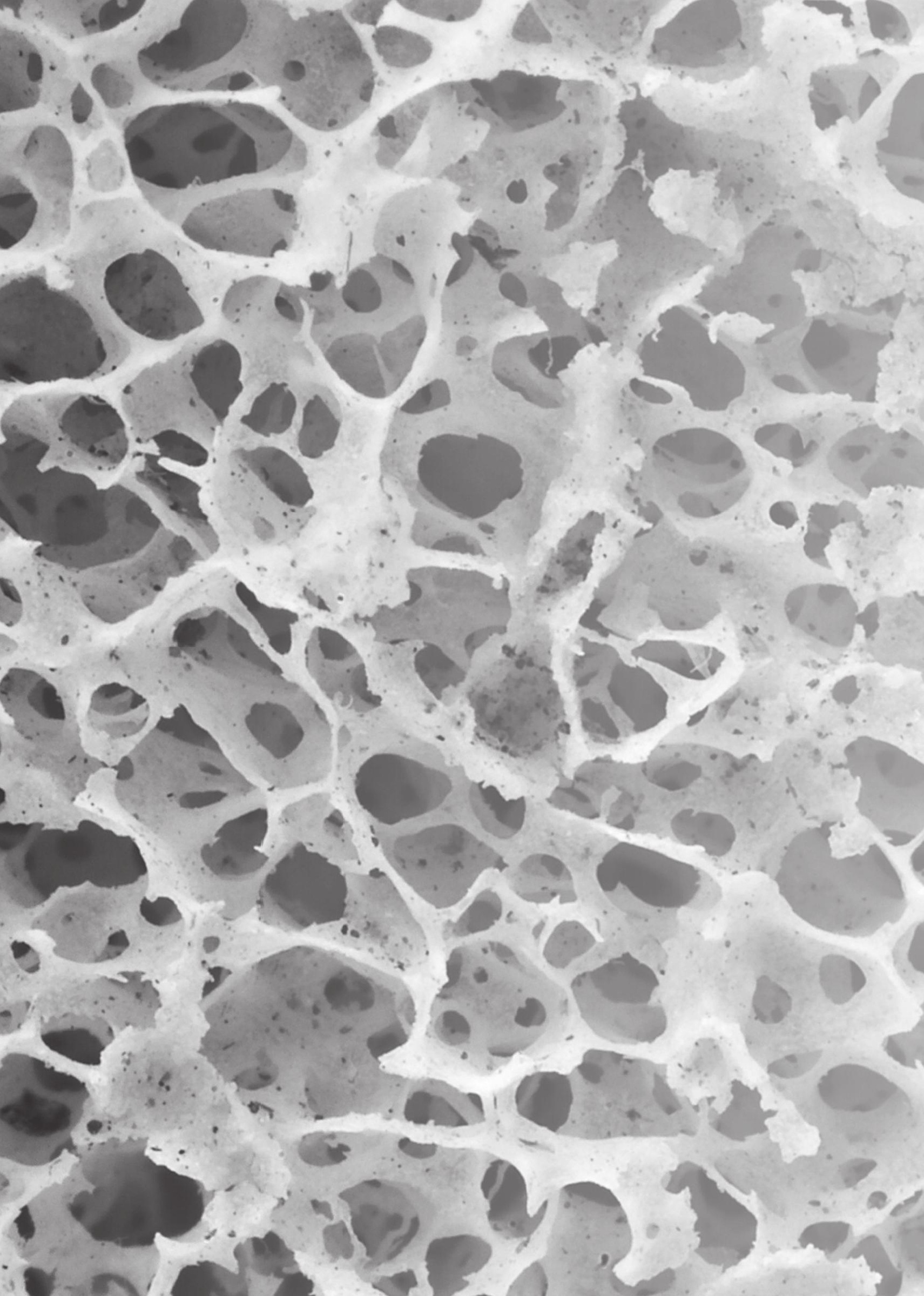




\section{Chapter Four}

\section{Cross-linked Compared with Historical Polyethylene in THA An 8-year Clinical Study}

Geerdink CH, Grimm B, Vencken W, Heyligers IC, Tonino AJ.

Clin Orthop Relat Res. 2009 Apr;467(4):979-84. 


\begin{abstract}
Wear particle-induced osteolysis is a major cause of aseptic loosening in THA. Increasing wear resistance of polyethylene (PE) occurs by increasing the crosslink density and early reports document low wear rates with such implants. To confirm longer-term reductions in wear we compared cross-linked polyethylene (irradiation in nitrogen, annealing) with historical polyethylene (irradiation in air) in a prospective, randomized clinical study involving 48 patients who underwent THAs with a minimum followup of 7 years (mean, 8 years; range, 7-9 years). The insert material was the only variable. The Harris hip score, radiographic signs of osteolysis, and polyethylene wear were recorded annually. Twenty-three historical and 17 moderately cross-linked polyethylene inserts were analyzed (five patients died, three were lost to followup). At 8 years, the wear rate was lower for crosslinked polyethylene $(0.088 \pm 0.03 \mathrm{~mm} /$ year $)$ than for the historical polyethylene $(0.142 \pm 0.07 \mathrm{~mm} /$ year). This reduction $(38 \%)$ did not diminish with time (33\% at 5 years). Acetabular cyst formation was less frequent (39\% versus $12 \%$ ), affected fewer DeLee and Charnley zones (17\% versus $4 \%$ ), and was less severe for the cross-linked polyethylene. The only revision was for an aseptically loose cup in the historical polyethylene group. Moderately cross-linked polyethylene maintained its wear advantage with time and produced less osteolysis, showing no signs of aging at mid-term followup.
\end{abstract}




\section{Introduction}

Wear particle-induced osteolysis is the major cause of aseptic loosening and (premature) revision in THA. The osteolytic effect of wear debris depends not only on particle size and shape but also mainly on the particle volume released into the surrounding tissue. ${ }^{14,24}$ Numerous authors have reported, with standard 28-mm heads, linear wear rates greater than $0.2 \mathrm{~mm}$ per year always produce wear particle-induced osteolysis, whereas this mostly is absent at annual wear rates less than 0.05 to $0.1 \mathrm{~mm}$ per year. ${ }^{1}$ $4,10,11,20,29,32,34,35$ Therefore, increasing wear resistance of the PE for acetabular cups has been a major target. This can be achieved by increasing the crosslink density of the PE. ${ }^{41} \mathrm{~A}$ wear simulator study suggested wear reduction of moderately cross-linked PE over historical PE is between $32 \%$ and $45 \%$ by volumetric wear rates. ${ }^{15}$ Cross-linking is a process usually initiated by gamma irradiation whereby hydrogen atoms are removed from the PE molecules, creating free radicals, which recombine by linking with free radicals of neighboring PE molecule chains. This new network of cross-linked PE chains dramatically increases the wear resistance but also increases the stiffness of the $\mathrm{PE}$ and makes it more brittle. ${ }^{21,28} \mathrm{~A}$ PE that is too stiff or brittle may have reduced fatigue strength, which in clinical applications may lead to stress cracking and subsequent failure of the locking mechanism, or when impingement occurs, the insert rim may crack and delaminate. ${ }^{39}$ However, not all free radicals created by the irradiation recombine to form cross-links. These residual free radicals are highly reactive and are responsible for early oxidation (aging) of the PE. ${ }^{12}$ Oxidized PE exhibits accelerated wear and delamination. Free radicals can be removed using two postirradiation heat treatments, remelting or annealing. Remelted PE is more oxidation-resistant but has less mechanical strength than historical PE. In annealed PE, strength is maintained, but because of residual-free radicals, oxidation should appear, which could lead to accelerating long-term wear rates. ${ }^{12,36}$ Our primary study question was whether crosslinked PE could maintain its increased wear resistance with time up to 8 years when oxidation and aging effects may have affected the original properties. A secondary study question was whether the reduced wear rate of cross-linked PE led to reduced signs of osteolysis. 


\section{Materials and Methods}

We compared the first-generation moderately (B 50-kGy total irradiation dose) crosslinked PE (Duration ${ }^{\mathrm{TM}}$; Stryker Orthopaedics, Mahway, NJ) with PE gamma-sterilized in air, a clinical standard at the time the study began but now considered and in the following referred to as historical PE. We enrolled 48 patients (48 hips) after informed consent and ethical approval in a randomized, prospective clinical study. Patients were included who had primary THAs who had a diagnosis of osteoarthritis, rheumatoid arthritis, avascular necrosis of the femoral head, or posttraumatic arthritis of the hip. The patients were between 48 and 74 years of age on enrollment. Patients were excluded if they had prior reconstructive procedures, such as surface replacement arthroplasty or fracture fixation, or hemiarthroplasties. We also excluded patients if they had active infections or if they had a malignancy in the area of the involved hip. We obtained the patients' medical histories, including demographics, joint disease diagnosis, and concurrent diseases. Included patients were assigned to either the historical PE insert (26 hips) or the moderately crosslinked PE insert (22 hips) by double-blind block randomization. Five patients died of unrelated causes and three were lost to followup, leaving 40 patients (23 historical, 17 Duration $^{\mathrm{TM}}$ ) for clinical and wear analyses. The historical PE and DurationTM PE groups were similar in terms of gender distribution (13 males/10 females versus 11 males/ six females), average age (64 years), body mass index $(28 \mathrm{~kg} / \mathrm{m} 2$ versus $29 \mathrm{~kg} / \mathrm{m} 2)$, preoperative (40 versus 39) and postoperative (93 versus 95) Harris hip scores ${ }^{19}$, stem size (4 versus 4), average cup diameter (54 mm versus 54 $\mathrm{mm})$, cup inclination $\left(47^{\circ}\right.$ versus $\left.48^{\circ}\right)$, liner thickness $(8 \mathrm{~mm}$ versus $8 \mathrm{~mm})$, and average followup ( 8 years). The randomization process resulted in good matching, leaving the insert material as the only variable of the study (Table 1 ). A priori power analysis $\left(G^{*}\right.$ Power 3; Düsseldorf University, Düsseldorf, Germany) ${ }^{13}$ was performed, assuming an annual wear rate of $0.15 \mathrm{~mm}$ per year for the historical PE based on published values $^{11}$ and a wear rate of $0.09 \mathrm{~mm}$ per year for the Duration ${ }^{\mathrm{TM}}$ PE based on the $45 \%$ reduction in linear wear rate predicted from a simulator study ${ }^{15}$. Assuming conservative standard deviations for the wear rate measurement $( \pm 0.07 \mathrm{~mm} /$ year) based on a pilot study and standard values for alpha $(a=0.05)$ and power $(b=80 \%)$, a total sample size of 46 was calculated. After loss to followup $(n=40)$, post hoc analysis confirmed a power of $b=92 \%$, benefiting mainly from the lower than assumed standard deviations. Both of the acetabular cup inserts used were of the same hemispheric design and were mated to an ABG1 II hydroxyapatite-coated hemispheric acetabular shell made of titanium alloy (Stryker) and matching press-fit hydroxyapatite-coated ABG1 II stem (Stryker). All femoral heads were of CoCr alloy and measured $28 \mathrm{~mm}$ in diameter. Both inserts were manufactured from ram-extruded rods converted from Hoechst GUR 415 resin by Poly Hi Solidur, Inc (Reading, PA) with a molecular weight between 5 and 6 million $\mathrm{g} / \mathrm{mol}$. The historical PE inserts were packaged and sealed in a double-plastic blister surrounded by air and the package then was irradiated at a dose of 30 kGy. The moderately cross-linked PE inserts were placed in two sealed blisters, which were 
evacuated and then flushed with nitrogen before sealing. The oxygen concentration in the inner blister was less than $0.5 \%(\mathrm{v} / \mathrm{v})$ and the concentration in the outer blister was less than $5 \%(\mathrm{v} / \mathrm{v})$ at the time of packaging. The completed package then was gamma-irradiated with a dose of $30 \mathrm{kGy}$. After irradiation, packages were placed in an oven for annealing at a temperature of 50C for 144 hours density by promoting free radical recombination. The elevated cross-link density of moderately cross-linked PE was verified using a small punch test. ${ }^{37}$ Additional mechanical tests showed strength, stiffness, and elongation to break as a measure of brittleness were not affected by the moderately crosslinked PE process. Clinical followup parameters were assessed at patient visits postoperatively at less than 6 weeks and at 1, 2, 3, 5, and 8 years postoperatively. Standard standing radiographs were obtained for subsequent wear measurement (5 and 8 years). Two of us (AJT, WV, blinded to PE insert used) identified migration, loosening, and potentially wear-related phenomena, such as osteolytic cyst formation and radiolucent lines, in the femur and acetabulum. Migration was defined as a change in distance between the proximal tip of the hip stem and trochanter major on anteroposterior radiographs reaching or exceeding $3 \mathrm{~mm}$ or greater than $3 \mathrm{~mm}$ displacement of the cup in any direction. Findings were located according to the seven zones of Gruen et al. ${ }^{18}$ for the femur and the three zones of DeLee and Charnley ${ }^{6}$ for the acetabulum. On the femur and acetabulum, osteolytic cysts or radiolucent lines were rated as present or nonpresent. On the acetabulum, where multiple cysts were seen, also the number, size, and shape (affected bone-implant interface) of cysts were evaluated and scored in a composite severity index. In the absence of a gold standard rating system, the following classification was used: one point was given to one small cyst covering a small proportion of the bone-implant interface; two points were given for either two such small cysts or one mediumsized cyst affecting approximately $1 / 2$ the bone-implant interface of the zone under investigation; two points also were given for a large cyst extending from a neighboring zone into the investigated zone affecting approximately $1 / 2$ the bone-implant interface; three points were given when two medium-sized cysts or a large cyst affected all or most of the bone-implant interface of the zone under investigation. With three acetabular zones, the total severity index ranged from 0 (no cysts) to 9 (extensive cysts in all three zones). A similar rating of radiolucent lines was not applied, as they were present in only one patient. Wear was measured by one blinded observer (WV) on standard anteroposterior standing digital radiographs (5- MPix resolution) determining femoral head penetration ${ }^{27}$ using the Roman V 1.70 software (Institute of Orthopaedics, Oswestry, UK). Accuracy, intraobserver and interobserver reliability of this method, and software reportedly are equal or superior to other common methods. ${ }^{16}$ We statistically compared the linear wear rates of both groups using the nonparametric two-tailed Mann-Whitney test. Proportions of patients with wear rates greater or less than clinically relevant thresholds were compared using Fisher's exact test. Also, the proportions of patients showing cysts as a sign of osteolysis were compared using Fisher's exact test. 
Table 1: Patient demographics; surgical and, implant parameters, and wear.

\begin{tabular}{|c|c|c|}
\hline & Historical PE & Duration $^{\mathrm{TM}} \mathrm{PE}$ \\
\hline Total / Available & $26 / 23$ & $22 / 17$ \\
\hline Age $[y r s]$ & $64(54-72)$ & $64(48-74)$ \\
\hline BMI & $28(23-49)$ & $28(24-36)$ \\
\hline Male/Female & $13 / 10$ & $11 / 6$ \\
\hline HHS pre-op & $40 \pm 19$ & $39 \pm 16$ \\
\hline Stem size & $4(2-5)$ & $4(3-5)$ \\
\hline Head diameter [mm] & 28 & 28 \\
\hline Cup diameter [mm] & $54(48-62)$ & $54(48-60)$ \\
\hline Cup inclination [deg] & $47 \pm 7$ & $48 \pm 6$ \\
\hline Liner thickness [mm] & $9(7-11)$ & $9(6-12)$ \\
\hline FU [yrs] & $8(7.2-8.8)$ & $8(6.9-9.0)$ \\
\hline HHS post-op & $93 \pm 14$ & $95 \pm 12$ \\
\hline Wear rate $[\mathrm{mm} / \mathrm{yr}]$ & $\underline{0.142} \pm 0.07$ & $\underline{0.088} \pm 0.03^{*}$ \\
\hline
\end{tabular}

Values are expressed as mean or mean \pm standard deviation, with range in parentheses; ${ }^{*} \mathrm{p}<0.01$; $\mathrm{PE}=$ polyethylene

\section{Results}

At 8 years' followup, the linear wear rates were less $(p=0.007)$ for the moderately cross-linked PE $(0.088 \pm 0.03 \mathrm{~mm} /$ year $)$ than for the historical PE $(0.142 \pm 0.07 \mathrm{~mm}$ per year). More patients $(p=0.006)$ with the historical PE had annual wear rates greater than $0.1 \mathrm{~mm}$ per year than did patients with the moderately cross-linked PE insert (17 of 23 versus five of 17 , respectively) (Fig. 1). More patients $(0=0.2)$ in the historical PE group also had high wear rates (greater than a threshold value of $0.2 \mathrm{~mm}$ per year) than in the moderately cross-linked PE group (four of 23 versus 0 of 17, respectively). At 5 years, the annual wear rate also was less $(p=0.02)$ for the cross-linked PE $(0.106 \pm$ $0.037 \mathrm{~mm} /$ year $)$ than for the historical PE $(0.152 \pm 0.062 \mathrm{~mm} /$ year $)$ group. The average reduction in wear rate with cross-linked PE at 8 years (38\%) did not decrease when compared with the rate at the 5 -year followup (30\%). One patient in the historical group had osteolysis with acetabular radiolucencies in all three DeLee and Charnley zones. This patient also had aseptic acetabular loosening and underwent revision surgery. The annual wear rate of this patient was at the higher end of the distribution at $0.22 \mathrm{~mm}$ per year. Acetabular radiolucencies or loosening were absent in the moderately cross- 
linked PE. Radiographic appearance of one or more osteolytic cysts in the acetabulum was greater $(p=0.057)$ in patients in the historical PE (nine of 23) group than in patients in the cross-linked PE (two of 17) group. When the number of affected DeLee and Charnley zones was counted, the proportion of zones showing cyst formation also was greater $(p=0.022)$ with historical PE $(12$ of $69,17 \%)$ than with cross-linked PE (two of $51,4 \%$ ). When cyst formation was weighted by size using the 0 - to 9 -point severity index, the higher level of cyst formation for the group with historical PE became even more pronounced $(14.5 \%$ versus $2.9 \%)(p=0.021)$. Although there were no femoral radiolucencies seen in either group, femoral osteolysis was noted in similar numbers $(p=0.489$ ) of patients in both groups (four of 23 for the historical PE group and two of 17 for the moderately cross-linked PE group).

Figure 1: A histogram shows annual linear wear rates for each patient measured at 8 years.

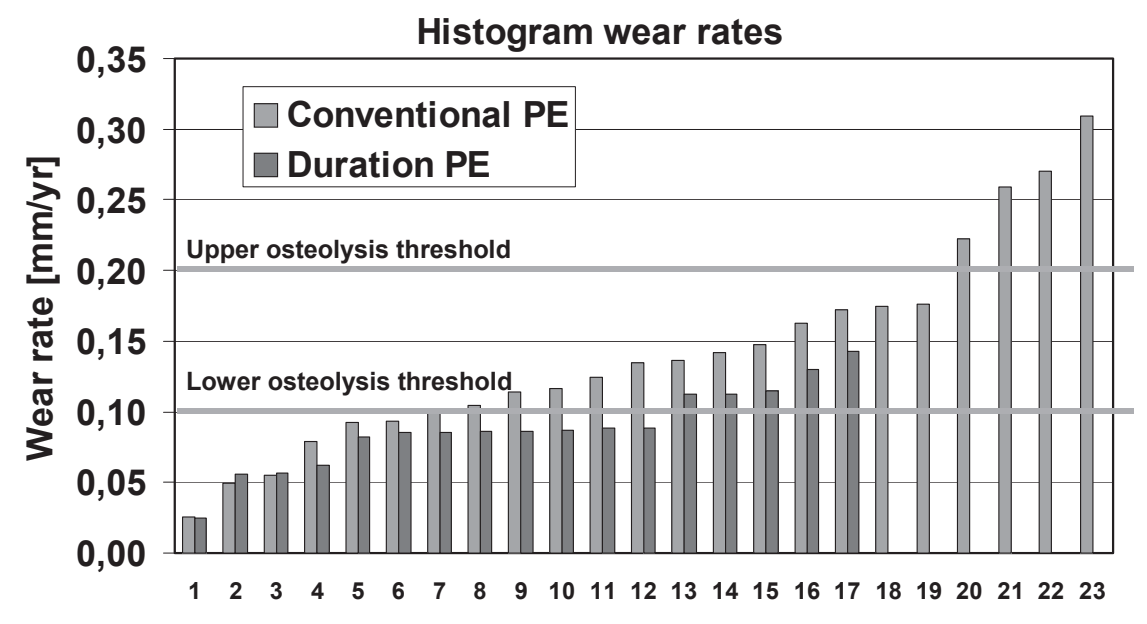

Patient number

\section{Discussion}

Wear particle-induced osteolysis is a major cause of aseptic loosening in THA. Wear resistance of PE may be enhanced by increasing the cross-link density. Simulator studies and short- to midterm clinical studies with as much as 6 years followup ${ }^{1-3,7-9 \text {, }}$ $15,17,21,22,25,30,31$ document reduced wear. However, aging may influence the material as in vivo oxidation may start to degrade the beneficial properties of cross-linked PE with its higher residual amount of free radicals, especially in material that is annealed and not remelted. We therefore asked whether cross-linked PE could maintain its increased wear resistance with time up to 8 years when oxidation and aging effects may have affected the original properties. Our secondary question was whether the reduced wear rate of cross-linked PE led to reduced osteolysis. This relationship is 
being scrutinized because wear particles of cross-linked PE have been suspected to have a higher osteolytic potential, and it can be investigated only when follow-ups are long enough for development and radiographic diagnosis of cyst formation.

Our study is limited by the relatively small group size, which nonetheless was sufficiently powered to investigate the first question regarding wear rate reductions but weakly powered to draw conclusions on the second question regarding effective reduction of osteolysis with crosslinked PE.

Quantifying osteolysis in an objective and reliable manner generally is difficult and was not well described before the study by Dumbleton et al. ${ }^{11}$ in 2002 . Our two experienced observers tried to classify size, number, and position in a composite severity index. However, periacetabular cyst formation can be evaluated only partially from anteroposterior radiographs, as approximately $1 / 2$ the periacetabular cyst is covered by the insert and projected in the anteroposterior plane. ${ }^{5,26,43} \mathrm{~A}$ set of oblique radiographs or three-dimensional CT may resolve this problem but poses ethical issues. As in any study trying to link wear rates to wear debris-induced osteolysis, the highly individual response of periprosthetic tissue to particle load (responders and nonresponders) probably confounds studies on wear and osteolysis unless joint registersized databases can be used. Although accurate and reliable digital wear-measurement software was used on high-resolution radiographs, the prospective nature of the study would have allowed radiostereometric analysis (RSA) to be used. This would have further increased accuracy and improved analysis of the wear angles and creep or liner settling.

Our study also is limited by the fact that the wear analysis was performed only at 5 and 8 years but not after short followup, so we have no information regarding whether both materials differed regarding creep or liner settling was completed after 6 to 24 months. Studies such as those of Digas et al. ${ }^{7,8}$ showed highly cross-linked PE has not only reduced steady-state wear rates at 5 years but also less creep and liner settling, which also tends to be completed earlier. If this would apply to a lesser degree also to the moderately cross-linked PE used in our study, the reduction in steady-state wear rate measured at 5 or 8 years could still be larger. However, with creep and liner settling measuring less than $0.1 \mathrm{~mm}^{9}$, the effect size is smaller than the pixel of a standard digital radiograph and thus hardly can be captured with conventional radiographic wear measurement but with RSA only.

Although many factors possibly confounding this comparative wear study were controlled or matched, activity level as a major factor affecting wear ${ }^{32}$ was not measured or controlled. Whereas demographics (gender, age, body mass index) and postoperative clinical outcome as measured using the Harris hip score were the same between groups, these provide only slight indication regarding functional capacity and overall activity level. With the advance of activity-monitoring technologies, wear studies such as this would benefit from information about activity.

Finally, a minimum of 7 years' followup is still too short to analyze and draw conclusions 
regarding long-term effects. However, PE intentionally cross-linked to reduce wear over PE gamma-irradiated solely for the purpose of sterilization was introduced for widespread clinical use in the mid- to late 1990s and thus clinical evidence from 8 to 10 years followup is the longest that can be reported at this stage. Although newer generations of highly cross-linked PE inserts reportedly have promising low wear rates, from $59 \%$ to greater than $95 \%$ wear reduction compared with rates of historical PE inserts in simulator or short-term clinical studies, the longest published followup of these studies is only 6 years, and prospective randomized comparisons between alternative PE inserts are scarce. ${ }^{2,3,7-9,17,22,31}$

We found the wear rates of the moderately cross-linked PE at 8 years were less than than those of historical PE. The reduction of $38 \%$ correlated well with reductions of $33 \%$ to $45 \%$ reported for comparisons of these materials in hip simulator studies. ${ }^{8}$ The absolute wear rate of the historical PE compared well with the rate in another wear study that measured penetration rates for PE not intentionally cross-linked for wear reduction (eg, $0.16 \mathrm{~mm} /$ year). ${ }^{33}$ The reduction of this first-generation cross-linked PE is less than the clinically reported wear rate reductions observed at 5 years for highly cross-linked PE, ranging between $59 \%{ }^{30}$ and $95 \%{ }^{7}$. Highly cross-linked PE inserts of newer generation than the Duration ${ }^{\mathrm{TM}} \mathrm{PE}$ used in our study have been exposed to much higher irradiation doses in the order of 100 kGy and thus have a much higher cross-link density and consequently wear resistance. The relative reduction also depends on which $\mathrm{PE}$ is used in the control group. The $38 \%$ reduction in wear rate observed at 8 years is not less than the $30 \%$ reduction measured at the 5 -year followup in our patients or the $33 \%$ reduction reported for larger groups comparing the same materials. ${ }^{15}$ It seems more that the benefit of using a cross-linked PE over historical PE may increase with time. Fears that cross-linked PE, especially the annealed versions such as Duration ${ }^{\mathrm{TM}}$ that have more free residual radicals prone to oxidation than the remelted alternatives 42, may degrade in vivo so that wear accelerates beyond the 5-year point cannot be supported based on our results. The fact that absolute annual wear rates decreased for both materials between 5 and 8 years may be attributable to lower activity levels as patients are aging during followup.

Cysts suggesting wear debris-driven osteolysis reportedly occur more frequently on the acetabulum than the femur. ${ }^{23}$ This can be expected because the acetabular boneimplant interface is closer to the origin of wear debris and because the interface between the proximal femur and hydroxyapatite-coated stem probably is better sealed against particle migration. ${ }^{40}$ It also may be a hint that the osteolysis observed is wear particle driven and not bone resorption owing to other effects such as stress shielding. Cysts on the acetabular side were observed less frequently, affected fewer zones, and were smaller for the cross-linked PE at good evidence level. The trend toward less osteolysis also was visible on the femoral side, although without statistical evidence. The only acetabular revision attributable to aseptic loosening was in a patient in the control group with one of the highest wear rates. Although strong correlations 
between wear rates and osteolysis were reported in a literature review ${ }^{11}$, such findings could be expected, as smaller particle volumes are released into the periprosthetic tissue triggering less cytotoxic response. However, a cell culture study ${ }^{38}$ suggested wear particles of cross-linked PE can be smaller and shaped differently from those of alternative PE and thus may have a higher cytotoxicity (functional osteolytic potential). As a result, cross-linked PE may produce equal or higher levels of osteolysis despite reduced wear volumes. The results of our study do not support this concern.

Moderately cross-linked PE reduced in vivo wear rates compared with historical PE at 8 years. The reduced wear was accompanied by reduced signs of osteolytic cyst formation. The wear reduction was maintained and even augmented between 5 and 8 years, indicating no oxidation effects had yet degraded the material at clinically noticeable levels. The wear rate reduction correlated well with simulator predictions, providing confidence in predictions for newer generations of cross-linked PE. Crosslinked PE seems to be a superior choice over historical material, even after longer times in vivo, therefore, cross-linked PE may deserve to become the new standard. 


\section{References}

1. Barrack RL, Folgueras A, Munn B, Tvetden D, Sharkey P. Pelvic lysis and polyethylene wear at 5-8 years in an uncemented total hip. Clin Orthop Relat Res. 1997;335:211-217.

2. Bragdon $C R$, Greene ME, Freiberg AA, Harris WH, Malchau H. Radiostereometric analysis comparison of wear of highly crosslinked polyethylene against 36- vs 28-mm femoral heads. J Arthroplasty. 2007;22(6 suppl 2):125-129.

3. Bragdon CR, Kwon YM, Geller JA, Greene ME, Freiberg AA, Harris WH, Malchau H. Minimum 6-year followup of highly cross-linked polyethylene in THA. Clin Orthop Relat Res. 2007; 465:122-127.

4. Castoldi F, Rossi R, La Russa M, Sibelli P, Rossi P, Ranawat AS. Ten-year survivorship of the Anatomique Benoist Girard I total hip arthroplasty. J Arthroplasty. 2007;22:363-368.

5. Claus AM, Engh CA Jr, Sychterz CJ, Xenos JS, Orishimo KF, Engh CA Sr. Radiographic definition of pelvic osteolysis following total hip arthroplasty. J Bone Joint Surg Am. 2003;85: 1519-1526.

6. DeLee JG, Charnley J. Radiological demarcation of cemented sockets in total hip replacement. Clin Orthop Relat Res. 1976; 121:20-32.

7. Digas G, Kärrholm J, Thanner J, Herberts P. 5-year experience of highly cross-linked polyethylene in cemented and uncemented sockets: two randomized studies using radiostereometric analysis. Acta Orthop. 2007;78:746-754.

8. Digas G, Kärrholm J, Thanner J, Malchau H, Herberts P. The Otto Aufranc Award. Highly cross-linked polyethylene in total hip arthroplasty: randomized evaluation of penetration rate in cemented and uncemented sockets using radiostereometric analysis. Clin Orthop Relat Res. 2004;429:6-16.

9. Dorr LD, Wan Z, Shahrdar C, Sirianni L, Boutary M, Yun A. Clinical performance of a Durasul highly cross-linked polyethylene acetabular liner for total hip arthroplasty at five years. J Bone Joint Surg Am. 2005;87:1816-1821.

10. Dumbleton JH, Manley MT. Letter to the editor. J Arthroplasty. 2003;18:537-538.

11. Dumbleton JH, Manley MT, Edidin AA. A literature review of the association between wear rate and osteolysis in total hip arthroplasty. J Arthroplasty. 2002;17:649-661.

12. Edidin A, Muth J, Spiegelberg S, Schaffner SR. Sterilization of UHMWPE in nitrogen prevents degradation for more than ten years. Trans Orthop Res Soc. 2000;25:0001.

13. Erdfelder E, Faul F, Buchner A. G*Power: A general power analysis program. Behav Res Methods Instrum Comput. 1996; 28:1-11.

14. Fang HW, Yang CB, Chang $\mathrm{CH}$, Huang $\mathrm{CH}$, Liu HL, Fang SB. The potential role of phagocytic capacity in the osteolytic process induced by polyethylene wear particles. J Int Med Res. 2006; 34:655-664.

15. Geerdink CH, Grimm B, Ramakrishnan R, Rondhuis J, Verburg AJ, Tonino AJ. Crosslinked polyethylene compared to conventional polyethylene in total hip replacement: pre-clinical evaluation, in-vitro testing and prospective clinical follow-up study. Acta Orthop. 2006;77:719-725.

16. Geerdink CH, Grimm B, Vencken W, Heyligers IC, Tonino AJ. The determination of linear and angular penetration of the femoral head into the acetabular component as an assessment of wear in total hip replacement: a comparison of four computer-assisted methods. J Bone Joint Surg Br. 2008;90:839-846.

17. Glyn-Jones S, Isaac S, Hauptfleisch J, McLardy-Smith P, Murray DW, Gill HS. Does highly crosslinked polyethylene wear less than conventional polyethylene in total hip arthroplasty? Adoubleblind, randomized, and controlled trial using roentgen stereophotogrammetric analysis. J Arthroplasty. 2008;23:337-343.

18. Gruen TA, McNeice GM, Amstutz HC. "Modes of failure" of cemented stem-type femoral components: a radiographic analysis of loosening. Clin Orthop Relat Res. 1979;141:17-27.

19. Harris WH. Traumatic arthritis of the hip after dislocation and acetabular fractures: treatment by mold arthroplasty: an endresult study using a new method of result evaluation. J Bone Joint Surg Am. 1969;51:737-755.

20. Harris WH. The lysis threshold: an erroneous and perhaps misleading concept? J Arthroplasty. 2003;18:506-510.

21. Heisel C, Silva M, de la Rosa MA, Schmalzried TP. Short-term in vivo wear of cross-linked polyethylene. J Bone Joint Surg Am. 2004;86:748-751. 
22. Heisel C, Silva M, Schmalzried TP. In vivo wear of bilateral total hip replacements: conventional versus crosslinked polyethylene. Arch Orthop Trauma Surg. 2005;125:555-557.

23. Herrera A, Canales V, Anderson J, García-Araujo C, Murcia-Mazón A, Tonino AJ. Seven to 10 years followup of an anatomic hip prosthesis: an international study. Clin Orthop Relat Res. 2004;423:129137.

24. Ingham E, Fisher J. Biological reactions to wear debris in total joint replacement. Proc Inst Mech Eng $\mathrm{H}$. 2000;214:21-37.

25. Jacobs CA, Christensen CP, Greenwald AS, McKellop H. Clinical performance of highly cross-linked polyethylenes in total hip arthroplasty. J Bone Joint Surg Am. 2007;89:2779-2786.

26. Kitamura N, Pappedemos PC, Duffy PR $3^{\text {rd }}$, Stepniewski AS, Hopper RH Jr, Engh CA Jr, Engh CA. The value of anteroposterior pelvic radiographs for evaluating pelvic osteolysis. Clin Orthop Relat Res. 2006;453:239-245.

27. Livermore J, Ilstrup D, Morrey B. Effect of femoral head size on wear of the polyethylene acetabular component. J Bone Joint Surg Am. 1990;72:518-528.

28. McKellop H, Shen FW, Lu B, Campbell P, Salovey R. Development of an extremely wear-resistant ultra high molecular weight polyethylene for total hip replacements. J Orthop Res. 1999;17:157-167.

29. Orishimo KF, Claus AM, Sychterz CJ, Engh CA. Relationship between polyethylene wear and osteolysis in hips with a secondgeneration porous-coated cementless cup after seven years of follow-up. J Bone Joint Surg Am. 2003;85:1095-1099.

30. Rajadhyaksha AD, Brotea C, Cheung Y, Kuhn C, Ramakrishnan R, Zelicof SB. Five-year comparative study of highly crosslinked (Crossfire) and traditional polyethylene. J Arthroplasty. 2009; 24(2):161-7.

31. Röhrl SM, Li MG, Nilsson KG, Nivbrant B. Very low wear of non-remelted highly cross-linked polyethylene cups: an RSA study lasting up to 6 years. Acta Orthop. 2007;78:739-745.

32. Schmalzried TP, Shepherd EF, Dorey FJ, Jackson WO, dela Rosa M, Fa'vae F, McKellop HA, McClung CD, Martell J, Moreland JR, Amstutz HC. The John Charnley Award. Wear is a function of use, not time. Clin Orthop Relat Res. 2000;381:36-46.

33. Sechriest VF 2 ${ }^{\text {nd }}$, Kyle RF, Marek DJ, Spates JD, Saleh KJ, Kuskowski MJ. Activity level in young patients with primary total hip arthroplasty: a 5-year minimum follow-up. J Arthroplasty. 2007;22:39-47.

34. Shih $\mathrm{CH}$, Lee PC, Chen JH, Tai CL, Chen LF, Wu JS, Chang WH. Measurement of polyethylene wear in cementless total hip arthroplasty. J Bone Joint Surg Br. 1997;79:361-365.

35. Sochart DH. Relationship of acetabular wear to osteolysis and loosening in total hip arthroplasty. Clin Orthop Relat Res. 1999;363:35-50.

36. Streicher RM. Ionizing irradiation for sterilization and modification of high molecular weight polyethylenes. Plast Rubber Proc Appl. 1988;10:221-229.

37. Test Method for Small Punch Testing of Ultra-High Molecular Weight Polyethylene Used in Surgical Implants (ASTM F 2183-02). Annual Book of ASTM Standards. Vol 13.01. West Conshohocken, PA: ASTM International; 2003.

38. Tipper JL, Galvin AL, Williams S, McEwen HM, Stone MH, Ingham E, Fisher J. Isolation and characterization of UHMWPE wear particles down to ten nanometers in size from in vitro hip and knee joint simulators. J Biomed Mater Res. 2006;78:473-480.

39. Tower SS, Currier JH, Currier BH, Lyford KA, Van Citters DW, Mayor MB. Rim cracking of the crosslinked longevity polyethylene acetabular liner after total hip arthroplasty. J Bone Joint Surg Am. 2007;89:2212-1127.

40. van der Wal BC, Rahmy AI, Grimm B, Blake GM, Heyligers IC, Tonino AJ. The influence of implant design on periprosthetic bone remodeling of two types of uncemented HA-coated hip stems: a two year follow-up study using DEXA. Hip Int. 2006; 16:8-17.

41. Wang A, Polineni VK, Stark C, Dumbleton JH. Effect of femoral head surface roughness on the wear of ultrahigh molecular weight polyethylene acetabular cups. J Arthroplasty. 1998;13:615-620.

42. Wolf C, Macho C, Lederer K. Accelerated ageing experiments with crosslinked and conventional ultra-high molecular weight polyethylene (UHMW-PE) stabilised with alpha-tocopherol for total joint arthroplasty. J Mater Sci Mater Med. 2006;17(12): 1333-1340.

43. Zimlich RH, Fehring TK. Underestimation of pelvic osteolysis: the value of the iliac oblique radiograph. J Arthroplasty. 2000;15: 796-801. 


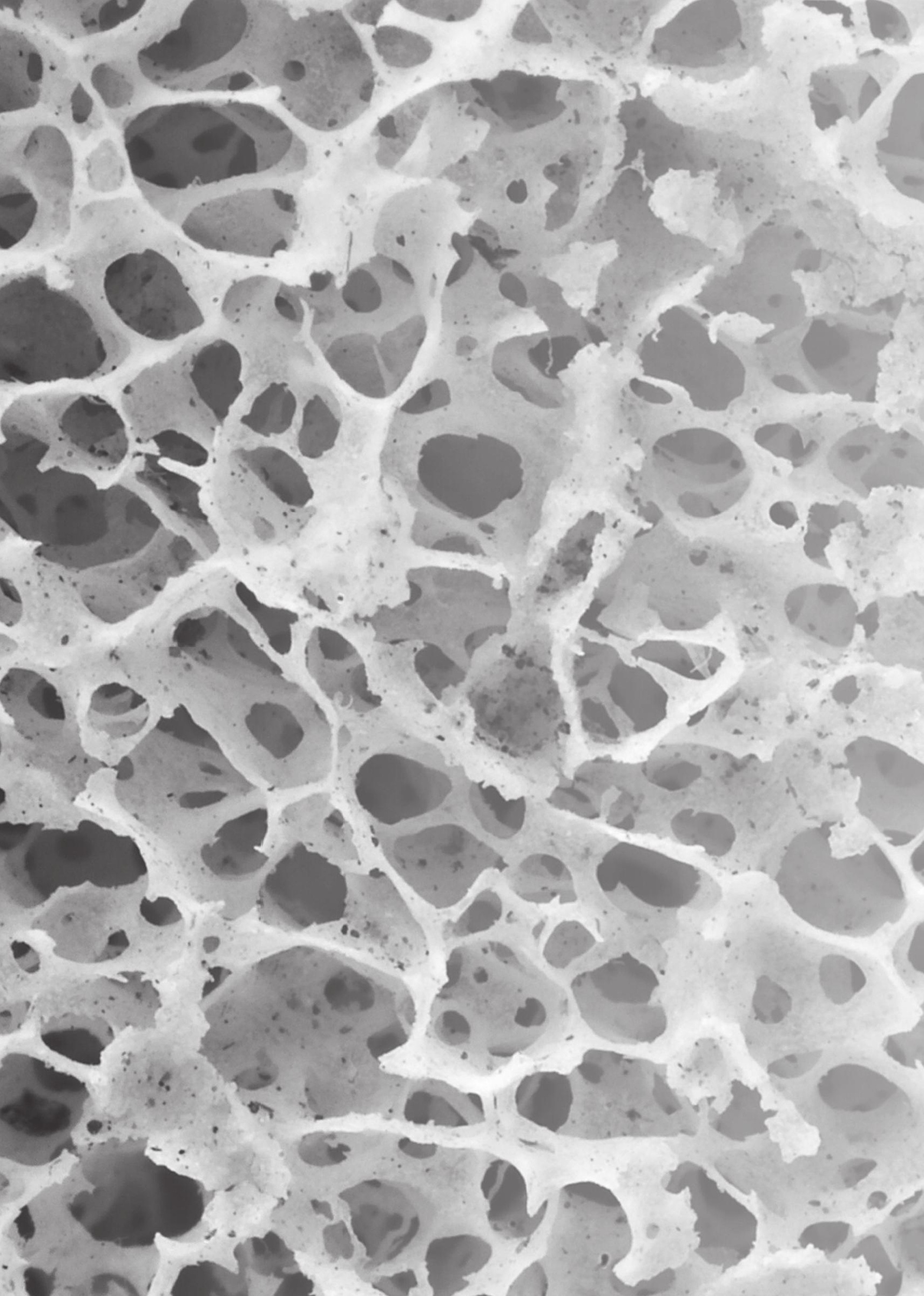




\section{Chapter Five}

\section{Correlation of Technetium}

scintigraphy, progressive acetabular osteolysis and acetabular component loosening in total hip arthroplasty.

Geerdink C.H., Grimm B., Rahmy A.I.A., Vencken W., Heyligers I.C., Tonino A.J. 


\begin{abstract}
In total hip arthroplasty (THA) Technetium scintigraphy can help to diagnose a loose implant by detecting elevated osteoblastic activity. It has been used for timing the revision of cemented implants. In uncemented cups it has been radiologically observed that progressive acetabular osteolysis can be present without the implant being loose yet. It seems imprudent to wait for cup-revision until the loosening process of the cup is complete. Can technetium scintigraphy diagnose osteolysis behind the uncemented acetabular component and forward the timing of a revision? Between 1990 and 1996500 hydroxyapatite-coated hip prosthesis were placed (follow-up range: 9-15 years). Technetium scintigraphy and plain radiography were performed each year postoperatively. Of this series 32 cups were revised for progressive acetabular osteolysis. We compared the per-operative findings (gold standard) with the pre-operative scintigraphic and radiographic results. The sensitivity and specificity for diagnosing progressive acetabular osteolysis were respectively $34 \%$ and $0 \%$ for technetium scintigraphy. Sensitivity and specificity for detecting a loose cup were respectively $38 \%$ and $73 \%$. The sensitivity and specificity of technetium scintigraphy for both detection of a loose cup as well as for progressive acetabular osteolysis are worse than reported for plain radiography. Despite a negative scintigraphy, there might be progressive bone loss at such a critical level that revision seems prudent. Thus scintigraphy in its current form has no additional value to plain radiography as a reliable indicator for timing cup revision in the process of progressive acetabular osteolysis.
\end{abstract}




\section{Introduction}

In total hip arthroplasty, osteolysis is regarded to be the main cause of mid- and long term aseptic loosening of the components ${ }^{1}$. The most common offending agent to cause osteolysis are micron-sized particles of polyethylene generated from the articulation of the femoral head with the acetabulum or from movement between the polyethylene liner and the metal acetabular shell of modular components. ${ }^{2-4}$ Higher wear rates give higher rates of osteolysis and result in the appearance of osteolysis at shorter times of follow-up. ${ }^{5-7}$ Some authors have promoted the concept of a wear threshold claiming that a wear rate of more than $0.2 \mathrm{~mm} /$ year is predictive for the development of progressive acetabular osteolysis. ${ }^{8}$

There is no general agreement as to reporting the degree of osteolysis in literature. Osteolytic lesions are progressive or stable, are localised or diffuse. Lesions behind the acetabular component are more likely to expand. ${ }^{9-11}$ At revision, osteolytic lesions usually are much larger in extent than the size predicted on pre-operative radiographs. ${ }^{12,13}$ Different pathways for osteolysis are effective in cemented and uncemented implants. ${ }^{14}$ Generally, cementless components show localized, expansible lesions (balloon like), especially in metal backed cups with multiple holes. At the same time the cup remains stable for a long time because of enduring rim fixation. ${ }^{15,16}$

Not all patients with augmented polyethylene wear have progressive acetabular osteolysis as reported for non-metal-backed polyethylene cemented cups. In metal backed cups some patients who show only minimal polyethylene wear may have huge osteolytic lesions while the cup is still stable. This is thought to be caused by the pressure gradient theory of oscillating interstitial fluids driven through the multiple holes in the metal backed cup during movement cycles. ${ }^{17,18}$ Especially this last group of patients is at risk as they loose bone stock very rapidly while having no or minimal clinical symptoms. To objectivate this process is still a diagnostic challenge.

In general, patients who experience pain and who have radiolucent lines in all of the three DeLee and Charnley zones ${ }^{19}$ around the acetabular component of their total hip arthroplasty present on the conventional radiograph are suspected to have a cup loosening. Also migration of the cup of more than two millimetres on serial radiographs is a severe indication that the cup has become loose. ${ }^{20}$ Apart from serial radiographs, bone scintigraphy always played a prominent role in the diagnosis of aseptic loosening of a total hip arthroplasty. ${ }^{21-25}$ In general, the skeletal deposition of intravenously administered Technetium-99m is elevated at sites where osteoblastic activity is high. ${ }^{26}$ In the process of progressive, polyethylene wear induced osteolysis around a total hip arthroplasty it is interesting to know if there is a raised osteoblastic activity in the peri-prosthetic bone. If so, one could be able to diagnose a group of patients at risk for aseptic loosening of their hip arthroplasty, and maybe even in an earlier stage than conventional radiographs can.

Therefore we looked at our prospective series of uncemented hydroxy-apatite coated hip arthroplasties which were assessed annually by bone scintigraphy. In these patients 
bone scintigraphy was used to detect if a changing scintigraphic pattern had any predictive value for the diagnosis of progressive acetabular osteolysis. In addition to the diagnostic value, it might even be wise to advise asymptomatic patients to choose for acetabular component revision before too much of their peri-prosthetic bone has disappeared and/or pain arises.

Fact is that the relationship between bone scintigraphy and osteolysis has not been reported yet.

This study investigates the feasibility of technetium scintigraphy in the assessment of progressive osteolysis with the potential to improve the timing of cup revision by: 1) calculating the diagnostic sensitivity and specificity of scintigraphy to detect periacetabular osteolysis 2) correlating the extent of osteolysis found at the time of the revision operation to the scintigraphic result pre-operatively and 3) calculating the diagnostic sensitivity and specificity of scintigraphy to detect a loose cup. 


\section{Patients and methods}

Between May 1990 and December 1995, 500 consecutive patients received a primary uncemented total hip arthroplasty (ABG I, StrykerHowmedica, New Jersey, USA) for symptomatic coxarthrosis and were followed up prospectively. The mean age at the index operation was 57 years (range 25-80).

Apart from clinical follow up, following patient consent, a Tc99 bone scintigraphy of the hip and standard AP and lateral radiographs of the hip were made annually. At the closing date of this survey (31 December 2005) a total of 32 cups were revised for progressive osteolysis. Progressive osteolysis was defined as the expansion of one or more cysts of more than one millimetre per year on serial radiographs and/or formation of new cysts in patients that already had one or more cysts on previous radiographs. In this series of 500 patients there was only one stem revision; for unendurable pain attributed to doubtful osseointegration and stabilisation of the stem at one year after the index operation. The mean age at cup-revision was 65 years (range 36-87). The mean follow up at the time of revision was 8.3 years (range 4-11.5).

32 patients were indicated for revision and diagnosed with progressive acetabular osteolysis by the standard criteria listed below.

1. a patient without pain, expected survival of more than 10 years, obvious progressive osteolytic lesions of the acetabulum on standard radiographs and agreement of patient and surgeon to perform a revision to limit further damage to the acetabulum $(n=2)$.

2. a patient with pain, obvious progressive osteolytic lesions of the acetabulum on standard radiographs, but with the cup radiographically still fixed/stable $(\mathrm{N}=16)$

3. a patient with pain and obvious (aseptic) loosening (migration or radiolucent lines in all three zones) of the acetabular component on standard radiographs $(n=14)$.

Revision operation was done within three months after the last scintigraphy and radiograph were made. Intra-operative findings were recorded by one surgeon (A.J.T.). Per-operatively, the acetabular component was called loose when it could be taken out only by a forceps and there was no bone ongrowth onto the surface with only a fibrous interface present. A well fixed cup had bone ongrowth onto parts of the surface and had to be cut out using a chisel. The osteolytic defects of the acetabulum were classified depending on the location and severity of bone loss using Paprosky's classification. ${ }^{27,28}$

\section{Observation of the radiographs}

One observer (W.V.) looked at the annually made AP and lateral images and identified migration of the cup and potentially wear-related phenomena, such as osteolytic cyst formation and radiolucent lines around the acetabulum. Migration was defined as a displacement of the cup in any direction of more than three millimetres on anteroposterior radiographs. Radiographic signs of osteolysis were located according to the three zones of DeLee and Charnley ${ }^{19}$ on the AP radiograph and three zones on the 
lateral image (anterior, midrange and posterior). Osteolytic cysts or radiolucent lines were rated as present or non-present. Also the number, size, and shape (affected boneimplant interface) of cysts were evaluated and scored in a composite severity index. In the absence of a gold standard rating system, a recently published classification system of Geerdink et al. ${ }^{30}$ was used: one point was given to one small cyst covering a small proportion of the bone-implant interface; two points were given for either two such small cysts or one medium sized cyst affecting approximately $1 / 2$ the bone-implant interface of the zone under investigation; two points also were given for a large cyst extending from a neighbouring zone into the investigated zone affecting approximately $1 / 2$ the bone-implant interface; three points were given when two medium-sized cysts or a large cyst affected all or most of the bone-implant interface of the zone under investigation. With six acetabular zones, the total severity index ranged from 0 (no cysts) to 18 (extensive cysts in all three zones on AP as well as lateral radiograph). Wear was measured by one blinded observer (WV) on standard antero-posterior standing digital radiographs (5 MPix resolution) determining femoral head penetration using the Roman V 1.70 software (Institute of Orthopaedics, Oswestry, UK). Accuracy, intraobserver and inter-observer reliability of this method, and software reportedly are equal or superior to other common methods. ${ }^{31}$ The observer was blinded to the scintigraphic findings.

\section{Imaging Technique of Scintigraphy}

Patients received an intravenous injection of $555 \mathrm{MBq}(15 \mathrm{mCi})$ of $99 \mathrm{mTc}$-labeled Methylene diphosphonate. Patients were instructed to drink as much water as possible during the waiting period and to void before scanning. After approximately three hours, 350,000 counts were obtained from the upper posterior thoracic vertebral region with a Siemens large-field-of-view gamma camera with an all-purpose collimator (Siemens Gamma Sonic, Hoffman Estates, IL). The time of this static image was noted and used as a preset time for the rest of the images. Anterior, posterior and lateral images of the hip implant were obtained and stored in the $128 \times 128$ matrix of a modem data-processing system (ADAC, Milpitas, CA) for subsequent analysis. Only the anterior and posterior images were used for analysis. The patient was positioned in the same manner for each examination so that comparable scintigrams were obtained.

Finally one observer (A.I.A.R.) evaluated the results and called the scintigraphic result either positive with elevated uptake around the acetabulum component in comparison to the previous scintigraphy from the same patient, or negative.

The observer was blinded for the radiographic findings.

\section{Statistics}

The per-operative findings with regards to the presence of osteolysis and whether the cup was loose or fixed were used as the so-called gold standard for calculating the diagnostic sensitivity, specificity and the positive predictive values of technetium 
scintigraphy for a.) detecting acetabular osteolysis and b.) detecting aseptic loosening of the uncemented acetabular component.

The sensitivity of scintigraphy to detect acetabular osteolysis was calculated by dividing the number of positive scintigraphies with present osteolysis (true positives) by the sum of this number plus the number of false negatives, ergo the number of subjects with present osteolysis but a negative scintigraphy.

In addition the correlation between the extent of acetabular damage (osteolysis) and pre-operative scintigraphic result was investigated by comparing the proportions of positive scintigraphies per Paprosky group assuming higher proportions for the higher Paprosky class (Fisher exact test, $\mathrm{p}>0.05$ ).

\section{Results}

Out of a group of 500 consecutive patients with uncemented total hip arthroplasty, 32 cups were revised for progressive acetabular osteolysis. All 32 patients (100\%) had one or more osteolytic lesion(s) on the plain radiographs. In all patients (100\%) the osteolysis was progressive according to the definition described in the methods section. The mean wear rate of this group of patients was $0.35 \mathrm{~mm} / \mathrm{yr}$ (range $0.13-1.67$ ). The cumulative severity index for the location and number of cysts as was measured on the radiographs are summarized in table 1 . A specific pattern or preferred location for cyst formation in this group of 32 patients was not found.

The sensitivity, specificity and predictive values for diagnosing progressive acetabular osteolysis are listed in table 2. Eleven true positive and 21 false negative outcomes resulted in a sensitivity of only $34 \%$ and a specificity of $0 \%$.

Intra-operatively, 50\% (16/32 cups) of the cups were called loose. 16/32 (50\%) cups were found stable at the time of operation. Per-operative evaluation of the acetabular defects resulted in the following numbers per classification: 14 patients Paprosky 2 (of which 3 cups loose), 18 patients Paprosky 3a (of which 13 cups loose).

In the Paprosky 3 a group eight out of eighteen patients (44\%) had a positive scintigraphy prior to revision. Of these eight patients seven had a loose cup intra-operatively. In the Paprosky 2 group only three out of 14 patients (21\%) had a positive scintigraphic result. Of these three patients only one cup was loose intra-operatively. [Table 3] The proportion of positive scintigraphies was slightly higher in Paprosky 3a (more severe osteolysis) but not significantly so $(p=0.163)$. The only significant difference found between the groups was that the proportion of loose cups was higher in Paprosky $3 a$ in general $(13 / 82=72 \%)$ and also with positive scintigraphy $(7 / 8=88 \%)$. Thus, the slightly elevated proportion of positives scintigraphies in the Paprosky 3a group is due to the higher proportions of loose cups and not the detection of more severe osteolytic damage.

In total, eleven patients $(11 / 32,34 \%)$ had a positive pre-operative scintigraphy of which eight $(8 / 11,73 \%)$ cups were called loose at operation. Sensitivity, specificity and predictive values of scintigraphy for detecting a loose cup are listed in table 4. 
Table 1: Cumulative severity index of 32 patients prior to cup revision. Location and total number of peri-acetabular cysts as were seen on the radiographs are presented.

\begin{tabular}{|l|l|l|l|}
\hline AP image & Delee-Charnley 1 & Delee-Charnley 2 & Delee-Charnley 3 \\
\hline Severity Index & 21 & 20 & 22 \\
\hline Lateral image & Anterior & Mid & Posterior \\
\hline Severity Index & 13 & 15 & 11 \\
\hline
\end{tabular}

Table 2: Diagnostic performance of Technetium scintigraphy in detecting peri-acetabular osteolysis

\begin{tabular}{l|l|l|l|l}
\hline Tc-99m scintigraphy & 11 \\
\hline True positive & 0 \\
False positive & 0 \\
\hline True negative & 21 \\
False negative & 0.34 \\
Sensitivity & 0 \\
Specificity & 0 \\
Negative predictive value & 1
\end{tabular}

Table 3: Relationship per-operative classified osteolysis, per-operative loose cup and preoperative scintigraphic result

\begin{tabular}{|c|c|c|}
\hline \multicolumn{2}{|c|}{ Pre-revision scintigraphy } \\
\hline Total $\mathbf{n}=\mathbf{3 2}$ & Positive $[$ [per-op loose cup] & Negative [per-op loose cup] \\
\hline Paprosky $\mathbf{2}[\mathbf{n = 1 4 ]}$ & $3(21 \%)[1]$ & $11(79 \%)[2]$ \\
Paprosky $\mathbf{3 a}[\mathbf{n = 1 8}]$ & $8(44 \%)[7]$ & $10(56 \%)[6]$
\end{tabular}


Table 4 Diagnostic performance of Technetium scintigraphy in detecting acetabular component loosening

\begin{tabular}{l|l|}
\hline Tc-99m scintigraphy & \\
\hline True positive & 8 \\
False positive & 3 \\
True negative & 13 \\
False negative & 8 \\
Sensitivity & 0.38 \\
Specificity & 0.73 \\
Negative predictive value & 0.38 \\
Positive predictive value & 0.73
\end{tabular}

\section{Discussion}

This study investigates the role of technetium scintigraphy in the diagnosis of osteolysis behind the acetabular component of an uncemented total hip prosthesis. Although this study reports on the value of scintigraphy in the diagnostics of acetabular osteolysis and cup loosening in one of the largest single implant, sinlge surgeon and single observer series reported, the total number of revisions performed to per-operatively validate the diagnostic predictions could, statistically spoken, still be even large to make conclusions with even higher confidence. Another limitation of this and other studies published on the subject is that for the objective quantification of the extent of acetabular osteolysis there is still no commonly accepted score. This is why we tried to apply a previously described severity index.

In general, it is difficult to predict whether and to what amount osteolysis will occur, however some contributing factors are well described in the literature. Polyethylene wear, especially when the wear rate exceeds 0.2 millimetres per year causes periacetabular osteolysis. ${ }^{5-8}$ This wear threshold for the development of osteolysis was exceeded in our study. In our patient group the mean wear rate was 0.35 millimetres per year. To which amount the wear debris can exert its pathogenic effect is partly dependent on the type of implant used. We used an uncemented hydroxyapatite coated cup with holes. Wear debris can make contact with the bone behind the cup through these holes and lead to balloon-like osteolytic cysts. This has been shown in histological slices of human post-mortem specimen. ${ }^{32}$ When these cysts reach a certain number or size the chance of loosening of the implant will increase. ${ }^{9-11}$

In clinical practice, plain radiography is the first imaging modality used when evaluating 
the status of a prosthesis. Once the development of osteolytic peri-acetabular cysts has started, clinicians would like to have more insight in this process and its progression to get more information about the status of bone loss behind the cup prior to the acute situation of loosening of the implant. With a low diagnostic sensitivity of $34 \%$ only shown in this study, technetium scintigraphy can not help us to detect early osteolysis. A general problem in this matter is that there is no consensus on how to classify osteolysis (cysts) of the acetabulum. ${ }^{8-11}$ Even with use of a severity index based on the number, size and location of cyst formation no specific pattern of progressive osteolysis was found. Although progressive osteolysis behind the acetabular component will eventually lead to loosening of the implant it cannot be predicted when this will happen in the individual patient. An established fact however is that when we wait until the cup has become loose, there is more damage to the acetabular bone. This is also confirmed by our results where in the group with Paprosky $3 a 72 \%$ of the cups were found loose at revision whereas in the Paprosky 2 group this was only the case in $21 \%$.

In this study the process of wear-related osteolysis behind an acetabular component of a total hip prosthesis cannot be visualized by technetium scintigraphy, not even when the osteolysis is progressive and involves a large part of the bone-implant interface. Sensitivity and specificity of respectively $34 \%$ and $0 \%$ are well below acceptable diagnostic thresholds. However once the cup has become loose, independent of the cause, scintigraphy can diagnose the lost fixation. In our study the sensitivity and specificity to detect a loose cup were $38 \%$ and $73 \%$ respectively. For radiography however the reported sensitivity and specificity are much better, $85 \%$ and $78 \%$ respectively. ${ }^{25}$ It can be concluded that in clinical practice, the use of technetium scintigraphy following the standard protocol as used in this study, has no additional value to plain radiography in detecting a loose acetabular component.

Thus for the time being, the decision to revise a cup because of progressive acetabular osteolysis is still dependent on the patient starting to complain about pain or on the moment that the implant has become loose as diagnosed on serial radiographs. For scintigraphy in its standard form as used in this study there is no place in this algorithm. Maybe additional lateral scintigraphy images or more modern techniques such as PETscan images could improve the diagnosis of early peri-prosthetic osteolysis to clinically relevant levels. Future investigations are necessary to get more insight in the process of peri-prosthetic osteolysis. 


\section{References}

1. Harris WH. The problem is osteolysis. Clin Orthop Relat Res. 1995 Feb;(311):46-53

2. Klapperich C, Graham J, Pruitt L, Ries MD. Failure of a metal-on-metal total hip arthroplasty from progressive osteolysis.j Arthroplasty. 1999 Oct;14(7):877-81

3. Yoon TR, Rowe SM, Jung ST, Seon KJ, Maloney WJ.Osteolysis in association with a total hip arthroplasty with ceramic bearing surfaces. J Bone Joint Surg Am. 1998 Oct;80(10):1459-68.

4. Willert HG, Bertram H, Buchhorn GH. Osteolysis in alloarthroplasty of the hip. The role of ultra-high molecular weight polyethylene wear particles.Clin Orthop Relat Res. 1990 Sep;(258):95-107

5. Kobayashi A, Freeman MA, Bonfield W et al. Number of polyethylene particles and osteolysis in total joint replacements. A quantitative study using a tissue-digestion method.J Bone Joint Surg Br. 1997 Sep;79(5):844-8.

6. Dowd JE, Sychterz CJ, Young AM, Engh CA. Characterization of long-term femoral-head-penetration rates. Association with and prediction of osteolysis. J Bone Joint Surg Am. 2000 Aug;82-A(8):1102-7

7. Livingston BJ, Chmell MJ, Spector M, Poss R. Complications of total hip arthroplasty associated with the use of an acetabular component with a Hylamer liner. J Bone Joint Surg Am. 1997 Oct;79(10):1529-38

8. Dumbleton JH, Manley MT, Edidin AA. A literature review of the association between wear rate and osteolysis in total hip arthroplasty.J Arthroplasty. 2002 Aug; 17(5):649-61.

9. Rubash HE, Sinha RK, Paprosky W, Engh CA, Maloney WJ. A new classification system for the management of acetabular osteolysis after total hip arthroplasty.Instr Course Lect. 1999;48:37-42.

10. Haddad FS, Masri BA, Garbuz DS, Duncan CP. Femoral bone loss in total hip arthroplasty: classification and preoperative planning.Instr Course Lect. 2000;49:83-96.

11. Campbell DG, Masri BA, Garbuz DS, Duncan CP. Acetabular bone loss during revision total hip replacement: preoperative investigation and planning.Instr Course Lect. 1999;48:43-56.

12. Soto MO, Rodriguez JA, Ranawat CS. Clinical and radiographic evaluation of the Harris-Galante cup: incidence of wear and osteolysis at 7 to 9 years follow-up.J Arthroplasty. 2000 Feb;15(2):139-45

13. Schmalzried TP, Brown IC, Amstutz HC, Engh CA, Harris WH. The role of acetabular component screw holes and/or screws in the development of pelvic osteolysis.Proc Inst Mech Eng [H]. 1999;213(2):14753.

14. Goodman SB, Huie P, Song Y, Schurman D, Maloney W, Woolson S, Sibley R. Cellular profile and cytokine production at prosthetic interfaces. Study of tissues retrieved from revised hip and knee replacements.J Bone Joint Surg Br. 1998 May;80(3):531-9

15. Zicat B, Engh CA, Gokcen E. Patterns of osteolysis around total hip components inserted with and without cement.J Bone Joint Surg Am. 1995 Mar;77(3):432-9.

16. Emans PJ, Broeke RH, Van Mulken JM, Kuijer R, Van Rhijn LW, Geesink RG. Results of total hip arthroplasties in the young patient; further evidence for a barrier against articular wear debris by hydroxyapatite coatings. Hip Int. 2009 Oct-Dec;19(4):343-51.

17. Walter WL, Clabeaux J, Wright TM, Walsh W, Walter WK, Sculco TP. Mechanisms for pumping fluid through cementless acetabular components with holes. J Arthroplasty. 2005 Dec;20(8):1042-8.

18. Walter WL, Walter WK, O'Sullivan M. The pumping of fluid in cementless cups with holes. J Arthroplasty. 2004 Feb; 19(2):230-4

19. DeLee JG, Charnley J. Radiological demarcation of cemented sockets in total hip replacement. Clin Orthop Relat Res 1976-121:20-32.

20. Wylde V, Blom AW. Assessment of outcomes after hip arthroplasty. Hip Int. 2009 Jan-Mar; 19(1):1-7.

21. Udomkiat $P$, Wan Z, Dorr LD. Comparison of preoperative radiographs and intraoperative findings of fixation of hemispheric porous-coated sockets. J Bone Joint Surg Am. 2001 Dec;83-A(12):1865-70.

22. Temmerman OP, Raijmakers PG, Deville WL, Berkhof J, Hooft L, Heyligers IC. The use of plain radiography, subtraction arthrography, nuclear arthrography, and bone scintigraphy in the diagnosis of a loose acetabular component of a total hip prosthesis: a systematic review. J Arthroplasty. 2007 Sep;22(6):818-27. Epub 2007 Mar 28. 
23. Temmerman OP, Raijmakers PG, Berkhof J et al. Diagnostic accuracy and interobserver variability of plain radiography, subtraction arthrography, nuclear arthrography, and bone scintigraphy in the assessment of aseptic femoral component loosening. Arch Orthop Trauma Surg. 2006 Jul;126(5):31623. Epub 2006 Mar 18.

24. Temmerman OP, Raijmakers PG, Berkhof J, Hoekstra OS, Teule GJ, Heyligers IC. Accuracy of diagnostic imaging techniques in the diagnosis of aseptic loosening of the femoral component of a hip prosthesis: a meta-analysis. J Bone Joint Surg Br. 2005 Jun;87(6):781-5

25. Temmerman OP, Raijmakers PG, David EF et al. A comparison of radiographic and scintigraphic techniques to assess aseptic loosening of the acetabular component in a total hip replacement. J Bone Joint Surg Am. 2004 Nov;86-A(11):2456-63

26. C.S.B. Galasko, D.A.Weber, Textbook; Radionuclide scintigraphy in orthopaedics, 1984

27. Paprosky WG, Magnus RE. Principles of bone grafting in revision total hip arthroplasty. Acetabular technique. Clin Orthop Relat Res 1994-298:147-55.

28. Paprosky WG, Perona PG, Lawrence JM. Acetabular defect classification and surgical reconstruction in revision arthroplasty. A 6-year follow-up evaluation. J Arthroplasty 1994;9-1:33-44.

29. Geerdink CH, Grimm B, Vencken W, Heyligers IC, Tonino AJ. Cross-linked compared with historical polyethylene in THA: an 8-year clinical study. Clin Orthop Relat Res. 2009 Apr;467(4):979-84.

30. Geerdink CH, Grimm B, Vencken W, Heyligers IC, Tonino AJ. The determination of linear and angular penetration of the femoral head into the acetabular component as an assessment of wear in total hip replacement: a comparison of four computer-assisted methods. J Bone Joint Surg Br. 2008 Jul;90(7):83946.

31. Tonino A, Oosterbos C, Rahmy A, Thèrin M, Doyle C. Hydroxyapatite-coated acetabular components. Histological and histomorphometric analysis of six cups retrieved at autopsy between three and seven years after successful implantation. J Bone Joint Surg Am. 2001 Jun;83-A(6):817-25. 


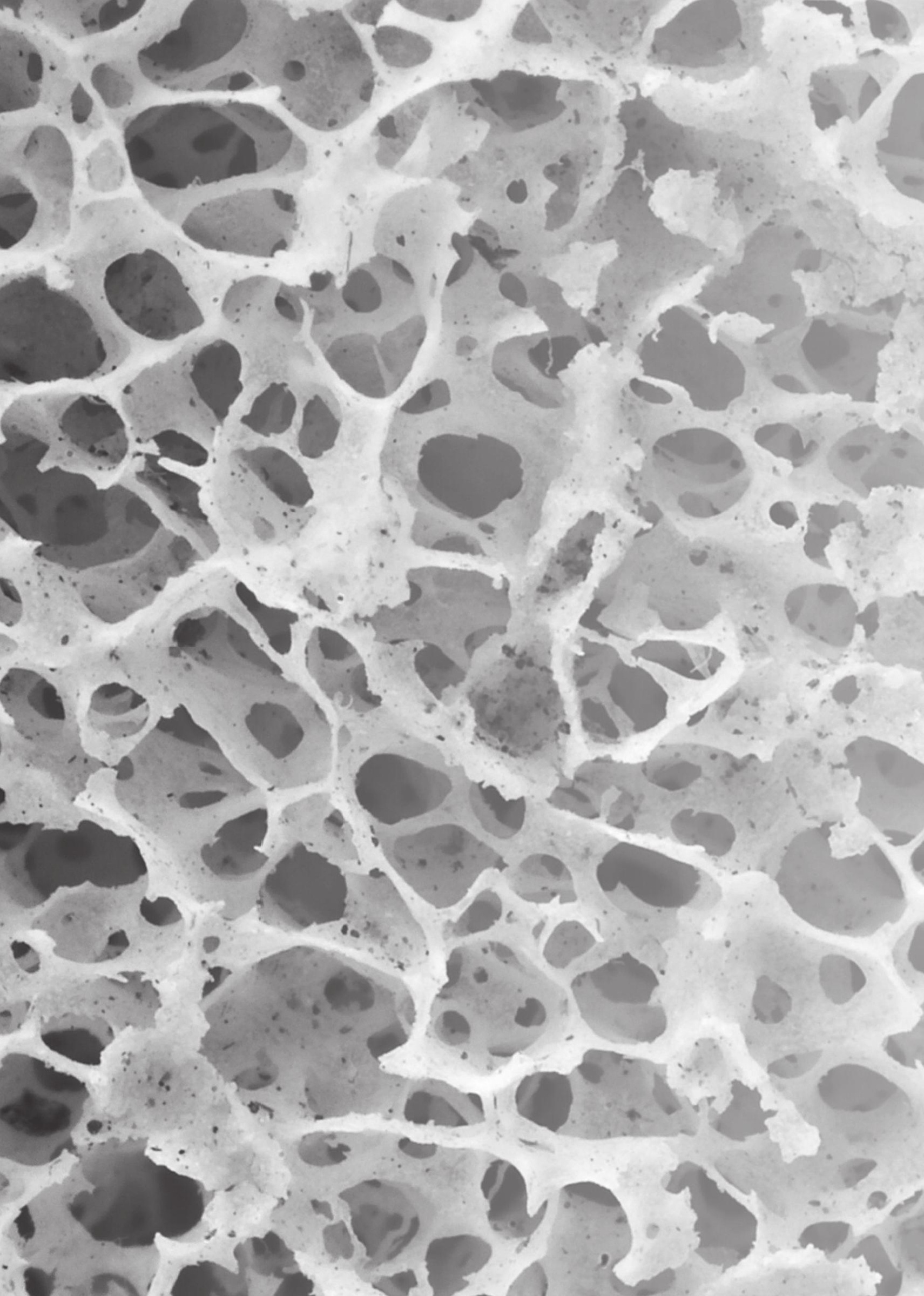




\section{Chapter Six}

\section{Hydroxyapatite-Coated Sockets for Acetabular Revision}

Geerdink CH, Schaafsma J, Meyers WG, Grimm B, Tonino AJ.

J Arthroplasty. 2007 Apr;22(3):369-76. 


\begin{abstract}
:
This study describes our experience with a hydroxyapatite-coated uncemented hemispherical component used for revision of 72 patients with aseptic loosening of the acetabular component. Preoperative Paprosky classification of the acetabular defects was 1 type I, 35 type II, and 36 type III; according to American Academy of Orthopaedic Surgeons, 14 segmental, 10 cavitary, and 48 combined. The mean follow-up was 7.6 years (range, 5.0-13.0). Complications were seen in 7 cases (9.6\%). Seventy acetabular components $(97.2 \%)$ showed bone ongrowth on the radiographs. The survival rate was $90.8 \%$ after a mean follow-up of 7.6 years (range, 5.0-13.0) when revision for any reason is the end point (confidence interval, $80.5 \%-100 \%$ ) and $98.1 \%$ (confidence interval, $94.5 \%-100 \%$ ) when aseptic loosening of the cup is the end point. We conclude that hydroxyapatite-coated cups for acetabular revision show promising results.
\end{abstract}




\section{Introduction}

Revision of a failed acetabular component is a major challenge, as both bone reconstruction and restoration of the anatomical hip center must be taken into consideration. Revision techniques include combinations of cemented cups with bulk grafts and bipolar prosthesis with bulk or morselized grafts or uncemented cups. They all have been tried but with varying success rates..$^{1-9}$ The advent of acetabular reconstruction rings or cages in combination with cemented cups and morselized bone grafts has improved survival rates. ${ }^{9-13}$ Although the best method for revising the deficient acetabulum is not yet known, it has become obvious that initial stability of the cup on the host bone is the primary goal to achieve a longterm cup fixation. As the host bone is highly compromised in revision cases, it is more difficult to achieve this initial stability. Fast bone ongrowth to the new implant is mandatory to shorten the time between primary mechanical stabilization and secondary biologic fixation. ${ }^{6,14,15}$ New bone bonding surfaces such as hydroxyapatite (HA) coatings have repeatedly shown to promote and accelerate bone ongrowth and lead to a stable and reliable biologic fixation in primary hip arthroplasty. ${ }^{16-21}$ We performed acetabular revision with a HA coated component under the hypothesis that the coating could theoretically compensate for the reduced amount and the reduced vitality of the host bone. Because fixation by bone ongrowth to the new cup has to come directly from the host bone and is related to the contact area, larger cups were used to enhance this effect. We report here the intermediate results of 72 cups, which were revised for aseptic loosening with a cementless HA coated hemispherical acetabular component. 


\section{Materials and Methods}

We carried out a consecutive cohort study of all acetabular revisions that had been performed for aseptic loosening between October 1990 and August 2000 using the ABG HA-coated acetabular prosthesis (Stryker, Winterthur Switzerland). The hemispherical metal cups were made of titanium alloy (Ti-6Al-4V) and fully coated with HA (Fig. 1). The HA coating was applied with a plasma-spray torch under a vacuum onto a sublayer of titanium to improve adhesion. The coating had an HA content of more than $90 \%$, a porosity of less than $10 \%$, and a calcium-to-phosphate ratio of 10:6. The crystallinity was $100 \%$ before coating and more than $75 \%$ after coating. The grain size was 20 to $50 \mu \mathrm{m}$; the tensile strength of the bond was 62 to $65 \mathrm{MPa}$. The thickness of the HA layer was $60 \pm 30 \mu \mathrm{m}$. The roughness of the cup was $9 \pm 2.5 \mu \mathrm{m}$ after sandblasting, $8.5 \pm 2.5 \mu \mathrm{m}$ after titanium spraying, and $5 \mu 1 \mu \mathrm{m}$ after HA coating. The criterion for inclusion in this study was loosening without infection of an acetabular component that had been inserted with or without cement. In total, 72 patients were included in this study. The mean age of these patients at their first total hip arthroplasty (THA) was 59.1 years (range, 26-80 years). The mean age of the patients at the index cup revision operation was 69.5 years (range, 39-91 years). The diagnosis at the first hip arthroplasty was osteoarthritis (65 cases), rheumatoïd arthritis (3), femoral neck fracture (3), and osteonecrosis (1). Seven patients had already had an acetabular revision before. In 54 cases $(75 \%)$, the stem was also revised for aseptic loosening in the same session. The mean preoperative Harris hip score was 38.1 points (range, 4-71 points), and the mean preoperative Merle d'Aubigne' (MdA) score was 8.3 points (range, 0-14 points). Among the 72 revised cups, 50 were originally cemented, and 22, uncemented (Table 1). The mean size of these cups was $50 \mathrm{~mm}$ (range, 44-58).

\section{Operative Technique}

All revision procedures were performed by 3 consultants in a standard operation room with vertical flow. No body exhaust suits were worn. Prophylactic anticoagulants (2850IE fraxiparine subcutaneous) were applied, and prophylactic antibiotics (Mandol $1 \mathrm{~g}$ ) were given after multiple cultures had been obtained. Antibiotics were not given after surgery. A straight lateral anterior approach (Hardinge- McFarland) was used in all cases. Trochanteric osteotomy was needed in 1 case. When it was necessary to remove a loosened stem (54 cases), it was done before removal of the loose acetabular cup. Much attention was paid to remove all cement, debris, and granulomatous tissue. The acetabular bone stock was classified depending on the location and severity of bone loss using Paprosky classification ${ }^{22,23}$ as well as the American Academy of Orthopaedic Surgeons (AAOS) classification. According to Paprosky classification, there was 1 type I defect, 35 type II defects, and 36 type III defects. According to the AAOS classifications, 14 hips had a peripheral or central segmental defect (type I), 10 had only cavitary defects (type II), and 48 had combined defects (type III). The entire acetabular rim was exposed, followed by reaming the acetabulum using 
Table I: Patient data and information from surgery.

\begin{tabular}{|c|c|c|}
\hline \multicolumn{3}{|l|}{ Diagnosis for revision THA } \\
\hline Aseptic loosening of cup & 72 & $(100 \%)$ \\
\hline Additional loosened stem & 54 & $(75 \%)$ \\
\hline Cemented cup & 50 & \\
\hline Uncemented cup & 22 & \\
\hline Age at primary THA & \multicolumn{2}{|c|}{59.1 (range 26-80) } \\
\hline Age at revision $\mathrm{THA}$ & \multicolumn{2}{|c|}{69.5 (range 39-91) } \\
\hline \multicolumn{3}{|l|}{ Diagnosis for primary THA } \\
\hline Osteoarthrosis & 65 & $(90 \%)$ \\
\hline Rheumatoid & 3 & $(4 \%)$ \\
\hline Femoral neck fracture & 3 & $(4 \%)$ \\
\hline Osteonecrosis & 1 & $(2 \%)$ \\
\hline \multicolumn{3}{|l|}{ Pre-revision Paprosky } \\
\hline Type 1 & 1 & $(1 \%)$ \\
\hline Type 2 & 35 & $(49 \%)$ \\
\hline Type 3 & 36 & $(50 \%)$ \\
\hline \multicolumn{3}{|l|}{ Pre-revsision AAOS } \\
\hline Segmental & 14 & $(19 \%)$ \\
\hline Cavitary & 10 & $(14 \%)$ \\
\hline Combined & 48 & $(67 \%)$ \\
\hline Spike fixation of cup & 34 & $(47 \%)$ \\
\hline Screw fixation of cup & 38 & $(53 \%)$ \\
\hline Complications & 7 & $(9.6 \%)$ \\
\hline Early dislocation & 3 & \\
\hline Late dislocation & 2 & \\
\hline Peroneal lesion & 1 & \\
\hline Sepsis & 1 & \\
\hline$\geq 5$ years follow up & 54 & oatients \\
\hline Mean follow-up years & 7.6 & (range 5-13) \\
\hline
\end{tabular}

progressively larger reamers. An intact rim and intact anterior and/or posterior columns were preserved. The size of the cup was provisionally decided from the size of the last reamer and confirmed with a trial cup. Now, the stability of the implant against supportive host bone was assessed. The need for bone grafting was decided in this stage. Any remaining smallto- moderate cavitary or segmental bone defect, contained 
and not contained, was impacted with morselized bone allografts with reverse reaming and by hand. Fresh frozen femoral heads were morselized using a hand-powered mill. No structural allografts were used in any of the revisions. Then the stability of a trial component in the augmented acetabulum was tested again. When the press fit appeared firm, mainly through intact rim fixation, only 2 spikes but no screws were used. When stability was not firm because of peripheral segmental bone loss as in all Paprosky stage III cases, at least 2 screws were applied into the superior quadrant of the ilium (38 cases). At this point, the definitive acetabular component was inserted and impacted with or without screws, as decided before. In patients in whom it was not possible to enlarge the acetabulum without damaging the anteroposterior containment, a high hip center was accepted (3 patients). Large cups were considered a jumbo cup when the diameter was $60 \mathrm{~mm}$ or more in men (16/27 patients) and $56 \mathrm{~mm}$ or more in women (34/45 patients). All patients were mobilized immediately after the operation with controlled, partial weight-bearing using 2 crutches. Further weightbearing was determined by the femoral construct.

\section{Follow-Up}

Seventy-two patients were included in a followup study using the MdA functional scoring system and the Harris functional scoring system. They were reviewed clinically and radiographically at 3, 6, and 12 months after surgery and yearly thereafter. All radiographic changes were analyzed by a single evaluator. Criteria from the literature were used to determine bone ingrowth and classify radiographic failure ${ }^{6,24,25}$ by documenting radiolucencies, migration, or tilting of the cup and breakage of a screw. Migration of the cup or changes of the inclination angle were determined with the ME Müller template (Protek AG, Bern, Switzerland), comparing the direct postoperative anteroposterior radiograph with the radiographs taken at follow-up. ${ }^{25}$ The X-line of the template was oriented to the distal edge of the teardrop, and the vertical line was adjusted so that it bisected the ipsilateral teardrop. The width of radiolucencies at the metal-backed cup to bone interface in each of the three DeLee and Charnley zones ${ }^{26}$ was measured. A component was designated as stable with bone ingrowth if there were no radiolucent lines extending across $50 \%$ or more of any zone, and there was no measurable migration of the component as 'stable' with fibrous ingrowth if radiolucent lines were present in all 3 zones but the component had not migrated, and as 'unstable' if there were radiolucent lines in all 3 zones and the cup had migrated three $\mathrm{mm}$ or more. ${ }^{24}$ Breakage of 1 or more screws was also defined as failure. To calculate survival rates of this cup, only results of patients who reached a minimum of 5 years of followup time were used. 
Figure 1: $A B G$ cup with screw and spike

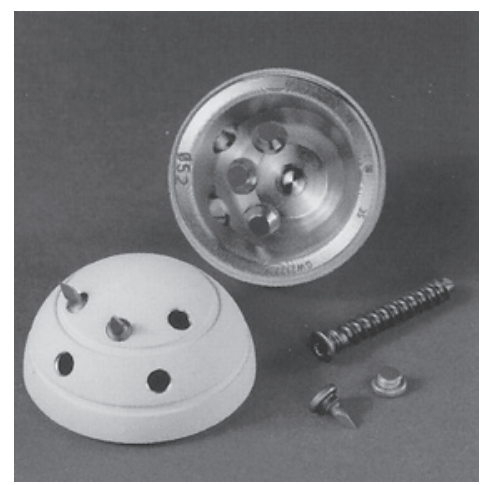

\section{Results}

None of the 72 patients was lost to follow-up, which was closed in August 2003. Of these 72 patients monitored during this study, 46 were still alive at this date; 26 patients had died before but 13 of them completed a 5-year follow-up. From the 13 patients who did not complete the 5 years of follow-up, the acetabular components showed bone ongrowth, and none gave evidence of any migration or change of position of the hip center at the final follow-up. In fact, their clinical parameters were never different from the patients who did reach the 5 years of follow-up time. From the 72 patients included in this study, complications were seen in 7 cases $(9.6 \%$ ) (Table 2). Those were 5 dislocations $(6.9 \%), 1$ peroneal lesion that did not heal, and 1 late sepsis in a patient who died 3.4 years after the cup revision. From the 5 dislocations, 3 occurred early and 2 late ( $>1$ year postoperatively), all in patients who also required stem revision. Only 1 dislocation (early) could be managed conservatively, whereas the other 4 had to be reoperated. In 3 of them, the acetabular component could be left in place; in 1 case, a longer neck length of the head was sufficient; in another case, the insert was reorientated, and one time, a reorientation of the femoral stem was required. The fourth case (late dislocation) was revised 7.1 years after the index revision with an exchange of the entire acetabular component which had to be cut out by a chisel because of the good fixation. The mean duration of follow-up of the 54 patients (13 dead and 41 alive) who had a minimum follow-up of 5 years was 7.6 years (range, 5-13years). The mean MdA score at maximum follow-up increased from a preoperative average of 8.7 to an average of 15.2 (range, 8-18). The mean Harris score increased from 37.9 preoperatively to an average value of 84.0 (range, 23-100) at maximum follow-up (Table 2). 
Table II: Average Harris Hip Scores and Merle d'Augbigné Scores in relation to follow up time.

\begin{tabular}{|c|c|c|c|c|c|c|c|c|c|c|}
\hline & \multicolumn{2}{|c|}{ Pre-revision } & \multicolumn{2}{|c|}{1 year } & \multicolumn{2}{|c|}{3 years } & \multicolumn{2}{|c|}{5 years } & \multicolumn{2}{|c|}{ Last Follow-up } \\
\hline$N$ & 72 & & 69 & & 60 & & 54 & & 54 & \\
\hline $\begin{array}{l}\text { Harris Hip Score } \\
\text { AVG (STD) Range }\end{array}$ & $38.1(8.3)$ & $4-71$ & $85.2(15.3)$ & $12-100$ & $88.6(16.1)$ & $19-100$ & 89.8 (15.8) & $48-100$ & 98.8 & $95-100$ \\
\hline $\begin{array}{l}\text { Merle d'Aubigné } \\
\text { Score } \\
\text { AVG (STD) Range }\end{array}$ & $8.3(2.7)$ & $0-14$ & $15.3(3.2)$ & 6-18 & $16.1(3.1)$ & $7-18$ & $15.9(3.2)$ & 8-18 & 17.8 & $17-18$ \\
\hline
\end{tabular}

The inclination of the acetabular components as measured on a standing anteroposterior radiograph was between $40^{\circ}$ and $55^{\circ}$ in $88 \%$ of the hips. In $2 \%$ of the hips, the angle was $55^{\circ}$ or more, whereas in $10 \%$ of the hips the angle was $40^{\circ}$ or less. According to the radiographic criteria, 70 of the acetabular components were stable through osseointegration in the form of bone ongrowth onto the cup (Fig. 2).

Figure 2: X-ray of patient with reumatoïd arthritis; pre-revision(a), direct post-revision(b) and two years after revision of the $\operatorname{cup}(\mathrm{c})$. A radiolucent line is visible in all three DeLee and Charnley zones which is pathognomonic for no bone ongrowth.

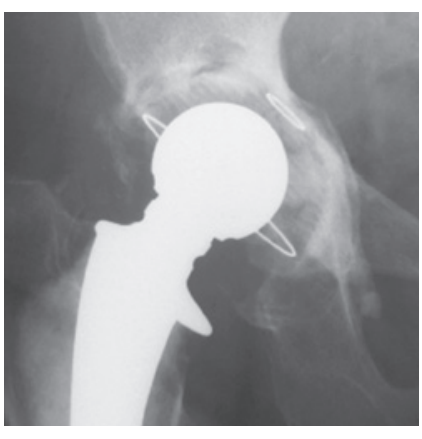

a

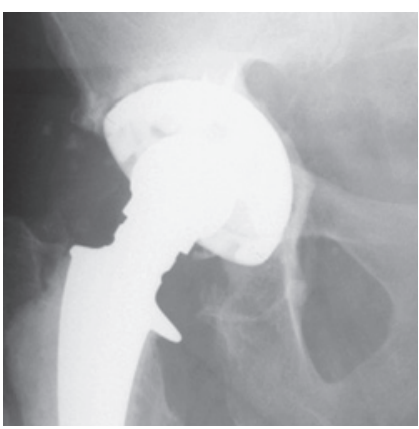

b

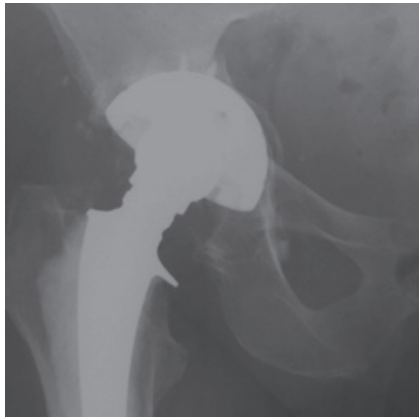

$\mathrm{C}$

Two cases were considered as failures. The first case was a man who received a left total hip replacement with a polyethylene cemented cup and a cemented curved Mueller stem in our hospital in 1975. Both components were revised at the same time in 1990 for aseptic loosening with the ABG HA coated hip system. Clinically, he performed well, but the x-ray at 13 years of follow-up showed that 1 of the 3 screws of the acetabular component was broken. The cup showed no radiolucent lines and had not migrated. In the second case, a radiolucent line next to a radiodense line persisted in all three DeLee and Charnley zones (Fig. 3). 
Figure 3: X-ray of patient with 13 years of follow up; pre-revision(a), direct post-revision(b) and after 13 years(c). No radiolucent lines are visible. Bone ongrowth onto the cup appears complete.

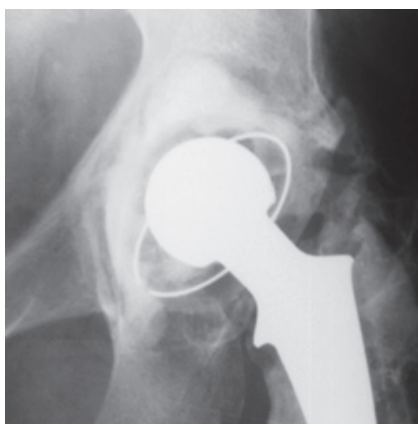

a

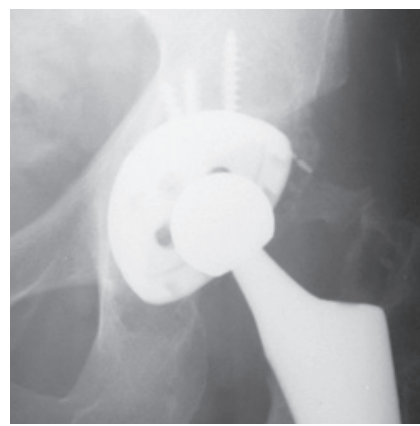

b

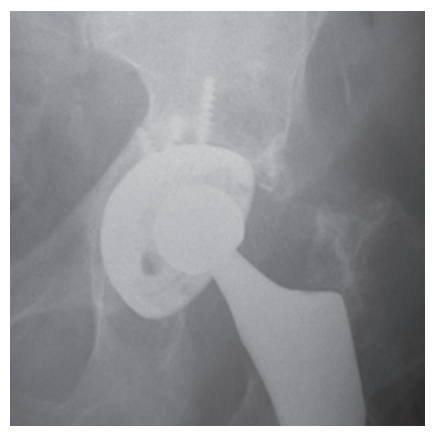

C

In this particular patient with rheumatoid arthritis, the primary THA was performed elsewhere in 1986 with a cemented Lubinus SP prosthesis (Waldemar Link, Hamburg, Germany) and an all polyethylene cemented cup. At revision, the bone loss was graded to Paprosky type II and AAOS type III. The new HA cup could be firmly inserted with spikes only, and no screws were needed for fixation. The hip functioned well for 1 year, after which the patient started complaining about pain in the groin. She was reoperated elsewhere, where it was found that the cup had become loose. The second cup that was revised was in a man who sustained a pelvic fracture at the index side in a car accident. This loosened the complete osseointegrated cup after 6.5 years of well functioning. The 3 patients with an accepted high hip center performed well and showed stable and enduring cup fixation by osseointegration (Fig. 4).

Figure 4: X-ray of a patient with a high hip centre; pre-revision(a), direct post-revision(b) and after 12 years follow-up(c).

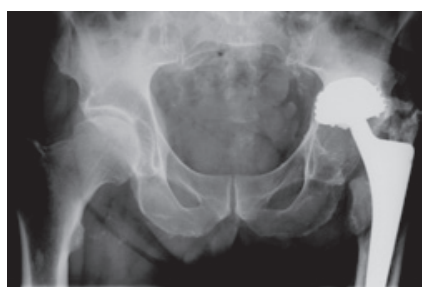

a

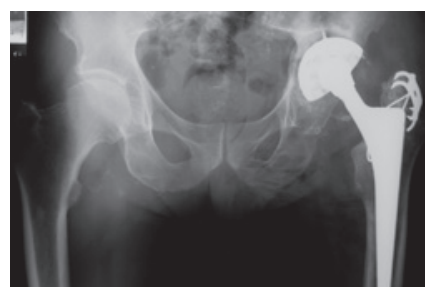

b

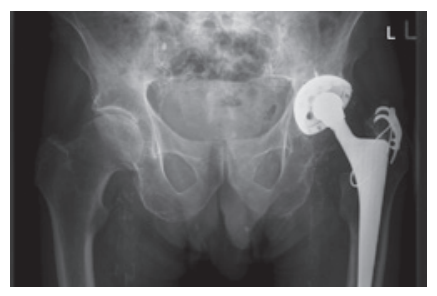

C

From one of the patients who died of cardiac failure 2 years and 7 months after the revision, the cup with the adjoining pelvis could be harvested post mortem after written consent during the patient's life. At the time of surgery, all anterior bone ring support was deficient, which was the reason to use 2 supplemental screws for fixation. At the time of harvesting, the cup was fixed mechanically stable in the acetabulum, but 
histology showed that in all 3 DeLee and Charnley zones, no bone contact was present in the anterior area, as was expected. Only in the posterior-inferior part was full bone ongrowth onto the cup evident, with percentages ranging between $37 \%$ and $43 \%$ for the 3 deLee and Charnley zones. The overall Kaplan-Meier probability of survival for this HA-coated cup used for acetabular revision was $90.8 \%$ after a mean follow-up of 7.6 years (range, $5-13$ years) when revision for any reason is the end point (confidence interval $[\mathrm{Cl}], 80.5 \%-100 \%)$. The survival rate was $98.1 \%(\mathrm{Cl}, 94.5 \%-100 \%)$ when aseptic loosening of the cup is the end point and $78.5 \%(\mathrm{Cl}, 43.9 \%-100 \%)$ when radiographic failure is the end point.

\section{Discussion}

The goal of this study was to evaluate the use of an HA-coated uncemented hemispherical acetabular component in acetabular revision. Cementless acetabular revision with porous-coated components of titanium fiber mesh or cancellous structured titanium have shown good intermediate results with low percentages of revision for radiologic loosening. ${ }^{27-30}$ In primary hip arthroplasty, HA-coated implants have shown to improve fixation by quick bone ongrowth. As a result, cup migration and radiolucent lines are less frequent, compared with uncoated implants. In the revision situation, where the amount of host bone is even more compromised, this positive effect of HA could be important. ${ }^{15}$

In our series, no unstable cups were found at follow-up. However, in 1 patient, the radiolucent lines around the newly inserted acetabular component did not disappear at follow-up. This is a prognostic sign for lack of bone ongrowth and impending loosening. When the radiolucent lines have disappeared on the x-ray within 2 years after operation, we might expect that late loosening will not occur spontaneously. ${ }^{15,31}$ Facing cementless acetabular reconstruction, the surgeon is pursuing 3 objectives: the mechanical, the biologic, and the anatomical objective. The mechanical objective is the most important. Only if primary mechanical stability is secured will secondary biologic fixation by osseointegration or bone ongrowth occur, which, in turn, can lead to long-term fixation. The way and amount of reaming is of paramount importance to get as much as viable supporting host bone without distorting an intact rim and/ or the still existing columns. When the rim is still intact as in the Paprosky stage II cases, it is mostly possible to get a press fit without the need for supplemental screws, as was noted in this series. This was also observed by Elke et al. ${ }^{27}$ They performed 171 acetabular revisions in hips with contained and small segmental defects using a press-fit monobloc cup without screws and noted that within the first 2 postoperative years, 44 of the original 171 cups had migrated mediolaterally and cranially by 2 to $6 \mathrm{~mm}$. However, all had stabilized after the second postoperative year, and none had been revised for aseptic loosening after a mean follow-up of 7.4 years (range, 5.0- 10.5 years). However, in the revision cases with large acetabular defects and a 
nonsupportive rim, as in all Paprosky stage III cases, primary stability can only be attained with the aid of supplementary screws. ${ }^{27}$

Apart from the screws, the cup design itself is also of paramount importance for implant longevity. Epinette et al ${ }^{32}$ suggested that threaded HAcoated cups may be superior to HA coated press-fit cups. However, in an observational study based on hip registry of 15340 patients with 17951 primary total hip arthroplasties, Muller et al ${ }^{33}$ found that both threaded and press-fit titanium cups showed significantly less aseptic radiologic loosening than alternative systems. Primary stability of both designs depends mainly on rim or peripheral press-fit fixation instead of polar or dome fit. This has been acknowledged by histomorphometric investigations of press-fit cups, retrieved at autopsy, where Tonino et $\mathrm{al}^{21}$ found that the predominant areas of cup-to-bone contact were at the rim of the acetabulum.

The biologic objective is mainly dependent on the amount of direct host bone contact and, therefore, closely related to the mechanical objective. Large quantities of osteoblasts from the host bone have to settle on the HA coating to provide fast and strong bone ongrowth onto the implant. The larger the direct surface contact area will be, the larger the amount of active osteoblasts at the interface. ${ }^{34}$ In our study, the average cup diameter of $50 \mathrm{~mm}$ at primary THA increased to an average of $62 \mathrm{~mm}$ at revision. As a result, the contact surface area available for biologic fixation increased to up to a maximum of $54 \%$. Supplementary screw fixation might further enhance this effect by securing more intimate and permanent contact between the host bone and the HA coating even during postoperative loading. The only revised cup in this study which failed on radiographic criteria was not fixed with screws but with spikes of 7-mm length. Supplemental screws in combination with press-fit cups do not improve survival in primary hip arthroplasty ${ }^{31,35}$ but may do so in revisions, especially when the cups are porouscoated or HA-coated. Intimate cup-to-bone contact is a prerequisite for strong bone ongrowth. The benefit of augmented cup fixation in cementless acetabular revision using screws has also been stipulated by Epinette et al. ${ }^{32}$ They routinely used 2 or more supplemental screws and reported a mechanical failure rate of $1.9 \%$ in 160 cups with a follow-up of 5 to 13 years.

Filling of the contained and uncontained bone defects with compacted morselized bone grafts was another measure to create larger contact surfaces between the HA-coated cup and bone. Bone formation and biologic stabilization can also proliferate from a fibrous interface ${ }^{36}$, as found in areas without direct cup-to-host bone contact. However, in the literature, several authors ${ }^{9,34,36-39}$ advise a minimum of $40 \%$ to $50 \%$ host bone contact for the use of uncemented cups in revision, and indeed, it might be premature to advise otherwise when using bone-conducting coatings. However, histomorphometric studies ${ }^{19}$ have shown that secure enduring socket fixation is provided by percentages of bone ongrowth ranging between $21 \%$ and $49 \%$, as was acknowledged in the presented histologic case. The good results with HA-coated cups for acetabular revision found in this study are confirmed by findings from Nivbrandt and Karrholm. ${ }^{15}$ They reported 
their short-term results (2 years) and showed that this implant has the smallest amount of migration so far reported in revision hip arthroplasty, even in cases where the cup had less than $50 \%$ contact with the living bone.

The anatomical objective: when aiming at a lasting result, the anatomical center of hip rotationmust be restored in acetabular revision. Large diameter or jumbo cups can facilitate this task. ${ }^{39}$ This was highlighted by Dearborn and Harris ${ }^{40}$ : "If the anteroposterior pelvic dimensions permit a jumbo acetabular component, such a component has the advantage of being an uncemented device with the potential to lower a high hip center while providing thicker polyethylene." However, this technique should not be used in pelvic discontinuity or in cases with a very high hip center and fairly small anteroposterior acetabular dimensions, as seen in 3 of our cases. Here, a high hip center has to be accepted. In our study Jumbo cups were used in $42.8 \%$ of the male patients and $67.4 \%$ of the female patients.

The high dislocation and complication rates reported for cup revisions by various authors raise concern. ${ }^{40-43}$ In a recent review of Medicare, 12956 revision THAs were shown to have a $14.4 \%$ dislocation rate in the early postoperative period. ${ }^{44}$ As can be expected, multiple prior surgery, major column defects, and femoral component revision at the same time increase the dislocation risk. ${ }^{39,41}$ This was confirmed in our study where dislocations were only seen in patients with concomitant stem revision $(6.9 \%$ [5/72]). In our study the rerevision rate for aseptic loosening was low $(1 / 72)$ and comparable with the best survival rates of several alternative techniques, such as $81 \%$ to $95 \%$ after 10 years for cemented cup revision in combination with morselized bone grafts ${ }^{11-13}$ and $90 \%$ to $98 \%$ in other series using cementless acetabular revision. ${ }^{27,30,41,45}$ In conclusion, acetabular revision with a HAcoated hemispherical cup gives very reliable results. This technique consists of (1) maximization of host bone contact by using large or jumbo cups, (2) attainment of peripheral rim-fit fixation when possible, (3) grafting of defects with bone allografts, and (4) the use of screws when needed. It was successful for all classes of deficient acetabula, even in cases where the relative percentage of host bone support was considered low. Considering the nature of the implant to host interface, which is a living bond between bone and the surface of the cup, it may be expected that these favorable results are enduring. 


\section{References}

1. Harris WH, Penenberg BL. Further follow-up on socket fixation using a metal-backed acetabular component for total hip replacement. A minimum ten-year follow-up study. J Bone Joint Surg Am 1987;69-8:1140.

2. Wilson $\mathrm{MG}$, Nikpoor $\mathrm{N}$, Aliabadi $\mathrm{P}$, et al. The fate of acetabular allografts after bipolar revision arthroplasty of the hip. A radiographic review. J Bone Joint Surg Am 1989;71-10:1469.

3. Gates III HS, McCollum DE, Poletti SC, et al. Bonegrafting in total hip arthroplasty for protrusio acetabuli. A follow-up note. J Bone Joint Surg Am 1990; 72-2:248.

4. Jasty M, Harris WH. Salvage total hip reconstruction in patients with major acetabular bone deficiency using structural femoral head allografts. J Bone Joint Surg Br 1990;72-1:63.

5. Mulroy Jr RD, Harris WH. Failure of acetabular autogenous grafts in total hip arthroplasty. Increasing incidence: a follow-up note. J Bone Joint Surg Am 1990;72-10:1536.

6. Hooten Jr JP, Engh Jr CA, Engh CA. Failure of structural acetabular allografts in cementless revision hip arthroplasty. J Bone Joint Surg Br 1994; 76-3:419.

7. Marti RK, Schuller HM, van Steijn MJ. Superolateral bone grafting for acetabular deficiency in primary total hip replacement and revision. J Bone Joint Surg Br 1994;76-5:728.

8. Papagelopoulos PJ, Lewallen DG, Cabanela ME, et al. Acetabular reconstruction using bipolar endoprosthesis and bone grafting in patients with severe bone deficiency. Clin Orthop Relat Res 1995;314:170.

9. Shinar AA, Harris WH. Bulk structural autogenous grafts and allografts for reconstruction of the acetabulum in total hip arthroplasty. Sixteen-year-average follow-up. J Bone Joint Surg Am 1997;792:159.

10. Garbuz D, Morsi E, Gross AE. Revision of the acetabular component of a total hip arthroplasty with a massive structural allograft. Study with a minimum five-year follow-up. J Bone Joint Surg Am 1996;785:693.

11. Schreurs BW, Slooff TJ, Buma P, et al. Acetabular reconstruction with impacted morsellised cancellous bone graft and cement. A 10- to 15-year follow-up of 60 revision arthroplasties. J Bone Joint Surg $\mathrm{Br}$ 1998;80-3:391.

12. Schreurs BW, van Tienen TG, Buma $P$, et al. Favorable results of acetabular reconstruction with impacted morsellized bone grafts in patients younger than 50 years: a 10- to 18-year follow-up study of 34 cemented total hip arthroplasties. Acta Orthop Scand 2001;72-2:120.

13. van der Linde $M$, Tonino A. Acetabular revision with impacted grafting and a reinforcement ring: 42 patients followed for a mean of 10 years. Acta Orthop Scand 2001;72-3:221.

14. Soballe K, Hansen ES, Brockstedt-Rasmussen $\mathrm{H}$, et al. Hydroxyapatite coating converts fibrous tissue to bone around loaded implants. J Bone Joint Surg Br 1993;75-2:270.

15. Nivbrant B, Karrholm J. Migration and wear of hydroxyapatite-coated press-fit cups in revision hip arthroplasty: a radiostereometric study. J Arthroplasty 1997;12-8:904.

16. Geesink RG, Hoefnagels NH. Six-year results of hydroxyapatite-coated total hip replacement. J Bone Joint Surg Br 1995;77-4:534.

17. Capello WN, D'Antonio JA, Manley MT, et al. Hydroxyapatite in total hip arthroplasty. Clinical results and critical issues. Clin Orthop Relat Res 1998;355:200.

18. Garcia Araujo C, Fernandez Gonzalez J, Tonino A. Rheumatoid arthritis and hydroxyapatite-coated hip prostheses: five-year results. International ABG Study Group. J Arthroplasty 1998;13-6:660.

19. Tonino AJ, Therin M, Doyle C. Hydroxyapatitecoated femoral stems. Histology and histomorphometry around five components retrieved at post mortem. J Bone Joint Surg Br 1999;81-1:148.

20. Tonino AJ, Rahmy AI. The hydroxyapatite-ABG hip system: 5- to 7-year results from an international multicentre study. The International ABG Study Group. J Arthroplasty 2000;15-3:274.

21. Tonino A, Oosterbos C, Rahmy A, et al. Hydroxyapatite-coated acetabular components. Histological and histomorphometric analysis of six cups retrieved at autopsy between three and seven years after successful implantation. J Bone Joint Surg Am 2001;83-A-6:817. 
22. Paprosky WG, Magnus RE. Principles of bone grafting in revision total hip arthroplasty. Acetabular technique. Clin Orthop Relat Res 1994;298:147.

23. Paprosky WG, Perona PG, Lawrence JM. Acetabular defect classification and surgical reconstruction in revision arthroplasty. A 6-year follow-up evaluation. J Arthroplasty 1994;9-1:33.

24. Manley MT, Capello WN, d'Antonio JA, et al. Fixation of acetabular cups without cement in total hip arthroplasty. J Bone Joint Surg Am 1998; 80-A:1175.

25. Zehntner MK, Ganz R. Midterm results (5.5-10 years) of acetabular allograft reconstruction with the acetabular reinforcement ring during total hip revision. J Arthroplasty 1994;9-5:469.

26. DeLee JG, Charnley J. Radiological demarcation of cemented sockets in total hip replacement. Clin Orthop Relat Res 1976;121:20.

27. Elke R, Berli B, Wagner A, et al. Acetabular revision in total hip replacement with a press-fit cup. J Bone Joint Surg Br 2003;85-8:1114.

28. Dorr LD, Wan Z. Ten years of experience with porous acetabular components for revision surgery. Clin Orthop Relat Res 1995;319:191.

29. Silverton CD, Rosenberg AG, Sheinkop MB, et al. Revision total hip arthroplasty using a cementless acetabular component. Technique and results. Clin Orthop Relat Res 1995;319:201.

30. Leopold SS, Rosenberg AG, Bhatt RD, et al. Cementless acetabular revision. Evaluation at an average of 10.5 years. Clin Orthop Relat Res 1999;369:179.

31. Udomkiat P, Dorr LD, Wan Z. Cementless hemispheric porous-coated sockets implanted with pressfit technique without screws: average ten-year follow-up. J Bone Joint Surg Am 2002;84-A-7:1195.

32. Epinette JA, Manley MT, Tillie B. The use of the hydroxyapatite coated Arc $2 f$ cup in acetabular revision surgery. New York: Springer; 2004. p. 365.

33. Muller U, Gautier E, Roeder C, et al. The relationship between cup design and the radiological signs of aseptic loosening in total hip arthroplasty. J Bone Joint Surg Br 2003;85-1:31.

34. Paprosky WG, Bradford MS, Younger TI. Acetabular reconstruction with massive allograft and cementless prosthesis. Chir Organi Mov 1994;79-4:379.

35. Oosterbos CJ, Rahmy AI, Tonino AJ, et al. High survival rate of hydroxyapatite-coated hip prostheses: 100 consecutive hips followed for 10 years. Acta Orthop Scand 2004;75-2:127.

36. Gross AE, Duncan CP, Garbuz D, et al. Revision arthroplasty of the acetabulum in association with loss of bone stock. Instr Course Lect 1999;48:57.

37. Saleh KJ, Jaroszynski G, Woodgate I, et al. Revision total hip arthroplasty with the use of structural acetabular allograft and reconstruction ring: a case series with a 10-year average follow-up. J Arthroplasty 2000;15-8:951.

38. Kobayashi S, Saito N, Nawata M, et al. Total hip arthroplasty with bulk femoral head autograft for acetabular reconstruction in developmental dysplasia of the hip. J Bone Joint Surg Am 2003;85-A4:615.

39. Whaley AL, Berry DJ, Harmsen WS. Extra-large uncemented hemispherical acetabular components for revision total hip arthroplasty. J Bone Joint Surg Am 2001;83-A-9:1352.

40. Dearborn JT, Harris WH. High placement of an acetabular component inserted without cement in a revision total hip arthroplasty. Results after a mean of ten years. J Bone Joint Surg Am 1999;81-4:469.

41. Stiehl JB, Saluja R, Diener T. Reconstruction of major column defects and pelvic discontinuity in revision total hip arthroplasty. J Arthroplasty 2000; 15-7:849.

42. Sutherland CJ. Treatment of type III acetabular deficiencies in revision total hip arthroplasty without structural bone-graft. J Arthroplasty 1996;11-1:91.

43. Munjal S, Leopold SS, Kornreich D, et al. CTgenerated 3-dimensional models for complex acetabular reconstruction. J Arthroplasty 2000; 15-5:644.

44. Mahomed NN, Barrett JA, Katz JN, et al. Rates and outcomes of primary and revision total hip replacement in the United States Medicare population. J Bone Joint Surg 2003;85A:27.

45. Ng TP, Chiu KY. Acetabular revision without cement. J Arthroplasty 2003;18-4:435. 


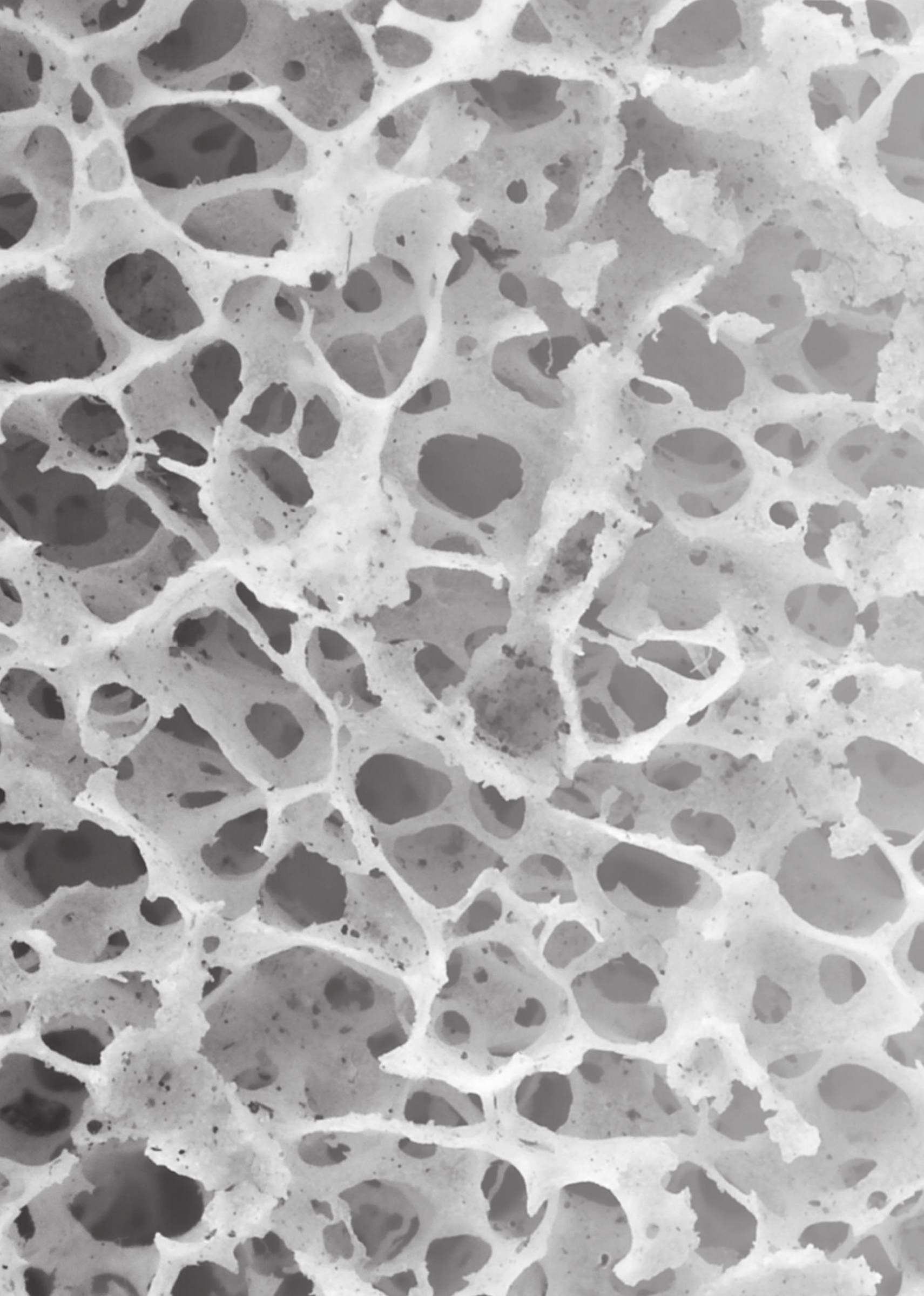




\section{Chapter 7}

Summary and General Discussion 
For more than 40 years polyethylene (PE) has played an important role in the success of total hip arthroplasty. Wear particles of the PE acetabular component can invoke an inflammatory tissue response in the adjacent bone, leading to peri-prosthetic osteolysis and loosening of the implant. The osteolytic effect of the wear debris depends on the cytotoxicity of the material, the size and morphology of the debris particles, the pathways available for particle migration, and the volume of wear particles produced and released into the peri-prosthetic tissue. Lower wear rates substantially reduce the incidence of osteolysis. With standard 28-mm heads, linear wear rates which exceed $0.2 \mathrm{~mm}$ per year always produce wear particle-induced osteolysis, whereas this is mostly absent at annual wear rates less than 0.05 to $0.1 \mathrm{~mm}$ per year. Therefore, measurement of PE wear is important. Once osteolysis has started, the progression in time should be monitored thoroughly because the process will eventually lead to failure of the implant. Finally, when the acetabular implant has become loose due to progressive osteolysis it is a major challenge to revise the component and fix the new cup into the deficient acetabulum.

This thesis describes five studies which address different problems concerning PE wear in the survival of total hip arthroplasties.

In chapter 2 we studied the distances and angles of linear penetration of the femoral head into the PE liners of acetabular components as a measure of wear. We have compared four computer-assisted methods to measure penetration of the femoral head into the acetabular component after a total hip replacement. These were the Martell Hip Analysis suite 7.14, Rogan HyperOrtho, Rogan View Pro-X and Roman v1.70. The images used for the investigation comprised 24 anteroposterior digital radiographs and 24 conventional acetate radiographs which were scanned to provide digital images. These radiographs were acquired from 24 patients with an uncemented total hip replacement with a follow-up of approximately eight years (mean 8.1; range 6.3 to 9.1). Each image was measured twice by two blinded observers. The mean annual rates of penetration of the femoral head measured in the eight-year single image analysis were: Martell, 0.24 (SD 0.19); HyperOrtho, 0.12 (SD 0.08); View Pro-X, 0.12 (SD 0.06); Roman, 0.12 (SD 0.07). In paired analysis of the sixmonth and eight-year radiographs: Martell, 0.35 (SD 0.22); HyperOrtho, 0.15 (SD 0.13); View Pro-X, 0.11 (SD 0.06); Roman, 0.11 (SD 0.07). The intra- and inter-observer variability for the paired analysis was best for View Pro-X and Roman software, with intraclass correlations of 0.97, 0.87 and $0.96,0.87$, respectively, and worst for HyperOrtho and Martell, with intraclass correlations of $0.46,0.13$ and $0.33,0.39$, respectively.

On the basis that clinical linear penetration rates become significant at approximately 0.05 to $0.10 \mathrm{~mm} /$ year, the image resolution for studies of clinical wear should not be less than $0.14 \mathrm{~mm}$ in a $5 \mathrm{Mpix}$ AP radiograph. The disappointing result for the Martell method contrasts with previous studies and suggests a systematic error, which we 
believe lies in the inability of the automatic edge detection algorithm to correctly identify the mean between the femoral head and the PE insert on direct digital images, which are increasingly becoming the standard format. Considering the positioning error for paired images, and the low accuracy of the baseline measurement, it seems that in clinical practice single-image analysis may be sufficient or even superior. Measurement of the angles of penetration of the head was far less reliable than the measurement of the distance of penetration. As there are various definitions of wear angles and wear directions in the literature, comparison between published values of the angles of penetration is more difficult than for wear distance. The definition of wear angles used in this study avoids the misleading term 'negative wear'. Negative wear distance or negative wear angles are only a function of the definition of the coordinate system, and these differ between the software methods used.

In conclusion, computer-aided measurement of linear penetration of PE can be accurate and reliable within the limits of image resolution. A 5 MPix pelvic radiograph should be the minimum requirement. Edge detection by a human observer is more accurate with the new direct digital images than with automated software, and circular interpolation is superior for metal-backed components. We found that the Roman and View Pro-X software were the best for the assessment of linear penetration of the head as a measure of PE wear in clinical practice. Although these methods were also more accurate in determining the wear angle, the intra- and inter- observer variability was high. Although measurement with the Roman software takes slightly more time, its compatibility with all common image formats and its free availability make it an attractive option.

In chapter 3 the basic material characteristics and the wear characteristics in-vitro and in-vivo of a new PE called Duration ${ }^{\circledR}$ are described. PE-wear-induced osteolysis is a major cause of implant loosening in total hip arthroplasty. New cross-linked PE's are presumed to give lower wear rates, but no long-term clinical results are available yet. The cross-link density and wear resistance of the new PE described in this study could be raised without increasing the radiation dose above the conventional sterilization levels, but only by modification of the process (nitrogen atmosphere, annealing at $50^{\circ} \mathrm{C}$ for $144 \mathrm{~h}$ ). At the same time, other mechanical properties such as crystallinity, creep strain, yield strength and elongation at break remained unchanged, suggesting that elevated cross-link density was achieved without increasing brittleness.

In a randomized double-blind 5-year clinical follow-up study, 133 hips (67 conventional,

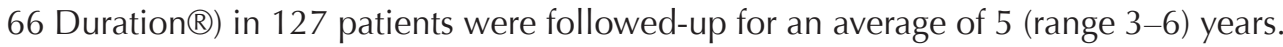
Wear rates were measured with use of a computer-based edge detection method. The radiographic appearances of wear-related phenomena were recorded. The Duration $\mathbb{R}$ PE showed a significantly lower in-vitro wear rate in the simulator study (mean 22 (SD 2.3 ) vs. 40 (SD 1.5) $\mathrm{mm} 3 / 106$ cycles). Also, the in-vivo wear was lower for Duration $\mathbb{R}$ (mean 0.083 (SD 0.056) mm/year) than for conventional PE (mean 0.123 (SD 0.082) 
$\mathrm{mm} /$ year). All radiographic signs of osteolysis were less frequent in the Duration $₫$ group. We found that even the relatively small step from conventional PE gammasterilized in air to PE gamma-sterilized in nitrogen with subsequent annealing was sufficient to reduce wear rates, diminish high-value outliers, reduce radiographic evidence of osteolysis, and to increase survival during a randomized 5-year study. The advantage of Duration ${ }^{\circ}$ over conventional PE in terms of clinical wear rate was confirmed in our wear simulator study. Our simulator study showed that the reduction in wear of Duration ${ }^{\circledR}$ relative to conventional PE became less as the number of cycles increased. Long-term clinical measurements of wear will be required to determine whether the benefits of Duration $®$ PE diminish over time in the same way as in the hip simulator, and whether wear debris leading to osteolysis and implant loosening also remains significantly reduced.

Because ageing may influence the material as in-vivo oxidation starts to degrade the beneficial properties of cross-linked PE with its higher residual amount of free radicals, especially in material that is annealed and not remelted, we investigated in chapter 4 whether Duration ${ }^{\circledR}$ could maintain its increased wear resistance for up to 8 years during which oxidation and ageing effects may have affected the original properties. Our secondary question was whether the reduced wear rate of cross-linked PE led to reduced osteolysis.

We compared the cross-linked Duration ${ }^{\circledR}$ PE (irradiation in nitrogen, annealing) with historical PE (irradiation in air) in a prospective, randomized clinical study involving 48 patients who underwent THAs with a minimum follow-up of 7 years (mean 8 years; range 7-9 years). The insert material was the only variable. The Harris hip score, radiographic signs of osteolysis, and PE wear were recorded annually. Twenty-three historical and 17 moderately cross-linked PE inserts were analyzed (five patients died, three were lost to followup). At 8 years, the wear rate was lower for cross-linked PE $(0.088 \pm 0.03 \mathrm{~mm} /$ year) than for the historical PE $(0.142 \pm 0.07 \mathrm{~mm} /$ year). This reduction $(38 \%)$ did not diminish with time (33\% at 5 years). Acetabular cyst formation was less frequent (39\% versus $12 \%)$, affected fewer DeLee and Charnley zones (17\% versus $4 \%$ ), and was less severe for the cross-linked PE. The only revision was for an aseptically loose cup in the historical PE group. Moderately cross-linked PE maintained its wear advantage with time and produced less osteolysis, showing no signs of aging at mid-term follow-up.

In chapter $\mathbf{5}$ the role of technetium scintigraphy in the process of osteolysis behind the acetabular component of an uncemented total hip prosthesis was investigated.

In total hip arthroplasty (THA) Technetium scintigraphy can help to diagnose a loose implant by detecting elevated osteoblastic activity. It has been used for timing the revision of cemented implants. In uncemented cups it has been radiologically observed that progressive acetabular osteolysis can be present without the implant being loose yet. It seems imprudent to wait for cup-revision until the loosening process of the cup 
is complete. Our main study question was: can technetium scintigraphy diagnose osteolysis behind the uncemented acetabular component?

Between 1990 and 1996500 hydroxyapatite-coated hip prosthesis were placed (follow-up range: 9-15 years). Technetium scintigraphy and plain radiography were performed each year postoperatively. Of this series 32 cups were revised for progressive acetabular osteolysis. We compared the per-operative findings (gold standard) with the pre-operative scintigraphic and radiographic results.

The sensitivity and specificity for diagnosing progressive acetabular osteolysis were respectively $34 \%$ and $0 \%$ for technetium scintigraphy. Sensitivity and specificity for detecting a loose cup were respectively $38 \%$ and $73 \%$. The sensitivity and specificity of technetium scintigraphy for both detection of a loose cup as well as for progressive acetabular osteolysis are worse than reported for plain radiography. Despite a negative scintigraphy, there might be progressive bone loss at such a critical level that revision seems prudent. We concluded on the basis of our results that scintigraphy in its current form has no additional value to plain radiography as a reliable indicator for timing cup revision in the process of progressive acetabular osteolysis.

The goal of the study in chapter 6 was to evaluate the use of a hydroxy-apatite (HA) -coated uncemented hemispherical acetabular component for revision in aseptic loosening of the acetabular component of a total hip arthroplasty.

In primary hip arthroplasty, HA-coated implants have been shown to improve fixation by quick bone ongrowth. As a result, cup migration and radiolucent lines are less frequent, compared with uncoated implants. In the revision situation, where the amount of host bone is compromised, mostly by wear particle-induced osteolysis, this positive effect of HA could be beneficial.

We used an HA-coated uncemented hemispherical component for revision in 72 patients with aseptic loosening of the acetabular component. Pre-operative Paprosky classification of the acetabular defects was 1 type I, 35 type II, and 36 type III; according to American Academy of Orthopaedic Surgeons, 14 segmental, 10 cavitary, and 48 combined. The mean follow-up was 7.6 years (range 5.0-13.0). Complications were seen in 7 cases (9.6\%). 70 acetabular components (97.2\%) showed bone ongrowth on the radiographs. The survival rate was $90.8 \%$ after a mean follow-up of 7.6 years (range 5.0-13.0) when revision for any reason is the end point (confidence interval $80.5 \%-$ $100 \%$ ) and $98.1 \%$ (confidence interval 94.5\%-100\%) when aseptic loosening of the cup is the end point. We conclude that acetabular revision with a HA-coated hemispherical cup gives very reliable results. This technique consists of (1) maximalization of host bone contact by using large or jumbo cups, (2) attainment of peripheral rim-fit fixation when possible, (3) grafting of defects with bone allografts, and (4) the use of screws when needed. It was successful for all classes of deficient acetabula, even in cases where the relative percentage of host bone support was considered low. Considering the nature of the implant to host interface, which is a living bond between bone and the surface of the cup, it may be expected that these favorable results will endure . 
The results presented in this thesis have helped us to understand better the PE wear related problems in total hip arthroplasty. They show us a way of measuring PE wear digitally and the effects attained when cross-linked PE is used. Once progressive PEwear-induced osteolysis has started, patients must be monitored regularly in order to diagnose the right moment for cup revison. There is no place for technetium scintigraphy in this process. When cup revision is indicated the technique we described will give the patient a very reliable result.

However, future studies are necessary. In particular, new generations of bearing materials need long term follow-up before they can be used in large patient groups. When PE wear is no longer the limiting factor in implant survival, other limiting factors will become noticeable and form the subject of future investigations. 


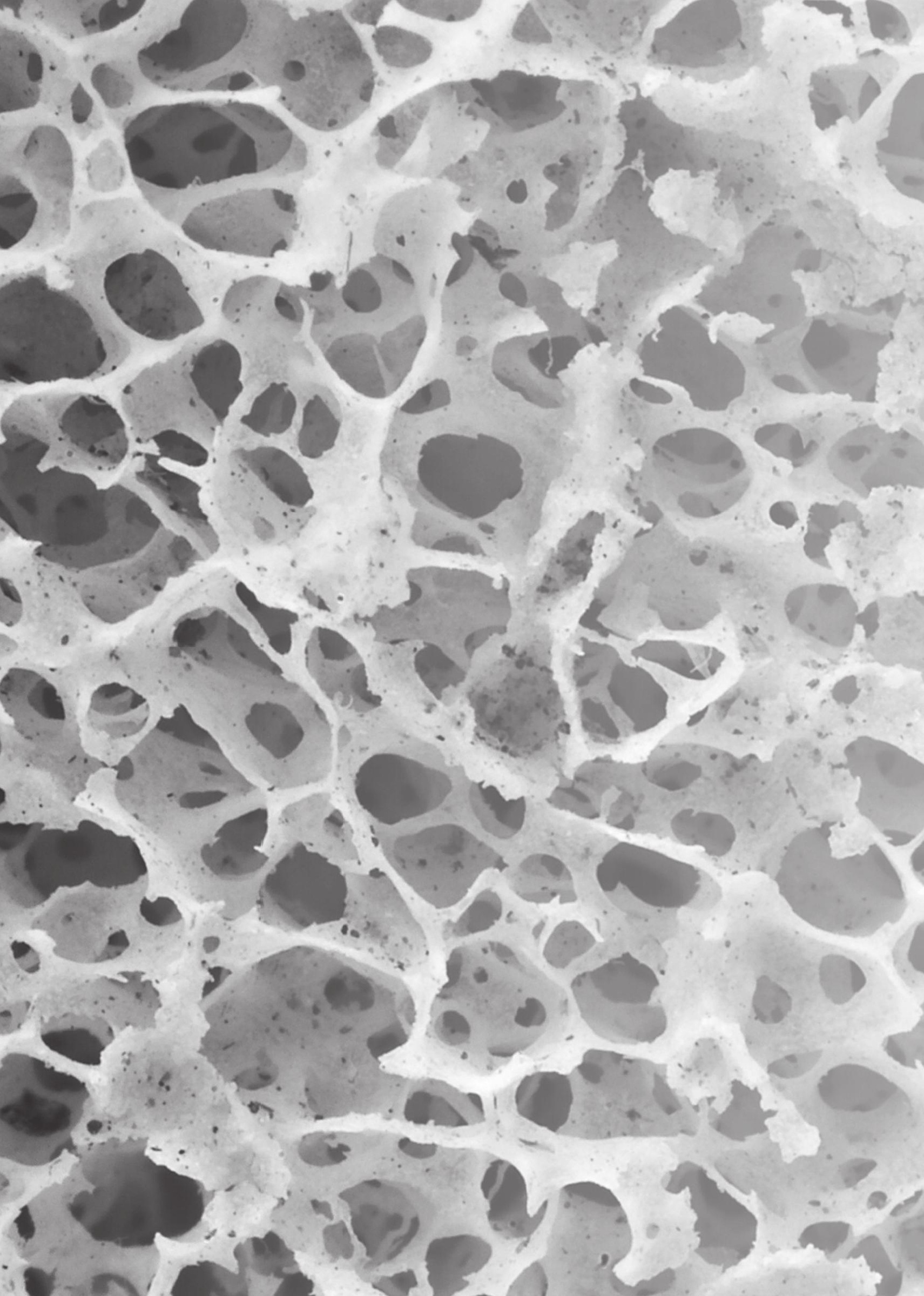




\section{Chapter 8}

Nederlandse Samenvatting 
Al meer dan 40 jaar speelt polyethyleen (PE), als onderdeel van een totale heupprothese, een belangrijke rol in de duurzaamheid van een totale heupprothese. Door wrijving van het femurkopje op het PE waarmee de binnenzijde van de cup is bekleed kunnen PE deeltjes ontstaan die in het omringende bot een ontstekingsreaktie veroorzaken welke vervolgens kan leiden tot verdwijnen van bot (osteolyse) en uiteindelijk loslating van de prothese. Hoe minder PE deeltjes hoe minder kans op osteolyse en hoe langer de levensduur van een totale heupprothese. Aangenomen wordt dat een slijtage van meer dan 0.2 millimeter per jaar (eng. wear rate) altijd osteolyse veroorzaakt. Het is dus belangrijk om de slijtage van het PE te meten en patiënten door de jaren te vervolgen. Ook dient men een PE soort te gebruiken die zo min mogelijk slijtage deeltjes produceert. Als toch loslating van de heupprothese heeft plaatsgevonden is het een grote uitdaging om een nieuwe prothese te bevestigen aan het door osteolyse ernstig beschadigde bot.

Dit proefschrift bevat vijf studies die elk betrekking hebben op de problemen die polyethyleenslijtage kan veroorzaken bij patiënten met een totale heupprothese.

In hoofdstuk 2 wordt een studie beschreven waarin vier computer programma's om polyethyleenslijtage te meten op digitale röntgenfoto's met elkaar worden vergeleken, te weten Roman v1.70, Rogan View Pro-X, Rogan HyperOrtho en Martell's Hip Analysis Suite 7.14. Deze programma's meten de verplaatsing van het femurkopje van de prothese ten opzichte van de metalen buitencup waarin het PE zich bevindt. Om een klinisch relevante lineaire verplaatsing van ongeveer 0.05 tot 0.1 millimeter per jaar te kunnen meten zal de röntgenfoto een kwaliteit moeten hebben van tenminste 5 Mpix waarbij de pixelgrootte dan 0.14 millimeter is. Er werden 24 antero-posterieure digitale röntgenfoto's en 24 ingescande conventionele röntgenfoto's gebruikt voor het onderzoek. De gebruikte röntgenfoto's waren afkomstig van 24 patienten met een ongecementeerde totale heupprothese met een gemiddelde follow-up van 8.1 jaar (spreiding 6.3-9.1). Elke foto werd twee maal gemeten door twee geblindeerde onderzoekers. De gemiddelde jaarlijkse verplaatsing van het femurkopje in millimeters was met behulp van de 'single image analysis' na 8 jaar: Martell 0.24 (SD 0.19); HyperOrtho 0.12 (SD 0.08); View Pro-X 0.12 (SD 0.06); Roman 0.12 (SD 0.07). Met behulp van de 'paired analysis' waarbij de 8 jaars röntgenfoto werd $®$ vergeleken met de foto na 6 maanden follow-up, was de gemiddelde jaarlijkse verplaatsing van het femurkopje: Martell 0.35 (SD 0.22); HyperOrtho 0.15 (SD 0.13); View Pro-X 0.11 (SD 0.06); Roman 0.11 (SD 0.07). De intra- en interobserver variatie met betrekking tot de 'paired analysis' was het beste voor de View Pro-X en de Roman software, met intraclass correlaties van respectievelijk 0.97, 0.87 en 0.96, 0.87, en het slechtst voor HyperOrtho en Martell met intraclass correlaties van respectievelijk 0.46, 0.13 en 0.33 , 0.39. Wij vonden een mogelijke verklaring voor dit slechte resultaat, namelijk dat het programma van Martell moeite heeft om de grens te vinden tussen de prothese en het bot op digitale röntgenfoto's zoals deze tegenwoordig steeds meer gebruikt worden. Deze grens is met het oog nauwkeuriger te bepalen dan door een 
computerprogramma. Omdat er twee keer een meetfout ontstaat in de 'paired analysis' vonden wij dat er nauwkeuriger gemeten wordt met de 'single image analysis' bij alle methoden. Voor wat betreft de richting waarin de verplaatsing plaatsvindt kan worden geconcludeerd dat deze meting veel onnauwkeuriger en ook minder reproduceerbaar is dan de lineaire verplaatsing. Tevens is het zo dat uitkomsten alleen vergeleken kunnen worden als hetzelfde coordinatenstelsel wordt gebruikt. De misleidende term 'negatieve verplaatsing' kan worden vermeden door een duidelijk coordinatenstelsel te definieren. Uit onze resultaten komt naar voren dat Roman en View Pro-X het meest nauwkeurig en het best reproduceerbaar lineaire verplaatsing van het femurkopje ten opzichte van de metalen cup kunnen meten. Hoewel het gebruik van Roman iets meer tijd kost heeft deze software toch de meeste voordelen omdat elk type digitale foto gemeten kan worden en het softwareprogramma zonder kosten verkregen kan worden op het internet.

In hoofdstuk 3 wordt het nieuwere, 'moderately cross-linked' Duration $®$ PE bestudeerd aan de hand van basale materiaaleigenschappen en de resultaten met betrekking tot slijtvastheid in een heup simulator. Tevens wordt het Duration ${ }^{\circledR}$ PE vergeleken met het conventionele PE in een klinische prospectief gerandomiseerde dubbel-blinde studie. Hieraan deden 127 patienten mee met 133 heupprothesen (67 conventioneel PE, 66 Duration ${ }^{\circledR}$ PE) met een gemiddelde follow-up van 5 jaar (spreiding 3-6). De hypothese was dat door het veranderde fabricageproces waarbij meer cross-links in het PE ontstaan, het nieuwere PE minder onderhevig zou zijn aan slijtage. Het steriliseren gebeurde met dezelfde stralingsdosis en tijd, maar niet in lucht maar in stikstof, waarna het vervolgens langzaam werd verhit tot net onder de smelttemperatuur (eng. annealing). Dit proces had geen invloed op de andere materiaaleigenschappen van het PE in vergelijk met het oudere conventionele PE. De gemiddelde slijtage per tijdseenheid (eng. wear rate) in-vitro was 22 (SD 2.3) mm3/106 cycli voor het Duration ${ }^{\circ}$ PE en 40 (SD 1.5) mm3/106 cycli voor het conventionele PE. In-vivo na gemiddeld 5 jaar follow-up was de gemeten slijtage voor Duration $\mathbb{R}$ PE 0.083 (SD 0.056) $\mathrm{mm} /$ jaar en voor conventioneel PE 0.123 (SD 0.082) mm/jaar. Tevens werden in de Duration ${ }^{\circledR}$ groep minder patiënten gezien met een extreem hoge mate van slijtage, minder kenmerken van osteolyse op de röntgenfoto en een grotere over-all overleving van de heupprothese. In de heupsimulator nam het positieve verschil tussen beide polyethyleensoorten echter wel af met de toename van het aantal bewegingen.

Om deze reden werd in hoofdstuk 4 onderzocht of het positieve effect van Duration $\mathbb{R}$ PE bij langere follow-up 'in- vivo' stand kon houden. Critici veronderstelden dat de vrije radicalen in het Duration $®$ PE ervoor zouden zorgen dat oxidatie een rol kan gaan spelen in de uiteindelijke overleving van het PE in het menselijk lichaam op langere termijn. Tevens zou het zo kunnen zijn dat de deeltjes die bij het slijtageproces van cross-linked polyethyleen vrijkomen veel schadelijker zijn voor het omringende bot, zodat een beetje slijtage van het polyethyleen al snel tot meer osteolyse zou kunnen leiden en op die manier de overlevingsduur van de prothese kan verkorten. Uit onze 
resultaten echter blijkt dat dit na 8 jaar follow-up nog niet is aan te tonen. In een prospectief gerandomiseerde studie werden 48 patienten geincludeerd met een totale heupprothese, 23 met conventioneel PE en 17 met Duraion PE. De gemiddelde followup was 8 jaar (spreiding 7-9) en het PE de enige variabele. De gemeten gemiddelde jaarlijkse slijtage was voor het Duration ${ }^{\circledR}$ PE $0.088 \pm 0.03 \mathrm{~mm} /$ jaar en voor het conventionele PE $0.142 \pm 0.07$ mm/jaar. Botcysten ontstaan door osteolyse waren bij

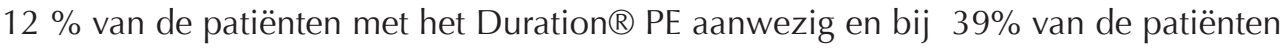
met het conventionele PE. De enige revisie als gevolg van aseptische loslating vond plaats bij een patient met conventioneel PE.

In hoofdstuk 5 wordt onderzocht of Technetium scintigraphy de door PE- slijtage veroorzaakte osteolyse kan aantonen. Dit in vergelijk met conventionele röntgen foto's. Omdat voortschrijdende osteolyse uiteindelijk leidt tot loslating van de heupprothese is het belangrijk om het proces van osteolyse bij patiënten te vervolgen. Een revisie van de prothese, met name aan acetabulaire zijde, wordt moeilijker als er uitgebreide botdefecten zijn ontstaan. Het zou waardevol zijn om naast de conventionele röntgenfoto een tweede objectieve indruk te hebben over de omvang van de ontstane osteolyse. Ook patiënten zonder klachten kunnen dan op de hoogte worden gebracht van de ernst van het proces om eventueel in een vroeg stadium al voor een revisieoperatie te kiezen. Een groep van 500 patienten met een hydroxyapatiet gecoate totale heupprothese werd gevolgd (follow-up 9-15 jaar). Jaarlijks werd bij deze patiënten een Technetium scintigraphy gedaan evenals een conventionele röntgenfoto. Bij 32 patienten werd een cuprevisie gedaan vanwege aseptische loslating van de cup door progressieve osteolyse van het acetabulum. Bij deze patiënten werden de per-operatieve bevindingen vergeleken met de resultaten van de pre-operatieve Technetium scintigraphy. Sensitiviteit en specificiteit van Technetium scintigraphy voor het aantonen van progressieve osteolyse van het acetabulum waren respectievelijk $34 \%$ en $0 \%$, en voor het aantonen van aseptische loslating van de cup respectievelijk $38 \%$ en $73 \%$. Geconcludeerd kan worden dat Technetium scintigraphy geen meerwaarde heeft in het aantonen van progressieve osteolyse noch voor het aantonen van loslating van de cup ten opzichte van conventionele röntgenfoto's.

In hoofdstuk 6 worden de resultaten geëvalueerd van het gebruik van een hydroxyapatiet (HA) gecoate cup voor revisie bij 72 patienten met aseptische loslating van de acetabulaire component van een totale heupprothese. Het ernstig beschadigde bot van het acetabulum, meestal ontstaan door osteolyse op basis van polyethyleen slijtage, vormt een groot probleem voor de initiele fixatie van de revisiecomponent. HA heeft de eigenschap om relatief snel botingroei op de prothese te waarborgen, zo is bewezen bij primaire HA-gecoate heupprothesen. Deze eigenschap zou de overleving van de acetabulaire component na revisie kunnen vergroten, zo was onze hypothese. In het algemeen geldt dat bij de revisie van een cup van een totale heupprothese drie aspecten van belang zijn, het mechanische aspect, het biologische aspect en het anatomische aspect. Hoe groter het osteolytische botdefect vooraf aan revisie 
is, hoe moeilijker het is om bij revisie aan de eisen te voldoen die elk van de drie aspecten stellen om van een succesvolle operatie te kunnen spreken. Alleen wanneer primaire mechanische stabiliteit wordt bereikt kan ook biologische ingroei (secundaire stabiliteit) plaatsvinden. Biologische stabiliteit van de cup wordt verder vergroot door een groter contactoppervlak na te streven. In onze serie werd de buitenmaat van de cup gemiddeld met 12 millimeter vergroot (50 naar $62 \mathrm{~mm}$ ), waardoor het contactoppervlak van het hydroxy-apatiet met het acetabulaire bot met maximaal 54\% werd vergroot. Bij de 72 patienten geincludeerd in deze studie was de verdeling van het per-operatief geclassificeerde Paprosky defect eenmaal type 1, 35 maal type 2 en 36 maal type 3; AAOS 14 segmentale defecten, 10 cavitaire defecten en 48 gecombineerd segmentaal- en cavitaire defecten. Na een gemiddelde follow-up van 7.6 jaar (spreiding 5-13) kon bij 70 patienten (97.2\%) van de patiënten botingroei worden aangetoond op de röntgenfoto. Met een overlevingspercentage van 98.1\% (Cl 94.5\%-100\%) van deze cup indien aseptische loslating als eindpunt wordt genomen zijn onze resultaten vergelijkbaar met de beste resultaten bekend van andere technieken voor cuprevisie. Het feit dat de verbinding van het HA met het bot een levende verbinding is kan onze goede resultaten op deze lange termijn verklaren.

De resultaten beschreven in dit proefschrift helpen ons om de problemen met betrekking tot polyethyleenslijtage bij totale heupprothesen beter te begrijpen. Ze wijzen ons een richting voor het meten van polyethyleenslijtage op digitale röntgenfoto's en onthullen de voordelen van het cross-linken van polyethyleen. Patiënten met progressieve osteolyse rondom de acetabulaire component van hun heupprothese moeten nauwkeurig gecontroleerd worden om het meest optimale moment voor een cuprevisie te kunnen bepalen. Technetium scintigraphy heeft geen meerwaarde in het aantonen van deze progressieve osteolyse. Wanneer wordt besloten een revisie van de cup te doen vanwege aseptische loslating al dan niet veroorzaakt door slijtagedeeltjes van polyethyleen kan de door ons beschreven techniek een betrouwbaar resultaat leveren.

Toch is verder onderzoek nodig. Met name van nieuwere materialen die gebruikt worden als onderdeel van een heupprothese dienen de lange termijns resultaten afgewacht te worden alvorens ze te gebruiken bij grote groepen patiënten. Wanneer polyethyleenslijtage niet langer meer de levensduur van een heupprothese bepaalt zullen andere factoren centraal komen te staan in toekomstige onderzoeken. 


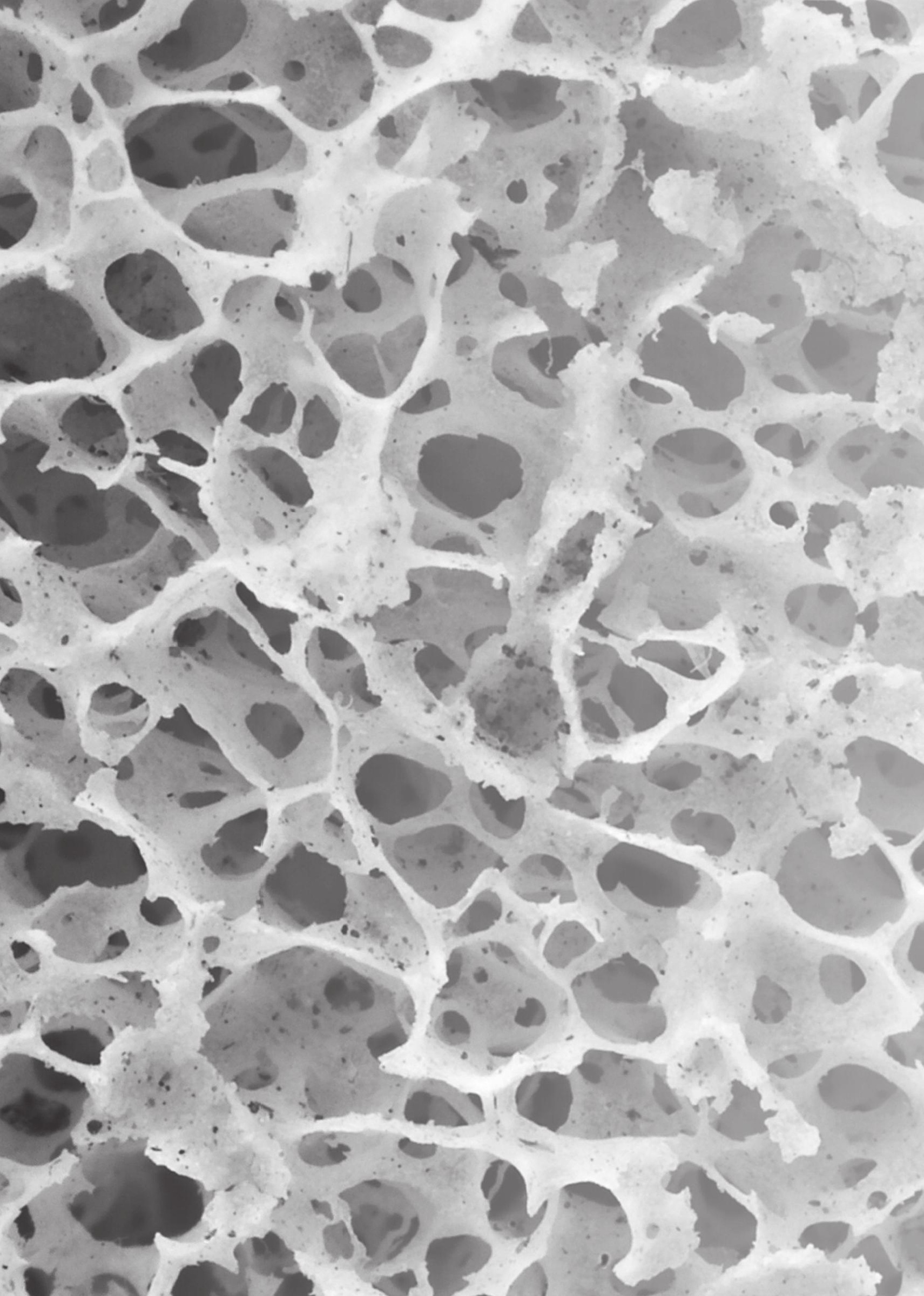



Dit hoofdstuk wil ik graag gebruiken om iedereen die een bijdrage geleverd heeft aan de totstandkoming van dit proefschrift heel hartelijk te bedanken.

Een aantal mensen wil ik in het bijzonder noemen.

Allereerst dank ik alle patiënten die hun medewerking hebben verleend aan de verschillende onderzoeken.

\section{Alphons Tonino}

Alphons, als grondlegger van dit proefschrift hebben jouw ideëen geleid tot vijf afzonderlijke wetenschappelijke artikelen die samengebracht zijn in mijn boekje. Altijd bereid tot meedenken en ondersteunen waar nodig. Jouw onuitputtelijke drive heeft mij enorm gestimuleerd om door te zetten en in tijden van veranderingen in mijn persoonlijke omstandigheden toch weer de draad op te pakken om het af te maken. 'Prima! Dan doen we het zo...' zijn jouw geruststellende woorden waarmee menig overleg eindigde en ik weer vooruit kon. Heel veel dank voor al je tijd en energie die je samen met Ariane onvoorwaardelijk in mij hebt gestoken.

\section{Bernd Grimm}

Bernd, zonder jouw inzet en toevoeging had dit proefschrift er heel anders uit gezien. De bijdragen in wetenschappelijke zin en de prettige manier van overleg zal ik nooit vergeten. Hele manuscripten heb je bekritiseerd en daarna nog weer geholpen om de 'reviewers critics' netjes en beleefd het hoofd te bieden. Soms tot midden in de nacht als dat nodig was. Je hebt mij veel kennis bijgebracht over de wetenschap in het algemeen. Ik wil je heel hartelijk danken voor je uitgebreide bijdrage aan mijn wetenschappelijke werk en wens je veel geluk samen met Beatrice in je leven toe.

\section{Ide Heyligers}

Beste Ide, hartelijk dank voor de moeite die je gedaan hebt in de eindfase van mijn promotietraject. Het is niet helemaal gelopen zoals wij het gepland hadden, maar dit is gelukkig niet ten koste gegaan van de goede afloop.

Prof. dr. Walenkamp

Beste Geert, hoewel je pas de laatste twee weken van het promotietraject betrokken bent geraakt bij mijn proefschrift ben je toch onmisbaar gebleken voor de afronding ervan. Een goede film heeft ook een goed einde nodig. Ik wil je heel hartelijk danken voor alle moeite die je het afgelopen half jaar voor mij hebt gedaan en het vertrouwen dat je mij gaf in de goede afloop. Bijna was ik de eerste promovendus die zonder promotor ging promoveren, maar gelukkig was jij bereid om het allemaal ook echt mogelijk te maken. Ik wens je een lage handicap en een lange golfcarriere toe en hoop binnenkort nog eens een rondje met je lopen. 
Wendy Vencken

Beste Wendy, data, data, data. Heel veel dank voor je bijdrage aan mijn proefschrift. Om soms dol van te worden zoveel data als jij hebt bijgehouden in je laptopje. Altijd kon ik je bellen als ik iets nodig had uit je computer, of om gewoon even een boterhammetje mee te eten als ik helemaal uit Rotterdam in Heerlen moest zijn. Zelfs op zondag.

Kathelijne, Teun en Maartje

Heel veel dank voor de tijd die ik van jullie kreeg om naast de opleiding en het werk deze promotie tot een goed einde te kunnen brengen. Jullie liefde en steun is heel belangrijk voor me.

\section{Ouders}

Lieve Mama, heel veel dank voor de mogelijkheden die jullie als ouders mij gegeven hebben om zonder zorgen door het leven te gaan en dit hoogtepunt in mijn carriere te bereiken. Helaas kan Papa het niet meer meemaken, maar ik weet zeker dat hij trots zou zijn en erg zou genieten van deze gebeurtenis.

\section{Schoonouders}

Lieve Emmy en Cor, enorm bedankt voor alle oppasdagen die het voor mij mogelijk maakten om voortgang te houden in de wetenschap. Zonder jullie zou het nooit afgekomen zijn. In ons huishouden van twee full-time banen met diensten en twee kleine kinderen is er vrijwel nooit gelegenheid om een aantal uren achter elkaar aan de computer te zitten, en soms is dit echt nodig. Nogmaals heel veel dank dat jullie dit voor mij mogelijk maakten.

Paranimfen

Bart van der Wal en Derek van Deurzen, samen assistent geweest, lief en leed met elkaar besproken, 'freude am fahren' in hart en bloedvaten, bedankt dat jullie mijn gewaardeerde paranimfen willen zijn.

Maatschap

Lex, Bob en Walter, bedankt voor jullie bijdrage aan en interesse in mijn proefschrift. 'Goed geregeld' is zoals onze maatschap bekend staat en dat is een voorwaarde om in rust naast je werk een groot project te kunnen volbrengen. Jullie zochten iemand die bijna gepromoveerd was. Dat ben ik lang geweest, maar nu moet het maar eens gebeuren. Mede door jullie heb ik veel plezier in mijn werk en daarvoor ben ik jullie erg dankbaar.

\section{Sponsoren}

Tot slot wil ik alle sponsoren heel hartelijk danken voor hun bijdragen. Ik waardeer de goede relatie die ik met jullie heb ervaren zeer en hoop op voortzetting ervan in de toekomst. 


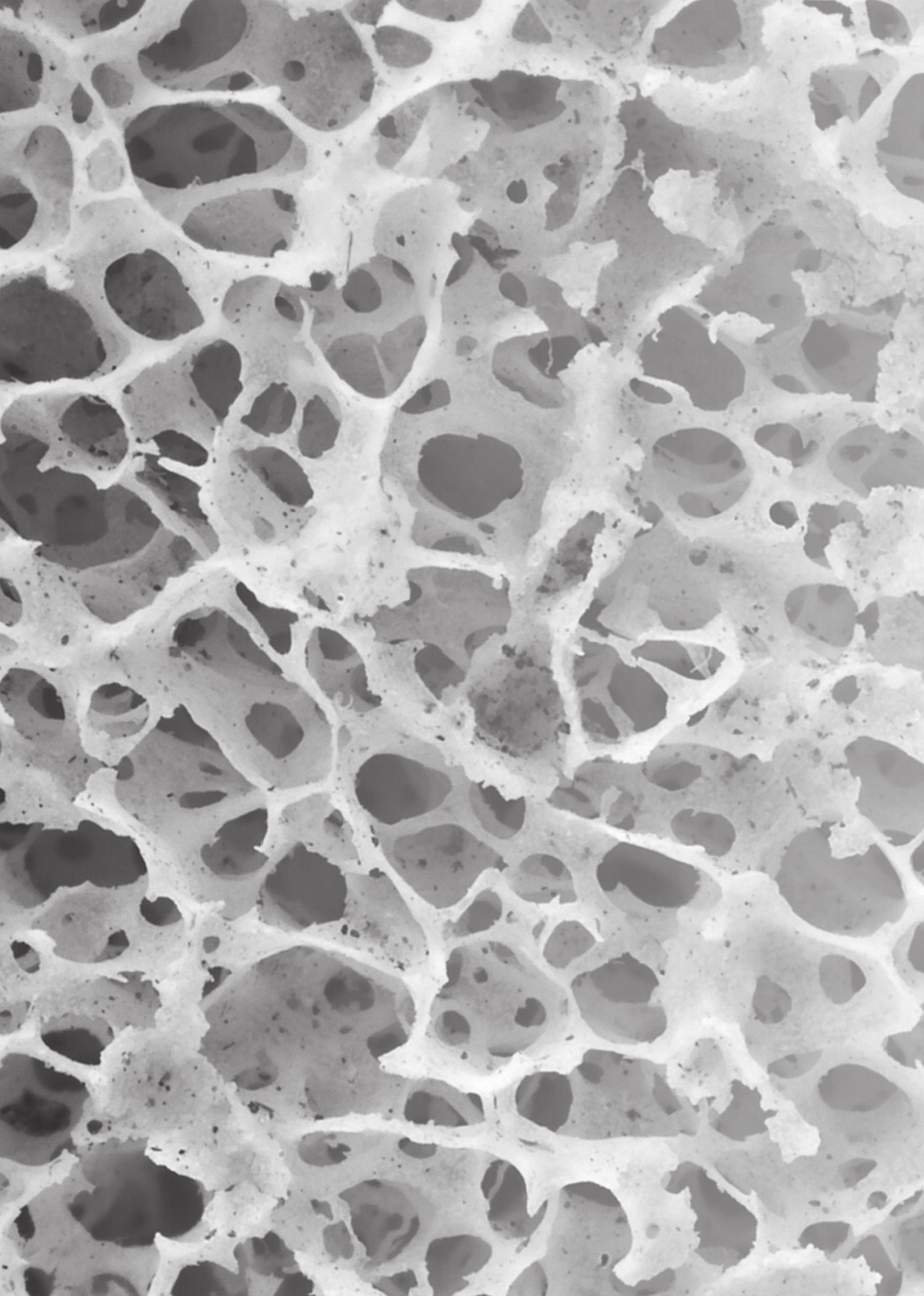




Carel Hein Geerdink was born on November 20th1971 in Schiedam, the Netherlands. $\mathrm{He}$ is the second child of three with an older sister and a younger brother. As a child he and his family moved several times so he attended two primary schools and three secondary schools. He graduated in 1991. From 1991 to 1998 he did medical school in Groningen. After a short period working as a resident in orthopaedics in Amsterdam, he started his surgical training in Leeuwarden and in 2002 his orthopaedic training in Heerlen and Maastricht. As head of the orthopaedic department in Heerlen, Alphons Tonino initiated the ideas of this thesis in 2004. In 2001 Carel met Kathelijne Koorengevel. They have two children, Teun and Maartje and are currently living in Mijnsheerenland. Since 2007, Carel is working as an orthopaedic surgeon in the Ikazia Hospital in Rotterdam. 
